Maria de Fátima Nunes Marucci

\title{
Aspectos nutricionais e hábitos alimentares de idosos, matriculados em ambulatório geriátrico
}


Maria de Fátima Nunes Marucci

Aspectos nutricionais e hábitos alimentares de idosos, matriculados em ambulatório geriátrico

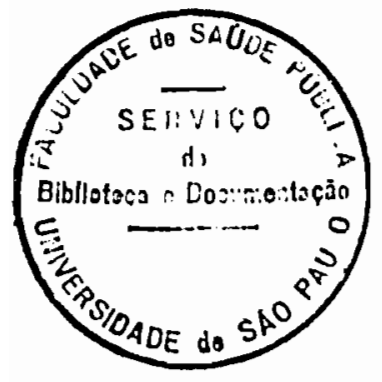

Tese apresentada à Faculdade de Saúde Pública da Universidade de São Paulo, Departamento de Nutriçāo, para a obtenção do título de "Doutor em Saúde Pública".

Orientador:

Prof. Dr. Donald Wilson

\section{SĀO PAULO}


DEDICATÓRIA 


\section{DEDICATÓRIA}

Aos meus pais:

Antonio e Filomena - "In memoriam", pela coragem e perseverança.

Ao meu marido:

Daniel, pela paciência e colaboração.

À minha filha:

Letícia,

literalmente alegria, de quem

foram roubados muitos momentos de convivência devido a este trabalho.

Aos idosos:

pela anuência e disponibilidade. 


\section{AGRADECIMENTOS}




\section{AGRADECIMENTOS}

A Deus por me dar condições para realizar este trabalho.

Ao Professor Donald Wilson pelo apoio, confiança e amizade.

Ao Daniel Marucci pela presença constante, pelo processamento dos dados, digitaçāo do texto e confecçāo dos gráficos.

À Professora Rosa Nilda Mazzilli pelo incentivo, amizade, indicação de referências bibliográficas e pelas sugestões, especialmente enquanto membro da banca examinadora.

À Professora Ana Maria Dianezi Gambardella pela amizade, apoio e pelo encaminhamento de referências bibliográficas.

À Professora Sonia Buongermino de Souza pela amizade e solidariedade, especialmente no que se relacionou à Disciplina Dietoterapia I.

Ao Doutor Eurico Thomaz de Carvalho Filho pela oportunidade de conhecer e trabalhar com os idosos no Serviço de Geriatria do HC - FMUSP e pelos comentários e sugestões oferecidos, especialmente enquanto membro da banca examinadora.

Aos Professores Ruy Laurenti, Wilson Jacob Filho, Maria Auxiliadora Cursino Ferrari e Lêda Teixeira Coelho pelos comentários, críticas e sugestōes, principalmente enquanto membros da banca examinadora.

À Diretora Janete Maculevicius, da Divisāo de Nutrição e Dietética do HC FMUSP, pela anuência na realização de estágio.

Às Nutricionistas Yara Carnevalli Baxter e Yole Aparecida Quental pela colaboração na colheita dos dados. 
À Nutricionista Elaine Donizetti Álvares pelo auxílio no cadastramento dos dados.

Às Professoras Maria José Roncada, Ignez Salas Martins, Sophia Cornbluth Szarfarc, Maria Lúcia Ferrari Cavalcanti e Maria Elisabeth Machado Pinto e Silva pela disponibilidade e interesse em colaborar.

À Professora Cássia M. Buchalla pela atenção e colaboraçāo quanto à utilização da Classificaçāo Internacional de Doenças.

À Doutora Yolanda Maria Garcia Alencar pela colaboração em vários momentos deste trabalho.

À aluna Vanessa Cristina D. de Castro, do Curso de Nutrição - FSP/USP, pelo cadastramento dos dados.

À Doutora Maria Elisabete Mendes, do Laboratório do HC - FMUSP, pela atenção e colaboração.

À Bibliotecária Ângela Maria Belloni Cuenca pela atenção e disponibilidade quanto à revisāo das referências bibliográficas

À Coordenadoria de Aperfeiçoamento de Pessoal de Ensino Superior (CAPES) pela bolsa de estudos recebida referente à pesquisa bibliográfica.

Ao Conselho Nacional de Desenvolvimento Científico e Tecnológico (CNPq) pela bolsa de estudos recebida no período de março/90 a fevereiro/91.

Aos docentes e funcionários do Departamento de Nutrição e a todos que contribuíram para a consecução deste trabalho. 


\section{INDICE}

Resumo . . . . . . . . . . . . . . . . . ii

Summary . . . . . . . . . . . . . . . . . iii

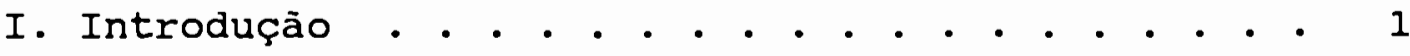

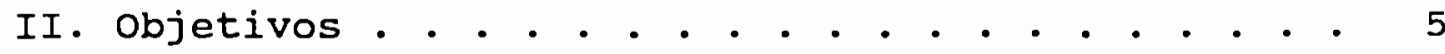

III. Metodologia . • . . . . . . . . . . . . . 7

1. População de estudo . . . . . . . . . . . 9

2. Métodos . . . . . . . . . . . . . . . 11

2.1. Recrutamento da população de estudo . . . 11

2.2. Perfil de morbidade . . . . . . . . . 11

2.3. Variáveis sangüineas . . . . . . . . . 11

2.4. Variáveis antropométricas . . . . . . 13

2.5. Aspectos dietéticos . . . . . . . . 14

IV. Resultados: Apresentação e discussão . . . . . 15

1. Caracteristicas da população estudada . . . 18

2. Perfil de morbidade . . . . . . . . . . 31

3. Análise das variáveis sangüineas . . . . . . 39

4. Análise das variáveis antropométricas . . . 50

5. Análise dos aspectos dietéticos . . . . . . 61

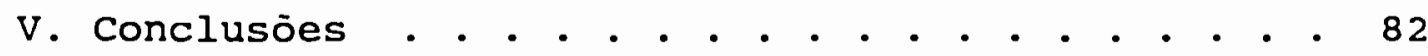

VI. Recomendaçōes . . . . . . . . . . . . 86

VII. Referências Bibliográficas . • • • • • • • • • . 88

VIII. Anexos . . . . . . . . . . . . . . . . 104 


\section{RESUMO}

O presente estudo analisou aspectos nutricionais e hábitos alimentares de idosos, de ambos os sexos (69,8\% mulheres e 30,2\% homens), matriculados em ambulatório geriátrico, com idade variando de 60 a 100 anos (média e mediana igual a 74 anos).

As variáveis sangüíneas, analisadas para 127 idosos, quando comparadas com valores de referência, mostraram que a albumina, a HDL-C, a VLDL-C e os triglicérides apresentaram valores normais quanto à média para ambos os sexos, mas as duas primeiras ficaram abaixo desses valores e as duas últimas acima, em certo percentual de idosos quando consideradas segundo o sexo. A glicose, o colesterol e a LDL-C apresentaram valores acima dos de referência tanto na média quanto em certo número de idosos, quando separados por sexo.

As medidas antropométricas, realizadas por nutricionistas treinadas, de acordo com metodologias previamente estabelecidas, foram analisadas também para 127 idosos e os resultados foram comparáveis aos de outros autores para peso e altura. A circunferência do braço apresentou-se excepcionalmente mais elevada nas mulheres do que nos homens. A prega cutânea triciptal e o índice de Quetelet são indicativos de obesidade, especialmente nas mulheres.

O perfil de morbidade, estabelecido para 308 idosos, a partir dos diagnósticos registrados nos prontuários, revelou que a doença hipertensiva foi a mais prevalente, acometendo $49 \%$ dos indivíduos, seguida pelas doenças do sistema osteomuscular e tecido conjuntivo e pelas doenças endócrinas e metabólicas.

A dieta habitual obtida em entrevista por nutricionistas treinadas, também em 308 idosos, mostrou que a freqüência de alimentos construtores e energéticos parece adequada, mas não a de reguladores e que os hábitos alimentares devem estar influenciando para a alteração de algumas variáveis sangüíneas. 


\section{SUMMARY}

The present study analised the nutritional aspects and food habits of elderly persons, of both sexes (69.8\% women and $30.2 \% \mathrm{men})$, registered at the geriatric out-patient service, with ages varying from 60 to 100 years (mean and median equal 74 years).

The blood variables, analised for 127 elderly persons, when compared with reference values, showed that albumin, HDL-C, VLDL-C and triglycerides presented normal values regarding the mean for both sexes, but the first and the second were below these values, and the remainder were over the reference values for a certain percentual of elderly persons, when considered according to sex. Glucose, cholesterol and LDL-C were over the reference values both the global mean and age and sex specific mean in certain number of aged.

The anthropometric measurements, carried out by trained nutritionists, according to previously established methodologies, were analised, too, for 127 elderly persons and the results for weight and height were comparable to the results of others authors. Arm circunference was greater in women than in men which is an exception. The triciptal skinfold and the Quetelet index are indicatives of obesity, especially in the women.

The morbidity profile, established for 308 elderly persons, from diagnoses registered, reveled that hipertensive disease was the most prevalent, present in $49 \%$ of individuals, followed by diseases of osteomuscular system and conjuntive tissue and endocrine and metabolic diseases.

The habitual diet obtained from interview by trained nutritionists, also for 308 elderly persons, showed that the frequency of constructor and energetic foods seemed to be adequate, but regulatory foods did not seem so. Food habits probably exert an influence on the alteration observed in some blood variables. 
I. INTRODUÇÃO 


\section{INTRODUÇÃO}

A população mundial vivencia uma situação especial de envelhecimento.

Atualmente existem mais indivíduos idosos como nunca antes fora constatado e esse fenômeno pode ser observado tanto em países desenvolvidos como naqueles em desenvolvimento, ainda que com características diferentes. Nos primeiros, o processo de envelhecimento ocorreu de maneira gradual, sendo acompanhado por transformaçōes sócio-econômicas que propiciaram melhores condições de vida da população como um todo e, em particular dos idosos. Essas alteraçōes nos padrōes de vida podem ser atribuídas aos avanços na área da saúde e da tecnologia e à elevação da qualidade de vida, possibilitada por melhores condiçōes de alimentação, moradia e higiene $(20,66,103)$.

Nos países em desenvolvimento, o aumento da população idosa tem ocorrido de forma muito rápida, sem correspondente modificação nas condições de vida. Assim, enquanto problemas de saúde como doenças infecto-contagiosas e parasitárias, características desses países, ainda não puderam ser resolvidos, outros, como as doenças degenerativas ou nāo transmissíveis, são mais prevalentes e ocupam lugar de destaque na mortalidade das pessoas $(66,103,123)$.

Esse fato aumenta a demanda por serviços de saúde, uma vez que essas doenças necessitam, frequentemente, de intervençōes caras, com alta tecnologia e tratamento por períodos prolongados, exigindo mais recursos materiais e humanos e competindo com outros segmentos etários da população $(15,48,66$, 103)

Vários fatores têm contribuído para essa modificação no panorama mundial: aumento da expectativa de vida, especialmente a partir de 1950, movimentos migratórios nacionais e internacionais, declínio nos coeficientes de fecundidade e de mortalidade, sendo estes dois últimos responsabilizados pelas chamadas transição demográfica e epidemiológica $(15,20,66,103,116)$.

A mudança na estrutura etária da população pode ser verificada pela média de idade, a sua mediana ou a proporção de indivíduos idosos em relação à 
população total. Considerando a população mundial, a média de idade aumentou 0,69 anos no período de 1970 a 1980, enquanto na América do Norte esse aumento foi de 1,72 anos $(100)$.

Estima-se que, na América Latina, a populaçāo total aumentará $120 \%$ no período de 1980 a 2000, enquanto aquela de 60 anos e mais terá um aumento de $236 \%$. No Brasil, espera-se que, entre 1950 e 2025, esse grupo cresça quinze vezes, o que deverá colocar o País com a sexta população de idosos do mundo em números absolutos $^{(66)}$. Esse segmento populacional representava, em $1960,5 \%$ da população total, $6,3 \%$, em 1980, devendo aumentar para $8 \%$, no ano 2000 e para cerca de $14 \%$, em $2025(15,103)$.

BERQUÓ e LEITE(15), analisando a evolução sócio-demográfica da população idosa brasileira, constataram que o crescimento desse grupo etário foi mais acelerado no período de 1940 a 1960, como consequênca, principalmente da queda de mortalidade, resultando em aumento da expectativa de vida de 41,5 para 51,6 anos, respectivamente em 1940 e 1960. Já no período de 1960 a 1980, o declínio na fecundidade apresentou a maior contribuiçāo para o aumento da proporçāo de indivíduos com 60 anos e mais. Esses autores verificaram também que o crescimento anual dos idosos foi de 4,3\% contra 2,9\% da população total entre 1960 e 1970. Na década seguinte, houve uma queda no crescimeto total para 2,5\%, enquanto para os idosos elevou-se para $5 \%$.

CAMARGO e $\operatorname{SAAD}^{(20)}$ também analisaram a transição demográfica no Brasil e verificaram que a população idosa apresentará um crescimento significativamente maior ( $4,9 \%$ ao ano) do que o grupo de 0 a 4 anos $(0,6 \%)$ e pouco maior do que os indivíduos de 15 a 59 anos $(3,1 \%)$, entre 1980 e 2000 .

Toda essa mudança na estrutura etária da população implica em transformaçāo nas suas características gerais, contribuindo para a chamada transição epidemiológica(123). Assim, além das alteraçōes nas idades das pessoas, as características biológicas, fisiológicas, patológicas e psico-sociais se modificam e se acentuam com o envelhecimento e têm relação com a dieta e seus diversos componentes $(63,116)$. 
As doenças, outrora predominantes (infecto-contagiosas e parasitárias), passam a ser substituídas pelas degenerativas ou nāo transmissíveis (cardiovasculares, neoplasias).

Os indivíduos idosos, em geral, sāo acometidos por várias dessas doenças ao mesmo tempo e portanto consomem maior número de medicamentos, os quais podem interferir na absorçāo e utilizaçāo de nutrientes e vice-versa, com repercussões no estado nutricional $(59,63,73)$. grupo etário(63).

Esses fatores justificam cuidados nutricionais específicos para esse

Estudos realizados por vários autores $(5,8,32,62,63,65,70,90,93$, $109,124)$ têm demonstrado que os problemas de saúde interferem nos padrões alimentares e que um e outro influenciam no estado nutricional de idosos.

Ainda que a população idosa necessite de maior atenção, tendo em vista as suas características e os seus problemas de saúde, não existem, ainda, pesquisas suficientes e abrangentes que contemplem esse grupo $(63,103)$. Dispōe-se apenas do número de idosos nas diversas partes do mundo e da sua "causa-mortis", mas desconhece-se a sua qualidade de vida: como vivem, como se alimentam, qual o estado de saúde, incluindo o nutricional, que tipo de cuidados recebem ${ }^{(14)}$.

Considerando todos esses aspectos, decidiu-se realizar o presente estudo, a fim de que se obtenham subsídios para o estabelecimento de normas e programas de atendimento nutricional ao idoso, de forma a contribuir para a melhor qualidade de vida desse segmento da população. 
II. OBJETIVOS 


\section{OBJETIVOS}

\section{GERAL:}

Estudar aspectos nutricionais e hábitos alimentares de idosos matriculados no Ambulatório de Geriatria do Hospital das Clínicas da Faculdade de Medicina da Universidade de São Paulo.

\section{ESPECÍFICOS:}

1. Identificar o perfil de morbidade dos idosos estudados.

2. Analisar os resultados dos exames sangüíneos das seguintes variáveis: glicose, albumina, colesterol total e suas frações (HDL, LDL e VLDL) e triglicérides.

3. Analisar as seguintes variáveis antropométricas: peso, altura, circunferência do braço, prega cutânea triciptal e índice de Quetelet.

4. Identificar a dieta habitual e a freqüência de consumo de alimentos. 
III. METODOLOGIA 
Este trabalho constitui parte de uma pesquisa maior e mais ampla, desenvolvida no Hospital das Clínicas da Faculdade de Medicina da Universidade de São Paulo (HC - FMUSP), no período de junho de 1988 a junho de 1990, junto à populaçāo idosa atendida pelo Serviço de Geriatria no Ambulatório do referido hospital.

A casuística prevista para essa investigação era de 1000 idosos, dos quais 400 seriam objeto deste estudo, mais especificamente a partir do número de ordem 601 até 1000. O levantamento dos dados desses 400 idosos era realizado às segundas, quartas e sextas-feiras pela manhã, horário de atendimento aos pacientes geriátricos naquele Ambulatório, no período de abril de 1989 a junho de 1990.

A colheita de dados foi feita por uma equipe multiprofissional constituída por:

- médica: coordenadora da pesquisa e encarregada do recrutamento, levantamento dos diagnósticos e exame clínico;

- enfermeira: encarregada da entrevista referente ao uso de medicamentos;

- nutricionista: encarregada do inquérito alimentar e das medidas antropométricas;

Ainda outros profissionais participaram da pesquisa, realizando a colheita de sangue e as dosagens sangüíneas.

Quando um membro da equipe estava ausente e não podia ser substituído o trabalho era suspenso naquele dia.

Todos os procedimentos a serem realizados em cada uma das etapas foram previamente estabelecidos e os membros da equipe devidamente treinados. 
O presente estudo analisou:

a) as características gerais dos idosos como: sexo, idade, cor, ocupação, e grau de instrução

b) o perfil de morbidade;

c) algumas variáveis sangüíneas como: glicose, albumina, colesterol total e suas fraçōes (HDL, LDL e VLDL) e triglicérides.

d) algumas variáveis antropométricas como: peso, altura, circunferência do braço, prega cutânea triciptal e índice de Quetelet.

e) alguns aspectos relacionados à alimentação.

Os ítens $\underline{\mathrm{a}} \underline{\mathrm{b}} \mathrm{e} \underline{\mathrm{e}}$ foram analisados para o total da população estudada

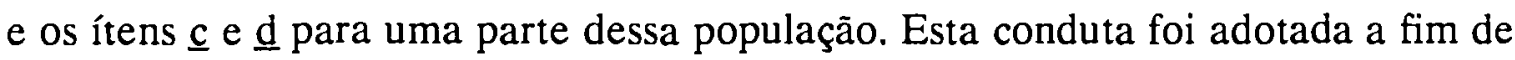
que se pudesse analisar um grupo que apresentasse todos os resultados de todas as variáveis sangüíneas e antropométricas propostas para o estudo.

Os dados obtidos foram registrados em formulário, especialmente elaborado para a pesquisa maior, cujo modelo pode ser apreciado no Anexo 1 e do qual foram extraídas as informações necessárias a este trabalho.

O levantamento dos dados era realizado enquanto os idosos aguardavam a sua consulta médica de rotina ou depois da mesma. Nāo havia um roteiro rígido estabelecido. Cada um deles podia estar numa fase diferente. Enquanto um era entrevistado pela enfermeira, outro o era pela nutricionista e outro ainda era examinado pela médica da equipe ou estava sendo atendido em sua consulta de rotina. O fundamental era que todos os idosos fossem examinados por todos os profissionais da equipe independentemente da ordem em que isto ocorria.

\section{POPULAÇĀO DE ESTUDO:}

Para este trabalho foram estudados os idosos atendidos de rotina pelo Serviço de Geriatria no Ambulatório do Hospital das Clínicas da Faculdade de 
Medicina da Universidade de São Paulo, com idade igual ou superior a 60 anos, de ambos os sexos.

As características gerais dessa população foram obtidas mediante entrevista com o próprio idoso ou com o seu acompanhante e constou da primeira parte (página 1) do formulário (Anexo 1), referente à identificação do paciente. Esta etapa podia ser realizada por qualquer membro da equipe: médica, enfermeira ou nutricionista.

Neste item, toi analisada a distribuição dos idosos quanto ao sexo, idade, cor, escolaridade e atividade. 


\section{MÉTODOS}

\subsection{Recrutamento da população de estudo:}

Os pacientes idosos agendados para consulta médica eram argüidos sobre o seu interesse e disponibilidade em participar da pesquisa, cujos objetivos lhes eram expostos e com o compromisso de que os resultados lhes seriam transmitidos oportunamente, em futuras consultas de rotina, uma vez que os mesmos permaneceriam em seus prontuários.

Os idosos tinham plena liberdade para aceitar ou não participar da pesquisa.

\subsection{Perfil de morbidade:}

O levantamento dos diagnósticos foi realizado a partir dos prontuários que se encontravam disponíveis, uma vez que eles acompanhavam os pacientes nas suas consultas, e registrados no ítem correspondente no formulário, página 1 (Anexo 1).

Os diagnósticos foram codificados segundo a Classificação Internacional de Doenças $(26)$ e o perfil de morbidade foi estabelecido de acordo com a Lista Básica para Tabulação $(95)$.

\subsection{Variáveis sangüíneas:}

Os idosos que aceitavam participar da pesquisa eram orientados a voltar em outro dia, em jejum, para colheita de sangue o qual seria examinado no laboratório do próprio HC - FMUSP.

As variáveis sangüíneas aqui estudadas foram: glicose, albumina, colesterol e suas frações (HDL, LDL e VLDL) e triglicérides e estão apresentadas no Quadro 1, bem como os métodos e equipamentos utilizados para o seu exame.

Os resultados obtidos foram comparados com os valores de referência, adotados por aquele laboratório. 
Quadro $n^{2} 1$

Variáveis sangüineas estudadas, métodos e equipamentos utilizados para a sua análise.*

\begin{tabular}{|c|c|c|}
\hline Variáveis & Método & Equipamento \\
\hline Glicose & $\begin{array}{l}\text { Enzimático } \\
\text { colorimétrico } \\
\text { automatizado }\end{array}$ & $\begin{array}{l}\text { VP Super system } \\
\text { Abbott Laboratories } \\
\text { Diagnostic Division }\end{array}$ \\
\hline Albumina & $\begin{array}{l}\text { Enzimático } \\
\text { colorimétrico } \\
\text { automatizado }\end{array}$ & $\begin{array}{l}\text { VP Super System } \\
\text { Abbott Laboratories } \\
\text { Diagnostic Division }\end{array}$ \\
\hline Colesterol & $\begin{array}{l}\text { Enzimático } \\
\text { colorimétrico } \\
\text { automatizado }\end{array}$ & $\begin{array}{l}\text { VP Super system } \\
\text { Kit AMES da Miles do } \\
\text { Brasil Ltda. (Bayer) }\end{array}$ \\
\hline HDL $-C$ & $\begin{array}{l}\text { Enzimático } \\
\text { colorimétrico } \\
\text { automatizado }\end{array}$ & $\begin{array}{l}\text { VP Super system } \\
\text { Kit AMES da Miles do } \\
\text { Brasil Ltda. (Bayer) }\end{array}$ \\
\hline$L D L-C$ & $\begin{array}{l}\text { Calculado pela fór- } \\
\text { mula de Friedwald }\end{array}$ & \\
\hline VLDL-C & $\begin{array}{l}\text { Calculado pela fór- } \\
\text { mula de Friedwald }\end{array}$ & \\
\hline Triglicérides & $\begin{array}{l}\text { Enzimático } \\
\text { colorimétrico } \\
\text { automatizado }\end{array}$ & $\begin{array}{l}\text { VP Super System } \\
\text { Abbott Laboratories } \\
\text { Diagnostic Division }\end{array}$ \\
\hline
\end{tabular}

Segundo metodologia utilizada pelo laboratório de análises clinicas e bioquímicas do HC-FMUSP. 


\subsection{Variáveis antropométricas:}

As variáveis antropométricas analisadas foram: peso, altura, circunferência do braço e prega cutânea triciptal. A metodologia utilizada para a sua realização está descrita a seguir:

PESO: Medido em quilogramas. Utilizou-se balança Filizola, pertencente ao HC FMUSP, com capacidade de 150 quilogramas e sensibilidade de 100 gramas.

Os idosos foram medidos com vestes leves (sem casacos ou paletós) e sem sapatos.

ALTURA: Medida em metros. Utilizou-se fita métrica inextensível, afixada na parede a $50 \mathrm{~cm}$ do chão, e um esquadro, pertencentes ao Departamento de Nutrição da Faculdade de Saúde Pública da Universidade de São Paulo.

Os idosos foram medidos descalços, em posição ereta, olhando para a frente, de forma a manter o chamado "plano de Frankfort", com as costas e a parte posterior dos joelhos encostados à parede.

CIRCUNFERÊNCIA DO BRAÇO: Medida em centímetros, no ponto médio entre o topo do processo acromial da escápula (ombro) e o processo do olécrano (cotovelo), no braço não dominante, utilizando-se fita métrica inelástica. Para marcar o ponto médio, o braço ficou fletido e para medir a circunferência, o braço ficou estendido.

PREGA CUTÂNEA TRICIPTAL: Medida em milímetros, no mesmo ponto da medida da circunferência do braço, utilizando-se paquímetro Lange. Foram feitas três mensurações e o resultado considerado foi a média delas.

Ainda, para complementar a avaliaçāo nutricional dos idosos por meio das medidas antropométricas, foi analisado o índice de Quetelet ou índice de massa corporal (IMC) dado pela relação: peso $(\mathrm{kg}) /$ altura $^{2}(\mathrm{~m})$. Como parâmetro, foram utilizados os critérios propostos por GARROW et al., referidos em DEURENBERG et al. (36). 
As medidas antropométricas foram realizadas pela própria autora deste trabalho ou por nutricionista do Hospital das Clínicas, sendo que a conduta e a metodologia adotadas foram previamente estabelecidas e treinadas.

\subsection{Aspectos dietéticos:}

A investigação nutricional e anamnese alimentar, assim como no caso das medidas antropométricas, foram realizadas pela autora deste trabalho e por nutricionista do Hospital das Clínicas em entrevista com o paciente e/ou o seu acompanhante.

formulário.

As informações obtidas foram registradas às folhas 3,4 e 5 do

Os dados referentes à anamnese alimentar foram analisados do ponto de vista qualitativo, de acordo com grupos de alimentos e segundo a freqüencia dos alimentos.

Após a entrevista, os responsáveis por ela, realizavam orientação nutricional com a entrega de um "manual" (Anexo 2), o qual consiste em orientação simples sobre os aspectos nutricionais para idosos. Esse "manual" foi elaborado por alunos do Curso de Nutrição da Faculdade de Saúde Pública da Universidade de São Paulo, estagiários do Hospital das Clínicas, sob a supervisão de nutricionistas da Divisāo de Nutrição e Dietética e foi adotado pela mesma para orientação de rotina. 


\section{RESULTADOS: APRESENTAÇÃO E DISCUSSÃO}

Embora a casuística prevista para este estudo fosse de 400 idosos, esse total não pôde ser atingido tendo em vista as recusas, perdas e suspensōes e também o término da pesquisa maior.

As recusas ocorriam quando os idosos eram consultados sobre o seu interesse e disponibilidade em participar da pesquisa e não aceitavam.

As perdas ocorriam quando os idosos iam embora sem terminar os exames. Vale lembrar que todo o levantamento era feito enquanto os idosos aguardavam a sua consulta médica de rotina ou após a mesma. Muitas vezes, o levantamento começava antes da consulta e só podia ser concluído depois dela, sendo que vários idosos acabavam indo embora quer talvez por esquecimento ou devido à pressa. Há que se levar em conta que os pacientes sāo orientados a chegar as 7 horas para a consulta e, no caso daqueles que participavam da pesquisa, dependendo do número total a ser atendido, não raro, considerando o tempo dispendido na espera para a consulta de rotina e os exames da pesquisa, eram liberados às $12-12: 30 \mathrm{e}$, às vezes, em alguns casos, até às 13 horas.

As suspensōes ocorriam quando, após a aceitaçāo pelo idoso em participar da pesquisa e depois de sua identificação, verificava-se que o mesmo não apresentava condições físicas (um necessitou transfusão sangüínea) ou psíquicas para se submeter aos exames propostos.

Assim, do total previsto (400), obteve-se 308 idosos, correspondendo a $76,9 \%$, sendo que as recusas atingiram $14,25 \%$ (57), as perdas $6,25 \%$ (25) e as suspensões $2,5 \%$ (10). Na prática, estes três ítens podem ser agrupados em um único, considerado como perda em relação à casuística prevista e totalizando $23,0 \%$.

Ainda há que se considerar o tempo necessário para o levantamento dos dados: 1 ano e 2 meses. Convém lembrar que o referido levantamento era realizado às segundas, quartas e sextas-feiras no período da manhã e, quando algum membro da equipe estava ausente e não podia ser substituído, o trabalho era suspenso naquele dia. Além disso, nesse período houve greve de motoristas de 
Onibus e também de funcionários do Hospital, o que prejudicou o andamento da pesquisa, uma vez que os pacientes agendados não compareciam para a consulta de rotina. Outro fator que contribuiu para o longo tempo de colheita de dados foi o fato de a pesquisa maior do Hospital da Clínicas ter iniciado um ano antes (junho de 1988), investigando o mesmo grupo populacional. Acontecia que, embora vários idosos pudessem comparecer ao ambulatório em um mesmo dia, muitas vezes alguns não podiam participar, pois já haviam sido investigados meses antes ou no ano anterior e, naquele momento, estavam voltando para consulta de retorno. 


\section{Características da população estudada:}

\subsection{Ouanto ao sexo:}

A população estudada abrangeu 308 idosos, sendo 93 do sexo masculino e 215 do sexo feminino, correspondendo, respectivamente a 30,2 e 69,8\%, como apresentado na Tabela $\mathrm{n}^{0} 1$.

Tabela $\mathrm{n}^{\mathrm{Q}} 1$.

Distribuição dos idosos estudados, segundo sexo. São Paulo, 1989-1990.

\begin{tabular}{|c|c|c|}
\hline \multirow[b]{2}{*}{ Sexo } & \multicolumn{2}{|c|}{ Idosos } \\
\hline & $\mathrm{N}^{2}$ & $\%$ \\
\hline Masculino & 93 & 30,2 \\
\hline Feminino & 215 & 69,8 \\
\hline TOTAL & 308 & 100,0 \\
\hline
\end{tabular}

Esses dados mostram que, na população estudada, o número de mulheres é maior que o dos homens, situação essa que também é observada em relação à população de um modo geral. No entanto, deve-se considerar ainda que outros fatores podem estar contribuindo para que o número de mulheres que procura os serviços de saúde seja maior do que o dos homens como, por exemplo, maior preocupação e interesse pelos cuidados com a própria saúde.

Trabalho recente, realizado pelos técnicos da Diretoria Adjunta de Estudos Populacionais (DAEP) da Fundação $\operatorname{SEADE}^{(22)}$ sobre a população idosa na Grande São Paulo, mostra que, nas áreas centrais dessa região, considerando os subdistritos do Município de São Paulo, o número de mulheres é maior na população total e principalmente no grupo etário de 60 anos e mais. 
Ainda segundo os dados da Fundação $\operatorname{SEADE}^{(48)}$, a esperança de vida ao nascer, no Estado de São Paulo, é maior para as mulheres do que para os homens, acentuando-se essa diferença com o passar dos anos. Em 1940, os valores eram 46,5 e 44,3 anos respectivamente; em 1985, esses valores passaram para 72,3 anos no sexo feminino e 64,9 anos no sexo masculino.

O mesmo acontece em relação à esperança de vida aos 60 anos. Em 1940 , as mulheres tinham 14,1 anos e os homens 12,6 anos de esperança de vida; já em 1985, os valores eram 19 e 16 anos, respectivamente.

Também a proporção de pessoas que atingem 60 anos é maior em relação às mulheres. Assim, ainda considerando os mesmos dados, têm-se que essa proporção era de 46,5 para as mulheres e 42,1 para os homens em 1940. Em 1985, essas proporções aumentaram para 83,7 e 70,1, respectivamente, correspondendo a praticamente o dobro no caso do sexo feminino.

O United Nations Development Program (UNDP) ${ }^{(115)}$, 1991, propõe a expectativa de vida como um dos indicadores sociais para medir o progresso e o desenvolvimento humanos.

\subsection{Quanto a idade:}

A idade da população estudada variou de 60 (marco adotado para participar da pesquisa) a 100 anos, sendo que a média foi 74,5 $\pm 7,1$ anos e a mediana 74 anos, igual para ambos os sexos.

Considerando apenas o sexo masculino, a média foi $74,9 \pm 6,8$ anos e para o feminino $74,3 \pm 7,3$ anos. 
Tabela $n^{2} 2$.

Distribuição dos idosos estudados, segundo sexo e grupo etário. São Paulo, 1989-1990.

\begin{tabular}{|c|c|c|c|c|c|c|c|}
\hline \multirow{3}{*}{\multicolumn{2}{|c|}{$\begin{array}{l}\text { Grupo etário } \\
\text { (anos) }\end{array}$}} & \multicolumn{4}{|c|}{ Sexo } & \multirow{2}{*}{\multicolumn{2}{|c|}{ Total }} \\
\hline & & \multicolumn{2}{|c|}{ Masc. } & \multicolumn{2}{|c|}{ Fem. } & & \\
\hline & & $\mathrm{N}^{2}$ & $\%$ & $\mathrm{~N}^{2}$ & $\%$ & $\mathrm{~N}^{2}$ & $\%$ \\
\hline 60 & -64 & 3 & 3,2 & 12 & 5,6 & 15 & 4,5 \\
\hline 65 & -69 & 17 & 18,3 & 42 & 19,5 & 59 & 19,2 \\
\hline 70 & -74 & 29 & 31,2 & 66 & 30,7 & 95 & 30,8 \\
\hline 75 & - 79 & 22 & 23,7 & 54 & 25,1 & 76 & 24,7 \\
\hline 80 & -84 & 15 & 16,1 & 20 & 9,3 & 35 & 11,6 \\
\hline 85 & -89 & 5 & 5,4 & 14 & 6,5 & 19 & 6,2 \\
\hline 90 & -100 & 2 & 2,2 & 7 & 3,3 & 9 & 2,9 \\
\hline ТОTА & & 93 & 100,1 & 215 & 100,0 & 308 & 100, \\
\hline
\end{tabular}

A Tabela $\mathrm{n}^{2} 2$ apresenta a distribuição dos idosos, segundo sexo e grupo etário e pode-se observar que o número de mulheres (41) com idades mais avançadas (80 anos e mais) é praticamente o dobro $(1,9)$ do número de homens (22). A mesma observação é válida se considerarmos o número de idosos com idade superior à média (74 anos), ou seja, a partir de 75 anos.

\subsection{Quanto à cor:}

Os idosos foram estudados quanto à sua cor e a Tabela $n^{2} 3$ apresenta os resultados quanto a esse ítem. 
Tabela $n^{2} 3$.

Distribuição dos idosos estudados, segundo sexo e cor. São Paulo, 1989-1990.

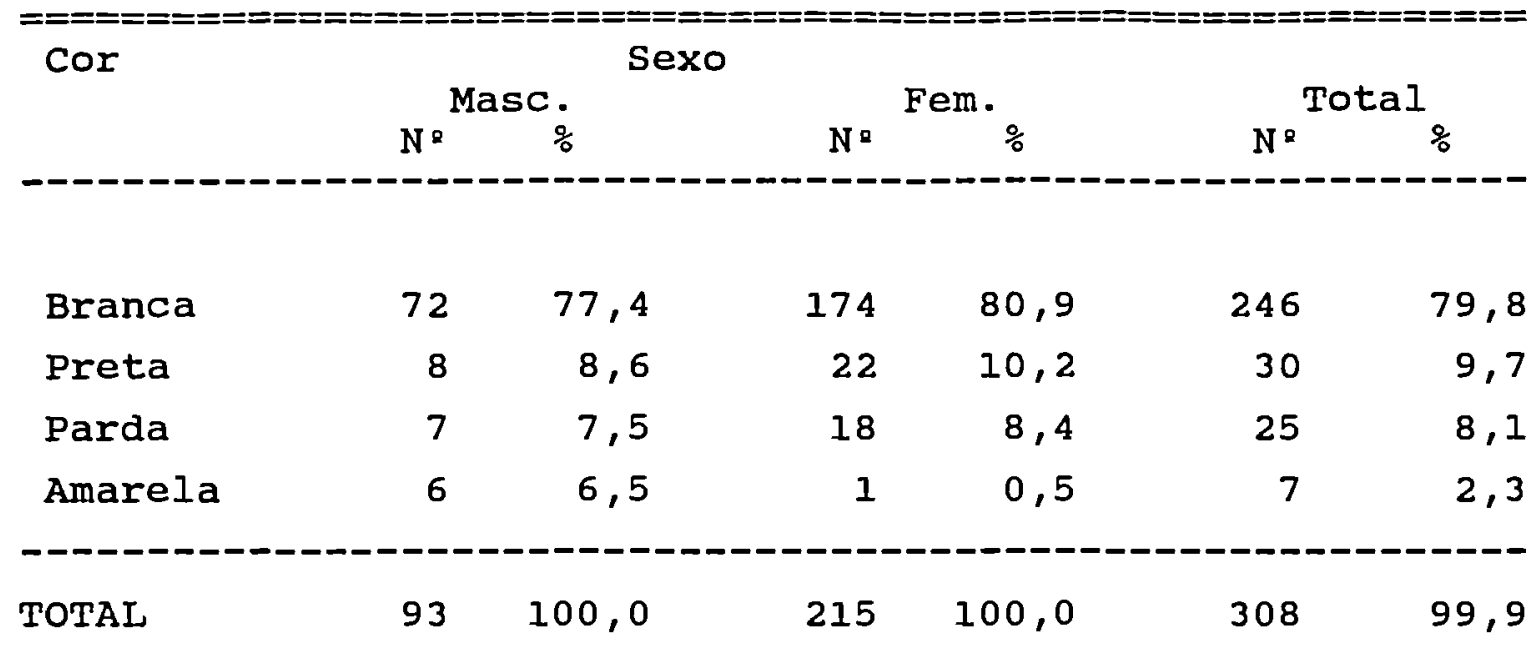

Observa-se, na Tabela $\mathrm{n}^{2} 3$, grande predominância da cor branca, para os idosos de ambos os sexos, correspondendo a $80 \%$ da população estudada.

Com exceção da cor amarela, onde os idosos do sexo masculino sobressaem-se em relaçāo ao feminino, este predomina nas demais cores. É possível que este fato esteja ligado à própria cultura oriental, na qual o respeito e os cuidados com as pessoas idosas constituem uma tônica.

\subsection{Quanto à escolaridade:}

Verificou-se a escolaridade dos idosos estudados, considerando a nomenclatura oficial adotada para os diversos níveis. Assim, os idosos que referiram apenas "ler e escrever" ou "ler e assinar" foram considerados como analfabetos. Ainda, para o primeiro grau atual (1.a a 8.a séries), utilizou-se a nomenclatura antiga de primário e ginásio.

$\mathrm{Na}$ Tabela $\mathrm{n}^{2} 4$, pode-se verificar que um terço $(33,1 \%)$ dos idosos são analfabetos e praticamente $50 \%$ deles estudaram até o primário. O estudo realizado por técnicos da Fundação $\operatorname{SEADE}^{(21)}$ mostra percentual semelhante quando se 
considera o primário, sendo que para os homens com 60 anos e mais, do Município de São Paulo, em 1980, o valor é 48,6\% e para as mulheres, 44,0\%. Já com relação aos idosos que não sabiam ler e escrever, na Capital, o sexo feminino apresenta percentual igual $(33,1 \%)$ ao total de analfabetos do presente estudo, enquanto para o sexo masculino esse valor diminui para a metade $(16,2 \%)$.

E interessante notar o número de idosos que declararam apenas ler e escrever. No sexo masculino, $11,8 \%$ dos idosos encontram-se nessa categoria, enquanto no sexo feminino esse valor é $4,7 \%$.

CAMARGO e YAZAKI ${ }^{(21)}$ também chamam a atençāo para esse fato. No Município de São Paulo, em 1980, quase 10\% dos homens idosos apresentavam essa condição, e 5 a $7 \%$ das mulheres, considerando a Capital e demais municípios da Grande São Paulo e interior do Estado de São Paulo.

Um número muito pequeno de idosos $(7,8 \%)$ chegou ao ginásio e percentagem ainda menor $(2,3 \%)$ concluiu o curso universitário. 
Tabela $n^{2} 4$

Distribuição dos idosos estudados segundo sexo e escolaridade. São Paulo, 1989-1990.

\begin{tabular}{|c|c|c|c|c|c|c|c|c|}
\hline \multirow[b]{2}{*}{ Escolaridade } & \multirow[b]{2}{*}{$N^{2}$} & \multicolumn{3}{|c|}{ Sexo } & & \multirow{2}{*}{\multicolumn{2}{|c|}{ Total }} \\
\hline & & $\begin{array}{c}\text { Masculi } \\
\text { \% }\end{array}$ & no $\div 2$ & $\mathrm{~N}^{2}$ & Femjinir & $0 \%^{2}$ & & \\
\hline $\begin{array}{l}\text { Analfabeto } \\
\text { (lê e escreve) * }\end{array}$ & $\begin{array}{l}28 \\
(11)\end{array}$ & $\begin{array}{l}30,1 \\
(11,8)\end{array}$ & $\begin{array}{c}9,1 \\
(3,6)\end{array}$ & $\begin{array}{c}74 \\
(10)\end{array}$ & $\begin{array}{l}34,4 \\
(4,7)\end{array}$ & $\begin{array}{l}24,0 \\
(3,2)\end{array}$ & $\begin{array}{l}102 \\
(21)\end{array}$ & $\begin{array}{l}33,1 \\
(6,8)\end{array}$ \\
\hline Mobral & 1 & 1,1 & 0,3 & 3 & 1,4 & 1,0 & 4 & 1,3 \\
\hline $\begin{array}{l}\text { Primária } \\
\text { incompleta } \\
\text { completa }\end{array}$ & $\begin{array}{l}16 \\
22\end{array}$ & $\begin{array}{l}17,2 \\
23,7\end{array}$ & $\begin{array}{l}5,2 \\
7,1\end{array}$ & $\begin{array}{l}54 \\
56\end{array}$ & $\begin{array}{l}25,1 \\
26,0\end{array}$ & $\begin{array}{l}17,5 \\
18,2\end{array}$ & $\begin{array}{l}70 \\
78\end{array}$ & $\begin{array}{l}22,7 \\
25,3\end{array}$ \\
\hline $\begin{array}{l}\text { Ginásial } \\
\text { incompleta } \\
\text { completa }\end{array}$ & $\begin{array}{l}7 \\
5\end{array}$ & $\begin{array}{l}7,5 \\
5,4\end{array}$ & $\begin{array}{l}2,3 \\
1,6\end{array}$ & $\begin{array}{l}4 \\
8\end{array}$ & $\begin{array}{l}1,9 \\
3,7\end{array}$ & $\begin{array}{l}1,3 \\
2,6\end{array}$ & $\begin{array}{l}11 \\
13\end{array}$ & $\begin{array}{l}3,6 \\
4,2\end{array}$ \\
\hline $\begin{array}{l}\text { Colegial } \\
\text { incompleta } \\
\text { completa }\end{array}$ & $\begin{array}{l}0 \\
2\end{array}$ & $\overline{2}, 2$ & $\overline{0}, 6$ & $\begin{array}{l}0 \\
4\end{array}$ & $\overline{1}, 9$ & $\overline{1}, 3$ & $\begin{array}{l}0 \\
6\end{array}$ & $\overline{1}, 9$ \\
\hline Técnica & 2 & 2,2 & 0,6 & 1 & 0,5 & 0,3 & 3 & 1,0 \\
\hline $\begin{array}{l}\text { Universitária } \\
\text { incompleta } \\
\text { completa }\end{array}$ & $\begin{array}{l}0 \\
2\end{array}$ & $\overline{2}, 2$ & $\overline{0}, 6$ & $\begin{array}{l}0 \\
5\end{array}$ & $\overline{2}, 3$ & $\overline{1}, 6$ & $\begin{array}{l}0 \\
7\end{array}$ & $\overline{2}, 3$ \\
\hline Outra** & 1 & 1,1 & 0,3 & 0 & - & - & 1 & 0,3 \\
\hline Sem informação & $==$ & $===$ & $===$ & 6 & 2,8 & 1,9 & 13 & 4,2 \\
\hline TOTAL & 93 & $100,2^{3}$ & 30,0 & 215 & 100,0 & 69,7 & 308 & $99,9^{3}$ \\
\hline $\begin{array}{l}1 \text { Refere-se ao } \\
2 \text { Refere-se ao } \\
3 \text { Não correspon } \\
\text { * decimais. } \\
\text { ** Foram conside } \\
\text { Refere-se a }\end{array}$ & $\begin{array}{l}\text { númer } \\
\text { númer } \\
\text { dem e: } \\
\text { rados } \\
10 \text { an }\end{array}$ & $\begin{array}{l}0 \text { dos id } \\
0 \text { total } \\
\text { xatament } \\
\text { como an } \\
\text { os de es }\end{array}$ & $\begin{array}{l}\text { osos es } \\
\text { dos idc } \\
\text { e a } 100\end{array}$ & $\begin{array}{l}\text { udad } \\
\text { dev e: }\end{array}$ & $\begin{array}{l}\text { os segur } \\
\text { studados } \\
\text { ido às }\end{array}$ & $\begin{array}{l}\text { lo } \mathrm{s} \\
\text { oroxim }\end{array}$ & es das & casa \\
\hline
\end{tabular}


Apenas $1 \%$ dos idosos estudou até o nível técnico e um idoso mencionou ter estudado durante dez anos no Japāo.

Não houve informação sobre a escolaridade em 4,2\% dos idosos.

Os resultados obtidos assemelham-se àqueles encontrados por GARCIA e col. ${ }^{(50)}$, os quais verificaram que de um grupo de 119 idosos $(80,7 \%$ de mulheres), atendidos em centro de saúde, $31,6 \%$ eram analfabetos e 54,7\% nāo haviam concluído o primário.

O Gráfico $n^{\circ} 1$ ilustra a distribuição percentual dos idosos segundo a escolaridade.

A escolaridade foi analisada, tendo em vista ser aspecto importante, uma vez que se relaciona a várias outros como atividade, renda, nível sócioeconômico e, em última instância, a condições de saúde. A escolaridade foi outro indicador social proposto pelo United Nations Development Program (UNDP) ${ }^{(115)}$, juntamente com a expectativa de vida, para medir o progresso e desenvolvimento humanos, e ambos indicadores associados com renda nacional.

Além disso, a escolaridade é informação extremamente necessária quando se pretende elaborar programas ou adotar medidas de saúde, incluindo educação nutricional, de forma a atender aos interesses da populaçāo alvo bem como aos objetivos propostos.

Para ilustrar este aspecto, vale citar estudo realizado por CURIATI e col. ${ }^{(31)}$, que submeteram 505 pacientes do Ambulatório de Geriatria do HC FMUSP a um teste sumário (10 ítens) de avaliação mental. Os resultados mostraram a escolaridade, entre outros, como um fator que diferenciou os idosos, sendo que o Grupo I, que apresentava maior porcentagem de analfabetos $(87,4 \%)$, acertou menor número de ítens (7 ou menos) em relaçāo ao Grupo II, com 32,6\% de analfabetos, que acertou de 8 a 10 ítens. 


\section{Escolaridade}

(\%)

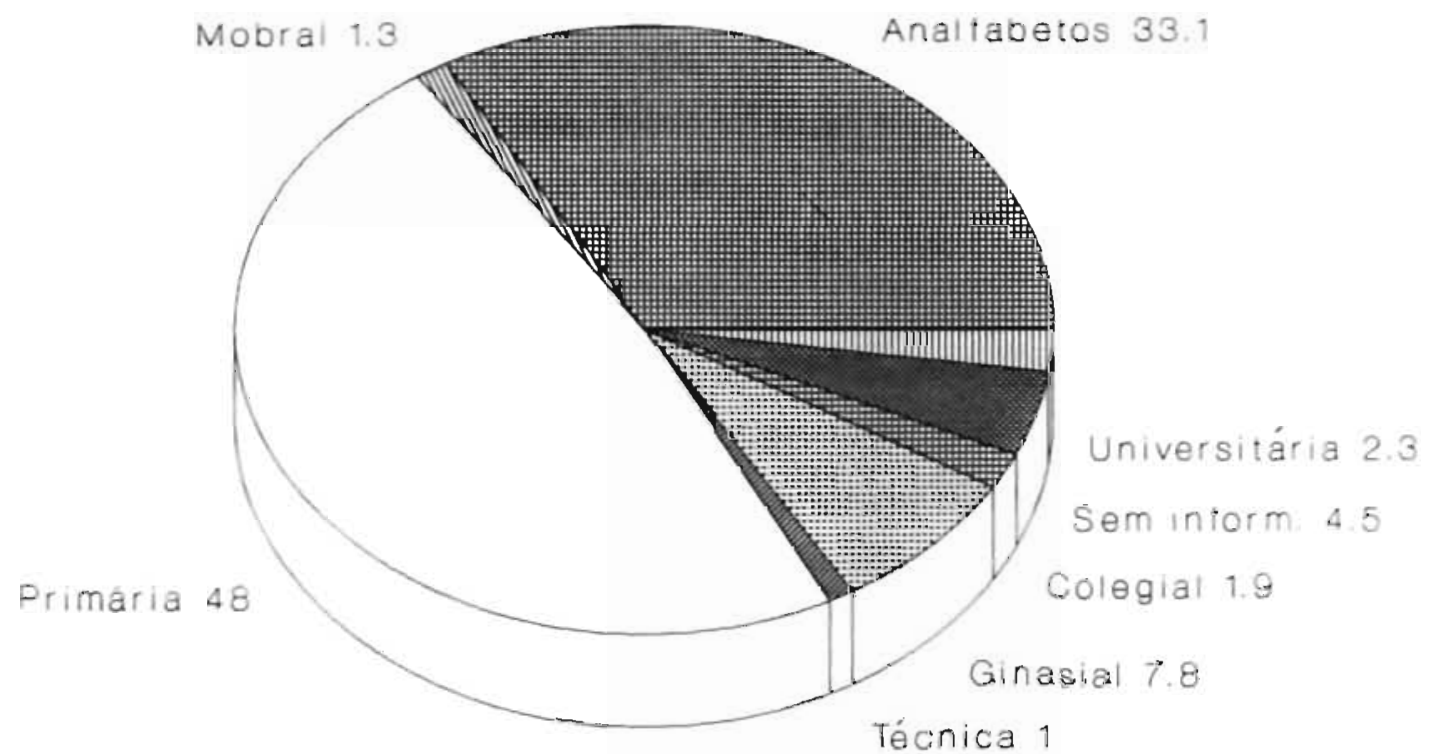

Gráfico $n^{2} 1$.

Distribuiçāo percentual dos idosos estudados, segundo escolaridade. Sāo Paulo, 1989-1990. 


\subsection{Quanto à atividade:}

A atividade referida pelos idosos pode ser verificada na Tabela $\mathrm{n}^{0} 5$.

Observa-se que, para o sexo feminino, predominam as prendas domésticas, atingindo $55,8 \%$ das mulheres, seguida pela categoria de inativas $(34,4 \%)$, considerando-se aqui a aposentadoria.

No sexo masculino, destaca-se maior número de idosos $(73,1 \%)$ como inativos.

Dentre o total de inativos, um homem (motorista) e duas mulheres (uma tricoteira e uma faxineira) declararam continuar trabalhando, ainda que em atividade diferente daquela exercida antes da aposentadoria.

Verifica-se que vários idosos, tanto do sexo masculino (20), incluindo: pedreiro, alfaiate, vendedor, vigia e outras atividades, como do sexo feminino (15), empregada doméstica, costureira, comerciante e outras, mencionaram estar trabalhando. Isto, provavelmente, se deve ao fato de exercerem atividade remunerada, embora este aspecto não tenha sido levantado. Por outro lado, é curioso notar o grande número de mulheres (120) que referiram prendas domésticas, atividade que em nossa sociedade costumeiramente não é vista como trabalho, uma vez que é exercida no próprio domicílio e nāo há remuneraçāo estabelecida. $\mathrm{Na}$ verdade, essa atividade é praticamente igual à da empregada doméstica, com uma única diferença: ausência de salário.

E interessante notar, também, que praticamente todas as atividades referidas requerem mais trabalho do ponto de vista manual do que intelectual. Este fato pode estar relacionado ao nível de escolaridade já mencionado anteriormente.

Dentro do ítem "Outras" foram incluídas atividades com apenas uma freqüência cada e estão relacionadas a seguir:

- sexo masculino: consultor em construção civil, jardineiro, artesão, zelador, técnico de raio $X$, faxineiro, mecânico, agricultor, marce-neiro, torneiro e advogado. 
- sexo temınino: tecelā, lavadeira, auxiliar de escritório, plantonista imobiliária e funcionária de copa e cozinha.

Não houve informação sobre a atividade em $3,6 \%$ dos idosos.

O Gráfico $\mathrm{n}^{2} 2$ apresenta a distribuição percentual da atividade dos idosos do sexo masculino, sendo que no ítem "Outras" foram incluídas as atividades que tiveram duas freqüências (alfaiate, vendedor e vigia), além daquelas com apenas uma freqüência.

O Gráfico $n^{2} 3$ apresenta a distribuição percentual da atividade dos idosos do sexo feminino, sendo que costureira e comerciante foram incluídas no ítem "Outras". 
Tabela $n^{0} 5$

Distribuição dos idosos estudados segundo sexo e atividade. São Paulo, 1989-1990.

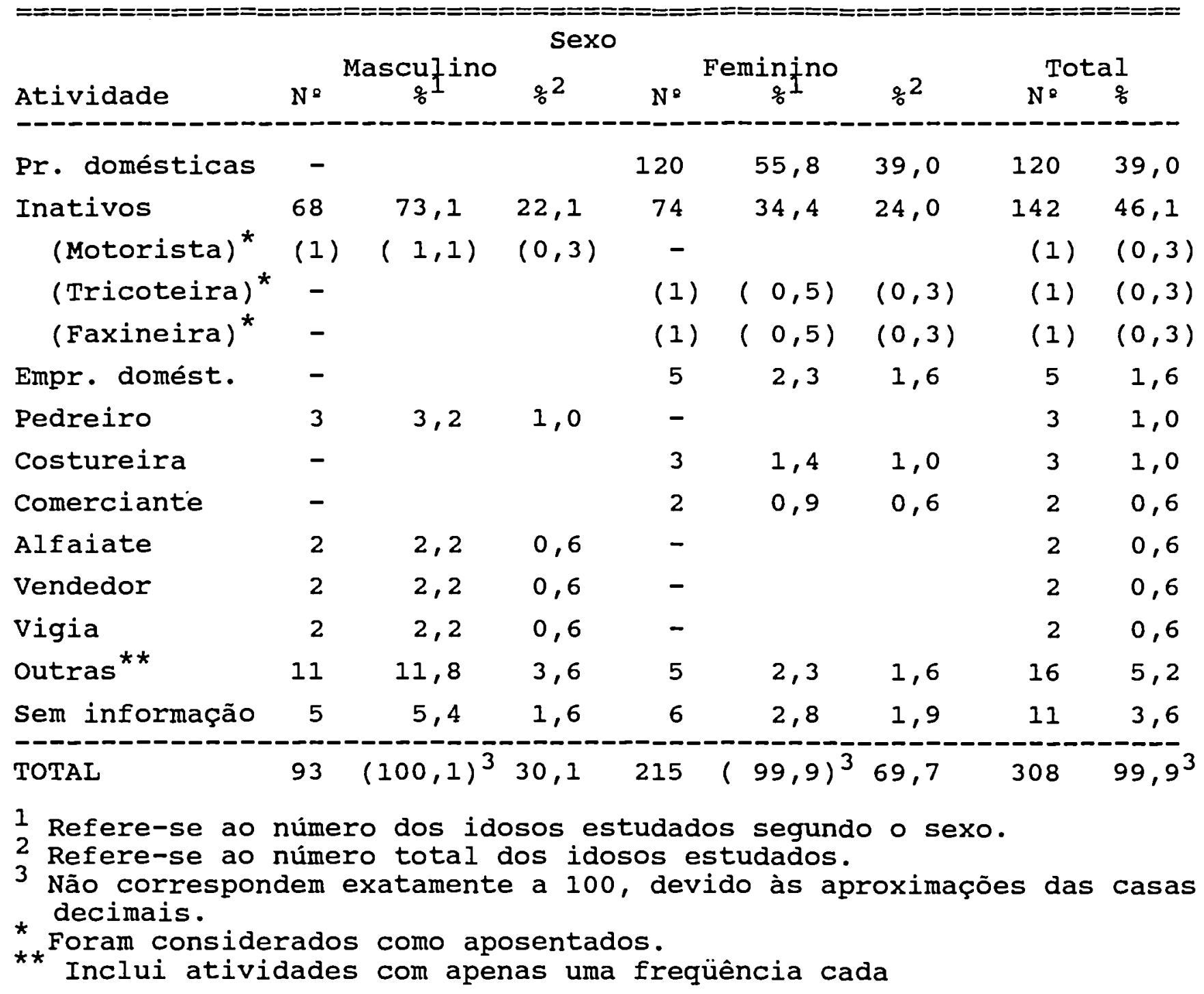




\section{Atividade Sexo masculino (\%)}

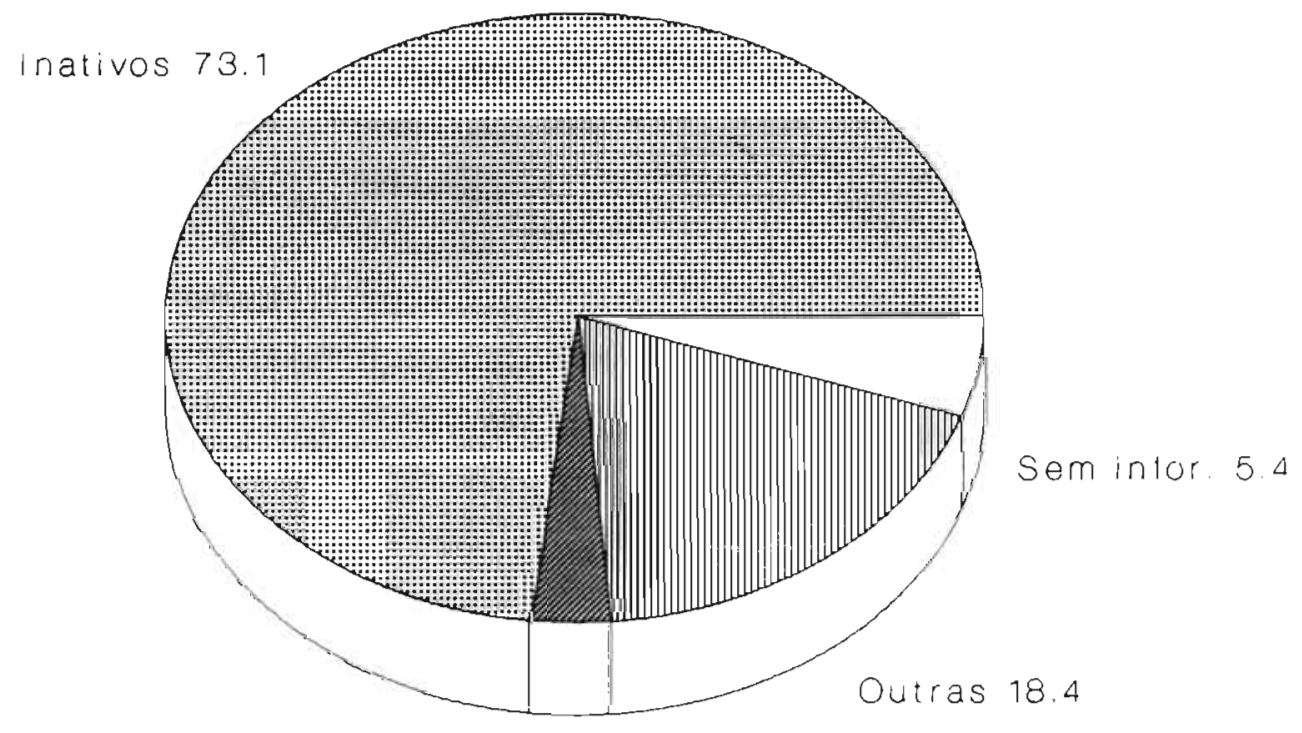

Pedreiro 3.1

Gráfico $n^{2} 2$.

Distribuição percentual dos idosos do sexo masculino, segundo atividade. São Paulo, 1989-1990. 


\section{Atividade Sexo feminino $(\%)$}

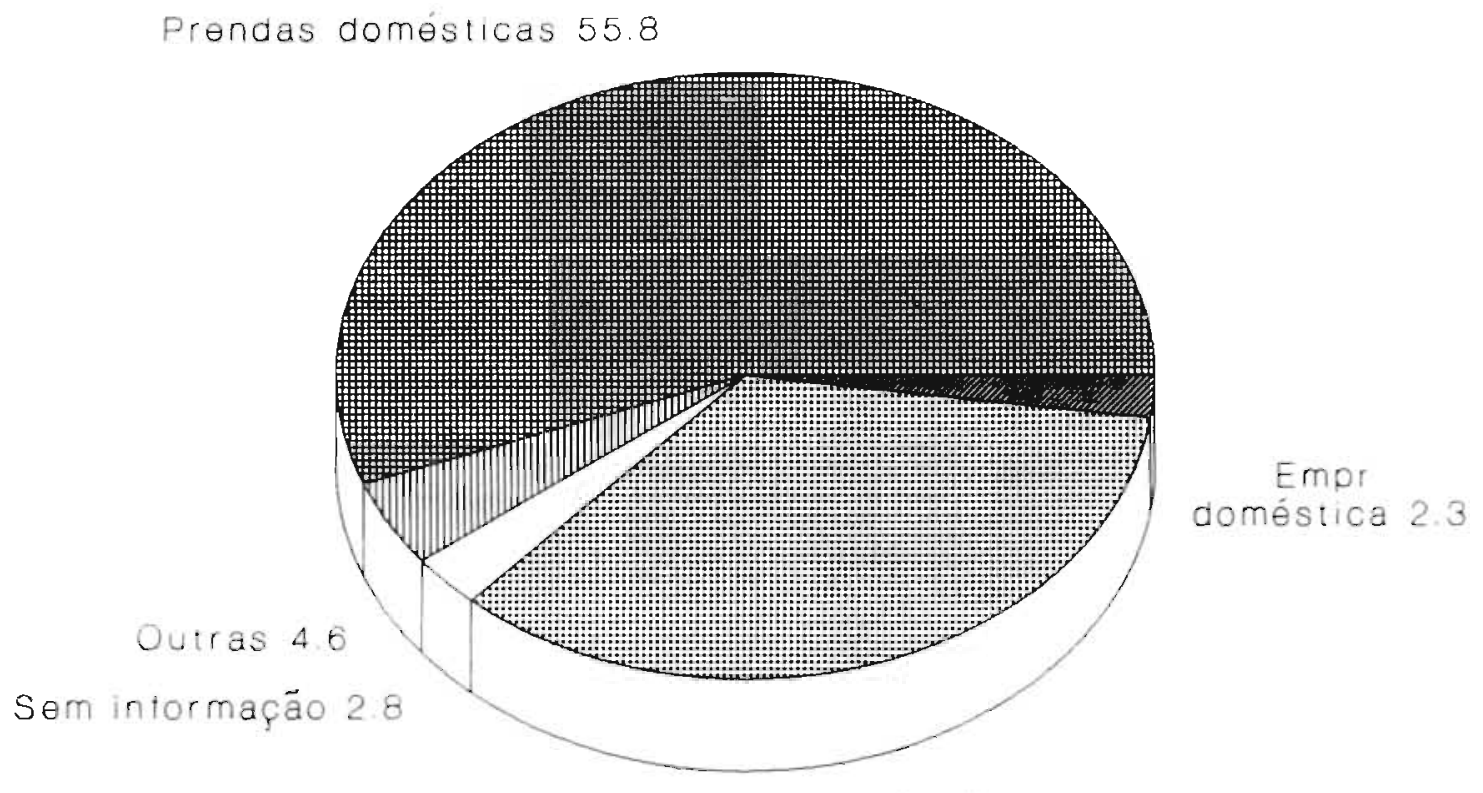

Inativas 34.4

Gráfico $n^{9} 3$.

Distribuição percentual dos idosos do sexo feminino, segundo atividade. São Paulo, 1989-1990. 


\section{Perfil de morbidade:}

Os diagnósticos clínicos dos idosos estudados foram colhidos nos respectivos prontuários e constatou-se que o número de diagnósticos por idoso variou de um a sete, com uma média de 2,3.

A Tabela $\mathrm{n}^{0} 6$ apresenta a distribuição de diagnósticos por idoso. Pode-se observar que apenas um idoso apresentou sete diagnósticos, sendo que praticamente metade $(49,4 \%)$ da população estudada tinha 2 ou 3 enfermidades diagnosticadas.

Tabela $n^{\circ} 6$.

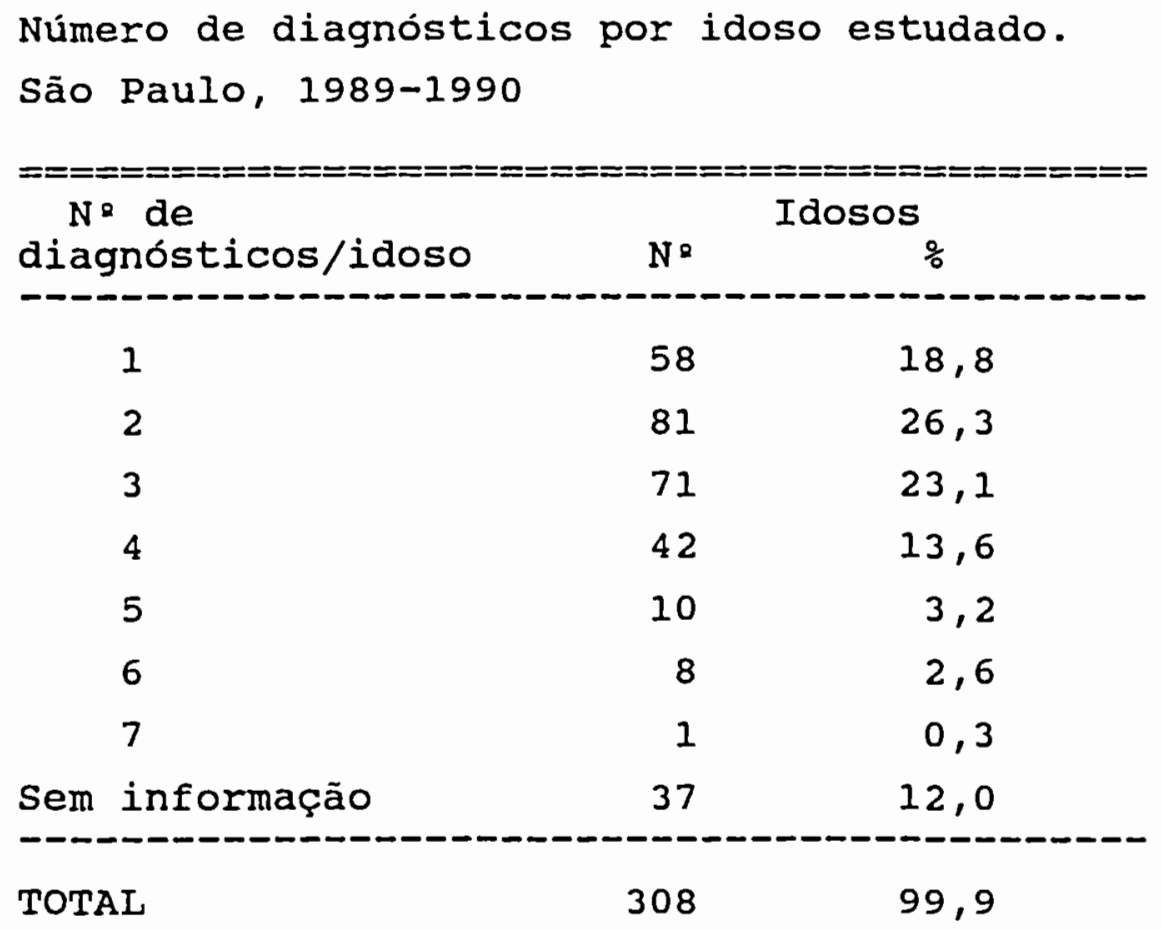

FABBRI e col. ${ }^{(40)}$ encontraram uma média de 3 afecçōes por idoso quando analisaram 303 idosos, 218 mulheres e 85 homens, com idade entre 60 e 101 anos, média de $76,8 \pm 9,9$ anos, atendidos ambulatorialmente. Note-se que esse grupo etário é praticamente igual ao estudado no presente trabalho, seja pelo número total de idosos pesquisados, seja pelas características quanto ao sexo, idade e forma de atendimento. 
Estudo realizado por HIRAMATSU e col. ${ }^{(60)}$ mostrou que essa média foi maior $(3,3)$, quando da análise dos diagnósticos clínicos de idosos com idade superior a 80 anos, matriculados em ambulatório geriátrico, tendo encontrado que o número máximo de diagnóstico/idoso foi 10.

FABBRI e GORZONI ${ }^{(39)}$, avaliando as afecções em idosos com 90 anos e mais encontrou uma média de 3,9 diagnósticos por paciente.

Pode-se perceber, pelas pesquisas feitas, que o número de doenças por indivíduo se eleva à medida que aumenta a idade.

Os diagnósticos clínicos, agrupados de acordo com a Classificaçāo Internacional de Doenças $(26)$, foram distribuídos segundo a Lista Básica para Tabulaçāo $(95)$ e podem ser observados na Tabela $n^{2} 7$. No Anexo $n^{2} 3$, essa distribuição está apresentada de forma mais detalhada.

Analisando os resultados, verifica-se que a doença hipertensiva prevalece tanto no que se refere ao total de dignósticos levantados $(21,4 \%)$, quanto ao número de idosos $(49,0 \%)$ que apresentam essa enfermidade. Seguem-se as doenças do sistema osteomuscular e do tecido conjuntivo, também com percentual elevado: $14,2 \%$ do total de dignósticos, atingindo $32,5 \%$ dos idosos estudados.

As doenças endócrinas e metabólicas representam $11,8 \%$ dos dignósticos e estão presentes em $27,0 \%$ dos idosos, com destaque para diabetes melito que contribui com mais de $50 \%$ dentro deste grupo de doenças. 
Tabela $n^{2} 7$.

Distribuição das doenças dos idosos estudados segundo o total de diagnósticos levantados e a proporção de idosos que apresentam o diagnóstico referido. São Paulo, 1989-1990.*

Tuberculose

Outras doenças bacterianas

Rickettsioses e outras

Outras doenças infec. e parasitárias

Neoplasmas

D. endócrinas e metabólicas

Transtornos glândula tireóide

Diabetes melito

obesidade

D. do sangue

Transtornos mentais

D. do sistema nervoso

Transtornos dos olhos e anexos

D. do ouvido

D. hipertensiva

D. isquêmica do coração

D. da circulação pulmonar e outras

formas de doença do coração

D. cerebrovascular

D. do aparelho circulatório

D. do trato respiratório superior

outras doenças do ap. respiratório

D. da bôca, gl. saliv. e maxilares

D. de outras partes do ap. digestivo

D. do aparelho urinário

D. dos órgãos genitais masculinos

D. dos órgãos genitais femininos

D. da pele e tec. celular subcutâneo

D. do sist. osteom. tec. conjuntivo

Sinais, sintomas e afec. mal definidos

TOTAL

* Segundo a Lista Básica para Tabulação -

2 Refere-se ao total de diagnósticos levantados. Refere-se à proporção de idosos que apresentam o diagnóstico referido.

3 A soma é superior a 100\%, porque cada idoso estudado pode apresentar mais de um diagnostico. 
A seguir, ainda de forma relevante, encontram-se as doenças de outras partes do aparelho digestivo, doenças da circulação pulmonar e outras formas de doença do coração e sinais, sintomas e afeç̧ōes mal definidos. Esta última chama a atenção porque mostra o grande número de diagnósticos mal definidos, corroborando a preocupação de THOMSEN e col.(113) quanto à necessidade de se investigar melhor os idosos, ainda que essa referência fosse feita especificamente para a função da tireóide, considerando que os sinais e sintomas dos distúrbios tireoideanos, muitas vezes, podem ser confundidos com alteraçōes características do processo de envelhecimento ou ainda com outras doenças. Também, o elevado percentual desse ítem $(10,4 \%)$ pode estar relacionado ao fato de que os idosos, em geral, apresentam múltiplas enfermidades ao mesmo tempo, como já foi mencionado, e que muitos sinais e sintomas não são patognomônicos de uma única doença e portanto podem estar presentes em diferentes doenças.

Considerando a prevalência das diversas enfermidades classificadas, estabeleceu-se o perfil de morbidade dessa população, o qual está apresentado no Quadro $\mathrm{n}^{\circ} 2$, em comparação com os dados de RAMOS, referidos por RAMOS e $\operatorname{SAAD}^{(102)}$.

Esse Quadro mostra que a doença hipertensiva e as doenças do sistema osteomuscular e tecido conjuntivo ocupam os dois primeiros lugares, na mesma posição, ainda que os dados apresentados tenham sido obtidos de maneira diferente. Enquanto a primeira coluna refere-se à ordenação de diagnósticos, obtidos a partir de prontuários, ou seja, após avaliaçāo médica, a segunda está baseada em informação fornecida, por indivíduos idosos com 65 anos e mais, a pesquisador leigo que foi submetido a treinamento. E importante salientar que esses dados, principalmente em relação à doença hipertensiva parecem coerentes, uma vez que os acidentes cardiovasculares encontram-se entre as principais causas de mortalidade nesse grupo etário ${ }^{(123)}$.

FABBRI e col. ${ }^{(40)}$ encontraram broncopneumonia e insuficiência cardíaca como algumas das principais causas de morte em um grupo de 18 idosos com 60 anos e mais. WOO et al. ${ }^{(121)}$ verificaram que as causas de mortalidade em idosos institucionalizados, em Hong Kong, foram, entre outras, doenças cardiorespiratórias e cerebrovasculares. Os resultados encontrados por esses autores demonstram, de alguma forma, que o grupo de idosos estudados neste 
trabalho está sujeito a sérios riscos de vida uma vez que apresenta perfil de morbidade muito semelhante aos grupos estudados pelos autores citados

Quadro $n^{2} 2$.

Perfil de morbidade dos idosos estudados*. São Paulo, 19891990, comparados aos dados de RAMos(102).

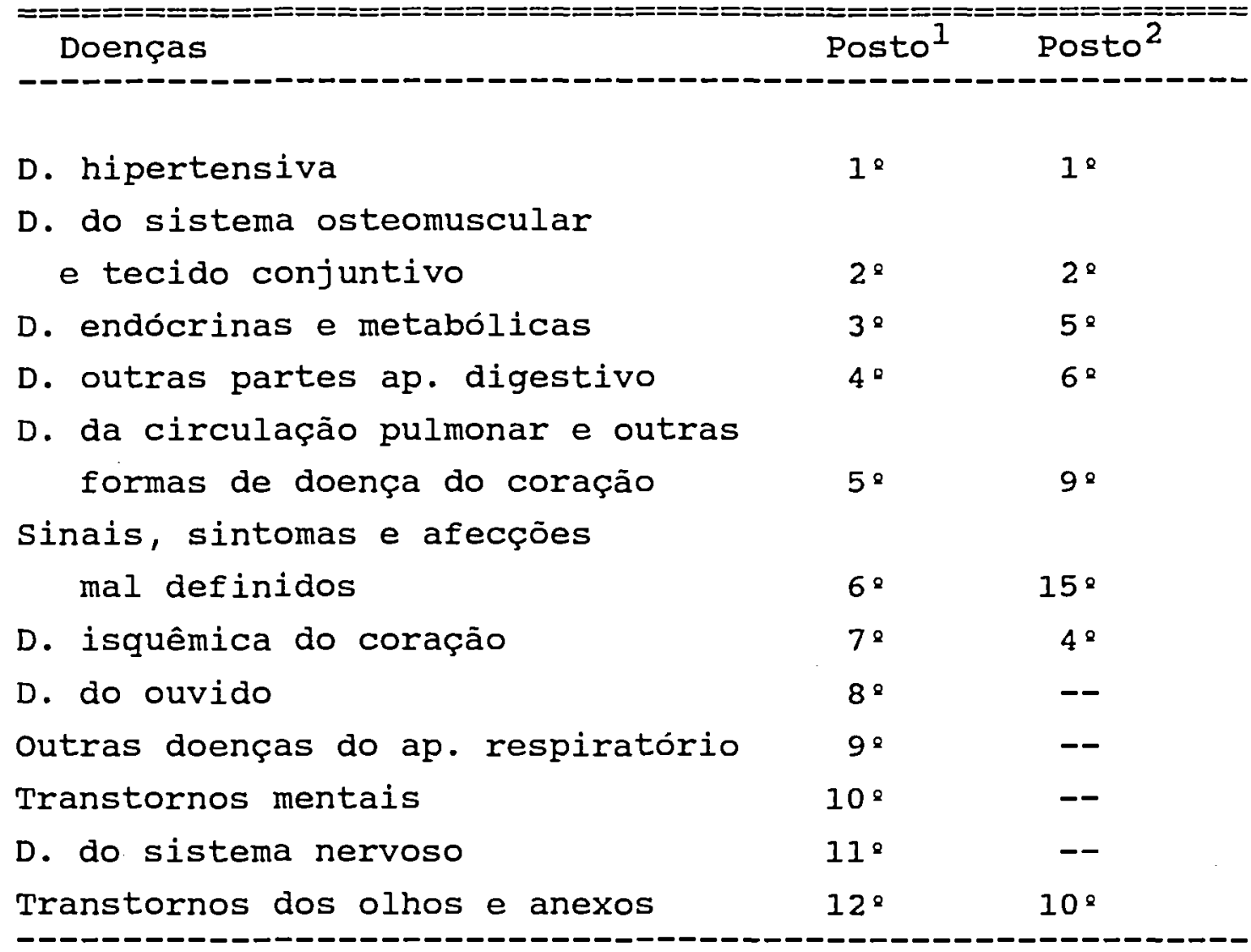

* Segundo a Lista Básica para Tabulação - OMS, 1985, v. .1 (95)

1 Refere-se aos dados do presente estudo. 2 Refere-se aos dados de RAMOS, mencionados por RAMOS e

As doenças do sistema osteomuscular e tecido conjuntivo, embora não se constituam, normalmente, como causas de morte, desempenham papel fundamental na qualidade de vida dos idosos, uma vez que podem torná-los incapacitados, prejudicando a sua independência e autonomia( 66,102$)$. 
As doenças endócrinas e metabólicas aparecem em $3^{\circ}$ lugar neste estudo e em $5^{\circ}$ na pesquisa de $\operatorname{RAMOS}^{(102)}$. Dentre elas, merece menção especial o diabetes, que contribui sobremaneira para o quadro de morbidade dos idosos $(57$, $68,102)$. Ainda, entre estas doenças, vale ressaltar a obesidade e os transtornos da glândula tireóide. Com relação a esta última, THOMSEN e col. ${ }^{(113)}$, estudando 568 idosos, de ambos os sexos, idade entre 60 e 95 anos, matriculados em ambulatório geriátrico, verificaram que 5,6\% apresentavam disfunção tireoideana, sendo $2,6 \%$ de hipertireoidismo, $1,7 \%$ de hipotireoidismo franco e $1,4 \%$ de hipotireoidismo subclínico. Segundo observação dos autores, esses dados são superponíveis aos de outras investigações em idosos, nas quais se verificaram valores de 0,5 a $3 \%$ para o hipertireoidismo e de 0,5 a 3,8\% para hipotireoidismo. Neste estudo os valores encontrados foram 0,3 e $3,6 \%$, respectivamente.

As outras enfermidades (a partir do $4^{Q}$ lugar), apresentadas no Quadro $\mathrm{n}^{0} 2$, ainda que não coincidam com a mesma colocação dos dados de RAMOS $^{(102)}$, são muito importantes na medida em que são as principais causas de internação, repercutindo, portanto, na saúde dos idosos e conseqüentemente na sua qualidade de vida.

Ainda que as informações sobre morbidade hospitalar sejam passíveis de restrições devido a vários fatores ${ }^{(102)}$, alguns dados podem indicar aquelas causas de internação. Assim, de acordo com pesquisa da Fundação $\operatorname{SEADE}^{(48)}$, as doenças do aparelho circulatório foram a primeira causa de internação, considerando pacientes egressos de 60 anos e mais, no Estado de São Paulo (1980), seguidas pelas doenças dos aparelhos respiratório e digestivo, neoplasmas, sinais, sintomas e afecções mal definidos, aparelho genitourinário e doenças endócrinas.

Dados mais recentes (1987) do Centro de Informações sobre Saúde, referidos pela Fundação $\operatorname{SEADE}^{(48)}$, acerca das principais causas de internação da população com 50 anos e mais, na rede previdenciária na Grande São Paulo, mostram que, com exceção das doenças dos aparelhos digestivo e respiratório, aquelas relacionadas ao aparelho circulatório se sobressaem.

No Quadro $\mathrm{n}^{\mathrm{Q}} 3$, estão apresentadas as principais causas de internaçāo, segundo os dados referidos. 
Quadro n².

Causas de internação* das populações com 60 anos $e$ mais (Estado de São Paulo - 1980) e com 50 anos e mais (Grande São Paulo - 1987).

\begin{tabular}{|c|c|c|}
\hline \multirow[b]{2}{*}{ Causas de internação } & \multicolumn{2}{|c|}{ População } \\
\hline & $\begin{array}{l}60 \text { anos } \\
\text { e mais }\end{array}$ & $\begin{array}{l}50 \text { anos } \\
\text { e mais }\end{array}$ \\
\hline $\begin{array}{l}\text { D. circulação pulmonar e outras } \\
\text { formas de doenças do coração }\end{array}$ & $1^{2}$ & 12 \\
\hline D. de outras partes do ap. digestivo & $3^{\circ}$ & $2^{\circ}$ \\
\hline outras doenças do ap. respiratório & $2^{\circ}$ & $3^{\circ}$ \\
\hline D. cerebrovasculares & - & $4^{2}$ \\
\hline Neoplasmas & $4^{2}$ & - \\
\hline D. hipertensiva & - & $6^{2}$ \\
\hline D. endócrinas e metabólicas & 78 & $7^{\circ}$ \\
\hline $\begin{array}{l}\text { D. isquêmica do coração/Outras } \\
\text { doenças do ap. circulatório }\end{array}$ & - & $8^{2}$ \\
\hline D. do aparelho urinário & $6^{\circ}$ & $9^{\circ}$ \\
\hline Sinais, sintomas e afec. mal defir & $5^{2}$ & $10^{\circ}$ \\
\hline
\end{tabular}

* Segundo a Lista Básica para Tabulação - OMS, 1985, v.1 (95)

1 Refere-se aos dados de FERREIRA e FARIA, mencionados pela Fundação SEADE $(48)$.

2 Refere-se aos dados do centro de Informą̧ões sobre saúde CIS, mencionados pela Fundação SEADE $(48)^{\text {? }}$.

WOO et al. ${ }^{(121)}$, estudando idosos institucio-nalizados, verificaram que as doenças mais comuns naquele grupo coincidiam, em grande parte, com aquelas apontadas como causa de internação em São Paulo e também com as apresentadas no perfil de morbidade (Quadro $n^{0} 2$ ). 
Os resultados sobre diagnósticos clínicos deste estudo coincidem, no todo ou em parte, com os de outros autores $(39,40,50,60,67)$, que também estudaram idosos, em condiçōes semelhantes de atendimento e características do grupo etário, analisado neste trabalho.

A presença de grande número de doenças em idosos, inclusive exigindo a utilização de quantidade considerável de medicamentos, é um fato que interfere na sua saúde e conseqüentemente na sua qualidade de vida.

O estudo de CURIATI e col. ${ }^{(31)}$ mostrou que o número de diagnósticos, bem como o de medicamentos foram fatores que contribuíram para que um grupo de idosos tivesse pior desempenho do que outro, quando da aplicação de um teste de avaliaçāo mental. Assim, no primeiro grupo, 44,6\% apresentavam quatro ou mais diagnósticos e 47,7\% utilizavam mais de três medicações, enquanto no segundo grupo esses valores diminuíram para 34,6 e 35,7\% respectivamente.

HIRAMATSU e col(61). entrevistaram 600 pacientes idosos, atendidos em ambulatório, $70,9 \%$ do sexo feminino e $29,1 \%$ do sexo masculino, com idade média de 77 anos, acerca do uso de medicamentos e constataram que o seu consumo foi grande, sendo que a média foi de 4,4 medicamentos por paciente nos seis meses anteriores à entrevista e 2,8 no momento da mesma.

A pesquisa de WOO et al. ${ }^{(121)}$ mostrou que mais da metade $(57,7 \%)$ dos pacientes estudados utilizavam medicamentos, cuja quantidade por indivíduo variava de um a mais de quatro. 


\section{Análise das variáveis sangüíneas:}

As variáveis sangüíneas estudadas foram: glicose, albumina, colesterol e frações (HDL, LDL e VLDL) e triglicérides.

Para o estudo destas variaveis foram considerados os resultados dos exames de 127 idosos, representando $41 \%$ do total, sendo $34 \%$ do sexo masculino e $66 \%$ do sexo feminino, distribuiçāo essa semelhante à da população total estudada. Esta conduta foi adotada a fim de que se pudesse analisar todas as variáveis propostas, uma vez que, até o momento do processamento dos dados, não se dispunha desses para todos os indivíduos estudados e não havia mais tempo hábil para esperar por eles.

Os resultados obtidos foram comparados com os valores de referência adotados pelo laboratório do HC-FMUSP e estão apresentados no Quadro n ${ }^{\circledR} 4$.

\section{Quadro n 4}

Médias e desvios-padrão das variáveis sangüineas estudadas e distribuição dos idosos estudados segundo sexo e variáveis.São Paulo, 1989-1990.

\begin{tabular}{|c|c|c|c|c|c|c|c|c|}
\hline \multirow[t]{2}{*}{$\begin{array}{l}\text { Var iáve is } \\
\text { sangüineas }\end{array}$} & $\begin{array}{l}\text { Valores de } \\
\text { referência }\end{array}$ & Médias $\pm \mathrm{DP}$ & \multicolumn{6}{|c|}{ * de idosos com valores: } \\
\hline & $M \quad F$ & $M$ & M & $F$ & M & $F$ & $\mathbf{M}$ & $F$ \\
\hline Glicose $(m g / d l)$ & $70-110$ & $112 \pm 40$ & 0 & 0 & 67 & 68 & 33 & 32 \\
\hline Albumine $(g / d l)$ & $3,5-5,0$ & $3,9 \pm 0,4$ & 14 & 13 & 86 & 87 & 0 & 0 \\
\hline Colesterol (mg/dl) & $\leq 200$ & $227 \pm 45$ & 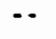 & -- & 51 & 13 & 49 & 87 \\
\hline$H D L-C(m g / d l)$ & $>35$ & $41 \pm 10 \quad 47 \pm 12$ & 26 & 52 & 74 & 48 & $\cdots$ & $\cdots$ \\
\hline$L D L=C(m g / d l)$ & $\leq 130$ & $163 \pm 79$ & $\cdots$ & $-\cdot$ & 42 & 15 & 58 & 85 \\
\hline VLDL = C (mg/dl) & $\leq 40$ & $27 \pm 12$ & $\cdots$ & $\cdots$ & 88 & 89 & 12 & 11 \\
\hline Triglicérides (mg/dl) & $\leq 200$ & $138 \pm 59$ & $\cdots$ & $\cdots$ & 84 & 87 & 16 & 13 \\
\hline
\end{tabular}




\subsection{Glicose}

Com relação à glicose, observa-se, no Quadro $\mathrm{n}^{\circ} 4$, que a média encontrada foi ligeiramente superior $(112 \mathrm{mg} / \mathrm{dl})$ ao valor de referência adotado $(110 \mathrm{mg} / \mathrm{dl})$, sendo $78 \mathrm{mg} / \mathrm{dl}$ o menor valor encontrado e $311 \mathrm{mg} / \mathrm{dl}$ o maior. Verifica-se, no entanto que, praticamente $1 / 3$ da população estudada (33\% dos homens e $32 \%$ das mulheres) apresentaram valores acima daquele considerado como referência.

Glicemia de jejum superior a $130 \mathrm{mg} / \mathrm{dl}$ pode ser considerada como um fator suspeito para diabetes melito ${ }^{(12)}$. Neste estudo, $29(22,8 \%)$ indivíduos apresentaram valores de glicose entre 111 e $130 \mathrm{mg} / \mathrm{dl}$ e 12 (9,4\%), valores superiores a $130 \mathrm{mg} / \mathrm{dl}\left(\right.$ Tabela $\left.\mathrm{n}^{2} 8\right)$.

Considerando que hiperglicemia é fator importante e frequente de diabetes melito e que esta enfermidade contribui sobremaneira para a morbidade das pessoas idosas, como já mencionado no ítem "Perfil de morbidade", torna-se necessário dedicar muita atençāo ao grupo que apresenta valores acima daqueles considerados normais. 
Tabela $n^{2} 8$.

Distribuição dos idosos estudados, segundo niveis de glicose e diagnóstico de diabetes melito. São Paulo, 1989-1990.

\begin{tabular}{|c|c|c|c|c|c|c|c|c|c|}
\hline \multirow{2}{*}{$\begin{array}{l}\text { Nive is de } \\
\text { glicose } \\
(m g / d l)\end{array}$} & \multicolumn{6}{|c|}{$\begin{array}{c}\text { Diagnóstico de diabetes melito } \\
\text { SIM NAO }\end{array}$} & \multicolumn{3}{|c|}{$\begin{array}{l}\text { Sem informaçáo } \\
\text { de diagnóstico }\end{array}$} \\
\hline & $\mathrm{N}^{2}$ & $\%^{1}$ & $\%^{2}$ & $\mathrm{~N}^{2}$ & $\%^{1}$ & $\%^{2}$ & $N^{2}$ & $\%$ & $\%$ \\
\hline $70-110$ & 5 & 29,4 & 3,9 & 74 & 74,7 & 58,3 & 7 & 63,6 & 5,5 \\
\hline $111 \cdot 130$ & 5 & 29,4 & 3,9 & 23 & 23,2 & 18,1 & 1 & 9.1 & 0,8 \\
\hline$>130$ & 7 & 41,2 & 5,5 & 2 & 2,0 & 1,6 & 3 & 27,3 & 2,4 \\
\hline TOTAL & 17 & 100,0 & 13,3 & 99 & 99,9 & 78,0 & 11 & 100,0 & 8,7 \\
\hline
\end{tabular}

Na Tabela $n^{2} 8$ verifica-se que dos 17 idosos que apresentaram diagnóstico de diabetes melito, $12(70,6 \%)$ tinham níveis de glicose acima de $110 \mathrm{mg} / \mathrm{dl}$ e $5(29,4 \%)$ estavam com níveis considerados normais.

Este aspecto pode sugerir que os idosos com níveis elevados de glicose não estejam em tratamento ou este é muito recente, ou, se antigo, pode estar sendo ineficaz, necessitando, portanto, de avaliação e controle. Já no que concerne aos idosos com níveis normais é possível supor que o tratamento e controle estejam adequados.

No caso dos idosos em que diabetes melito não constava como uma das enfermidades entre os diagnósticos registrados para esses idosos, observa-se que $25 \%$ deles apresentavam valores superiores àqueles de referência. Esse fato pode estar relacionado à queda do metabolismo de glicose, levando à intolerância para esse nutriente, situação comum em idosos, tendo em vista as alterações resultantes do processo de envelhecimento $(33,105)$. 
Ainda há que se considerar que os diuréticos são causadores de distúrbios do metabolismo de carboidratos ${ }^{(101)}$. Assim, ainda que não tenha sido objetivo deste trabalho identificar os medicamentos utilizados pela população estudada pode-se supor que o uso de diuréticos é elevado. Esta afirmação está pautada no fato de que a doença hipertensiva foi a mais prevalente e drogas antihiper-tensivas geralmente usadas para o controle dessa enfermidade são os diuréticos. KLEIN e col. ${ }^{(68)}$ referem que esses medicamentos foram os predominantes em $98,8 \%$ de 82 pacientes diabéticos. Essas drogas podem desenvolver intolerância à glicose em indivíduos diabéticos mal controlados, prédiabéticos e mesmo em indivíduos não diabéticos, causando um efeito diabetogênico (101). Dos 25 idosos que apresentaram valores de glicose acima do normal e não tinham diagnóstico para diabetes melito, 15 (60\%) apresentavam hipertensão.

MATHIAS e col. ${ }^{(82)}$ estudaram 152 indivíduos clinicamente sadios e com bom estado nutricional, estrati-ficados por sexo e idade, a fim de estabelecer faixas de normalidade de variáveis hematológicas e bioquímicas para os indivíduos adultos. O grupo de idosos era constituído por 34 pessoas ( 20 homens e 14 mulheres) com idade acima de 50 anos. Os autores encontraram média de $97 \pm 19 \mathrm{mg} / \mathrm{dl}$ para glicose, considerando os valores entre 73 e 137 como a faixa de normalidade, correspondendo, respectivamente, aos percentis 5 e 95 . De acordo com esses valores, maior número de indivíduos deste estudo seriam classificados como normais quanto aos níveis de glicose, ressalvando-se o limite de idade estabelecido para caracterizar o indivíduo como idoso.

\subsection{Albumina}

Com referência a essa fração protéica, os valores encontrados na população estudada variaram de 2,82 a $4,62 \mathrm{~g} / \mathrm{dl}$ e a média obtida foi $3,9 \pm 0,4 \mathrm{~g} / \mathrm{dl}$, a qual se encontra dentro dos valores de referência adotados. A maioria da população estudada ( 86 e $87 \%$, homens e mulheres respectivamente) apresenta níveis normais.

Os resultados obtidos neste estudo são semelhantes àqueles encontrados por HAVLIR et al. ${ }^{(56)}$. Esses autores estudaram 38 pacientes com 65 anos e mais de Palmares, Costa Rica, e obtiveram média de $3,6 \pm 0,6 \mathrm{~g} / \mathrm{dl}$ de albumina para ambos os sexos e valores variando de 2,4 a 4,3 para os homens e 2,4 a 
4,7 para as mulheres, não encontrando, no entanto, indivíduos com desnutrição protéico-calórica.

MUNRO et al. ${ }^{(88)}$ encontraram valores mais elevados: $4,23 \mathrm{e}$ $4,11 \mathrm{~g} / \mathrm{dl}$ em homens de 60-75 e 76 anos e mais, respectivamente; e 4,20 e 4,05g/dl, em mulheres nos mesmos grupos etários, constatando diferença significativa $(p<0,01)$ nos grupos de ambos os sexos, com 76 anos e mais.

Ainda que o valor médio obtido possa ser considerado adequado, tendo em vista encontrar-se dentro dos limites estabelecidos como normais, verificase, no Quadro $\mathrm{n}^{\circ} 4$, que $14 \%$ dos homens e $13 \%$ das mulheres estão com níveis abaixo daqueles de referência. Idosos nessas condições merecem atenção e as causas dessa hipoalbuminemia devem ser investigadas, pois pesquisa de WOO et al. ${ }^{(121)}$ mostra que baixos níveis de albumina podem ser preditores de mortalidade. Esses autores estudaram idosos institu-cionalizados, em Hong Kong, com o objetivo de identificar variáveis nutricionais e outras que pudessem servir como preditores de mortalidade em meses subsequentes e verificaram que os idosos que morreram nos 3 meses seguintes à investigação eram aqueles que tinham desnutrição protéicocalórica, revelada por várias formas, inclusive níveis de albumina significantemente $(\mathrm{p}<0,001)$ mais baixos do que aqueles que sobreviveram.

COOPER \& $\operatorname{GARDNER}^{(29)}$, estudando 101 indivíduos, aparentemente saudáveis, com idades de 55 a 101 anos, concluíram que a hipoalbuminemia em pacientes idosos está mais relacionada com doenças, podendo ser indicadora destas, do que com processo de envelhecimento.

O'KEEFE \& DICKER ${ }^{(53)}$ avaliando 546 pacientes hospitalizados, concluíram que a concentração de albumina não é muito útil como informação do estado nutricional de indivíduos doentes, mas constituem melhor indicador do grau de doença e risco de mortalidade. Esses autores constataram que os pacientes que eram admitidos com baixas concentraçōes de albumina, eram aqueles que apresentavam as mais altas taxas de mortalidade.

Há que lembrar que os idosos estudados apresentam média de 2,3 enfermidades por indivíduo e, portanto, aqueles com baixos níveis de albumina devem receber cuidado especial, porque estāo mais susceptíveis aos riscos de mortalidade. 


\subsection{Colesterol e fraçōes}

No Quadro $\mathrm{n}^{\circ} 4$, verifica-se que a média de colesterol obtida foi $227 \pm 47 \mathrm{mg} / \mathrm{dl}(112-327 \mathrm{mg} / \mathrm{dl})$, valor superior àquele considerado de referência ( $200 \mathrm{mg} / \mathrm{dl}$ ), adotado pelo HC - FMUSP

O valor de colesterol :encontrado neste trabalho é semelhante àquele mostrado por outros estudos feitos em nosso meio $(24,25,77)$, cuja média, para ambos os sexos, foi cerca de $220 \mathrm{mg} / \mathrm{dl}$ de colesterol em indivíduos idosos, sendo sempre maior nas mulheres do que nos homens.

As orientações do National Cholesterol Education Program (NCEP) e a American Heart Association (AHA) também estabelecem 200mg/dl como limite para o colesterol total nos indivíduos com 20 anos e mais. Esta recomendação foi adotada, tendo em vista a relação linear positiva entre níveis sangüíneos elevados de colesterol e risco de doença coronariana, revelada pelos conhecimentos adquiridos por meio de pesquisa básica, ensaios clínicos, estudos experimentais e epidemiológicos, acumulados durante décadas $(13)$.

FIGUEIRA e col. ${ }^{(43)}$ realizaram pesquisa junto a 79 idosos normais de ambos os sexos, com idades variando de 60 a 93 anos, com o objetivo de identificar o perfil lipídico dessas pessoas e estabelecer padrōes de normalidade para a nossa população. Os resultados desse grupo foram comparados com os de 115 indivíduos jovens normais de ambos os sexos com idade de 20 a 40 anos. O valor de colesterol total para os homens idosos ficou muito próximo daquele estabelecido pela NCEP e pela AHA, ou seja, $199 \pm 43 \mathrm{mg} / \mathrm{dl}$. Já para as mulheres, a média foi superior: $233 \pm 47 \mathrm{mg} / \mathrm{dl}$. Tanto no sexo masculino como no feminino, os valores foram mais elevados do que nos indivíduos jovens que apresentaram médias de $179 \pm 38 \mathrm{mg} / \mathrm{dl}$ e $179 \pm 30 \mathrm{mg} / \mathrm{dl}$ respectivamente. Note-se que o valor do colesterol dos jovens de ambos os sexos foi igual e que os dados, comparados com os dos idosos, mostra tendência de aumento do colesterol com o avanço da idade.

MATHIAS e col. ${ }^{(82)}$, também com o objetivo de estabelecer padrões de normalidade para população do nosso meio, estudaram indivíduos jovens, 
adultos e idosos e encontraram média de $197 \mathrm{mg} / \mathrm{dl}$ de colesterol, considerando a faixa de normalidade entre 135 e $260 \mathrm{mg} / \mathrm{dl}$.

Pesquisa realizada por MARTINS e col.(79) em 3792 indivíduos, matriculados em centro de saúde, com idade entre 20 e 59 anos, subdivididos em grupos etários, encontraram, no grupo de 50 - 59 anos, valores médios de colesterol total de $220 \pm 41 \mathrm{mg} / \mathrm{dl}$ e $285 \pm 513 \mathrm{mg} / \mathrm{dl}$ para homens e mulheres, respectivamente. Estes indivíduos estavam incluídos no grupo daqueles considerados isentos de fatores de risco para doença cardiovascular.

ALENCAR e col.(3), analisando os níveis de colesterol total e suas frações em 435 indivíduos com 60 anos ou mais, atendidos em ambulatório geriátrico, verificaram que $69,6 \%$ dos idosos apresentaram níveis de colesterol acima de $200 \mathrm{mg} / \mathrm{dl}$. PRATES e col. ${ }^{(99)}$ encontraram níveis de $216,93 \pm 39,18$ e $187,14 \pm 40,34 \mathrm{mg} / \mathrm{dl}$ para mulheres e homens, respectivamente, com idade entre $57 \mathrm{e}$ 80 anos, atendidos ambulatorialmente.

O estudo de HAVLIR et al. ${ }^{(56)}$ apresenta média de $263 \pm 80 \mathrm{mg} / \mathrm{dl}$ de colesterol, nos indivíduos avaliados, sendo que os valores mais altos foram encontrados em $28 \%$ dos homens e $50 \%$ das mulheres. Embora os autores considerem esses dados apenas descritivos devido ao pequeno tamanho da amostra, apontam-nos como muito importantes, tendo em vista o aumento de doenças cardiovasculares em Costa Rica. Comentam que esses níveis elevados podem estar sofrendo influência das grandes quantidades de gordura, utilizadas para o preparo de alimentos.

Os resultados do Quadro $\mathrm{n}^{\circ} 4$ revelam ainda que $49 \%$ dos homens e $87 \%$ das mulheres apresentam médias de colesterol total acima do valor considerado normal.

Esses dados, bem como o valor elevado da média, podem estar associados aos padrōes alimentares do grupo estudado, a serem analisados no ítem $\mathrm{n}^{2}$. 5, como também à utilização de medicamentos anti-hipertensivos. Estudos referidos por DECOURT ${ }^{(34)}$ têm mostrado que essas drogas (alguns tipos de diuréticos e beta-bloqueadores) podem elevar os níveis de colesterol total e, assim como referido no ítem 3.1 (Glicose), é provável que a populaçāo estudada utiliza esses medicamentos em grande quantidade. 
Níveis elevados de colesterol são reconhecidos como os maiores fatores de risco e preditivos para o desenvolvimento de aterosclerose e doenças coronarianas e o grupo etário de 60 anos e mais é aquele que apresenta a mais alta prevalência para esses níveis $(1,35)$

Ainda que os níveis de colesterol total possam não ter relação com a presença de complicações de aterosclerose em pacientes com 80 anos e mais ${ }^{(4)}$ e não serem considerados fator de risco específico para doenças coronarianas em indivíduos idosos $(35,106)$, sua relação com estas é positiva e fração significante de todas as enfermidades desse tipo, nesse grupo etário, pode ser atribuída aos seus níveis elevados.

Estudo realizado por RON et al.(106), em octagenarianos saudáveis, mostrou que os níveis de colesterol total foram significantemente mais altos no grupo positivo para a doença isquêmica do coração em ambos os sexos.

KORNITZER \& BARA ${ }^{(70)}$ consideraram o colesterol total como a principal diferença entre os fatores de risco para coronariopatias, com níveis significantemente mais altos, em todas as idades, nos indivíduos residentes no sul da Bélgica, quando comparados com os do norte.

Assim, considerando esses aspectos e a magnitude do problema das doenças coronarianas, faz-se necessário o controle e tratamento dos indivíduos que apresentam níveis elevados de colesterol $(13,35,38)$.

DENKE et al. ${ }^{(35)}$ recomendam, como primeiro passo para esse tratamento, a modificação da dieta. Esta, associada a outras condutas, contribuiu para a reduçāo do colesterol total de 227,1 para $217,5 \mathrm{mg} / \mathrm{dl}$ em idosos, orientados a cumprir a dieta da fase I, preconizada pela A.H.A. ${ }^{(25) .}$

No entanto, além do colesterol total, que no caso particular dos idosos, especialmente do sexo masculino, pode não significar fator de risco para aquelas doenças $(38)$, importa conhecer os níveis de suas frações para se avaliar melhor o estado de saúde dos indivíduos ${ }^{(111)}$. Nesse sentido, verifica-se, no Quadro $\mathrm{n}^{2} 4$, que a lipoproteína de alta densidade (HDL-C), considerada fator protetor em relação às doenças coronarianas, apresenta-se abaixo do valor de referência em 
$26 \%$ dos homens e $52 \%$ das mulheres, ao passo que a lipoproteína de bảixa densidade (LDL-C), identificada, juntamente com o colesterol total, como o principal fator de risco para aquelas doenças, apresenta-se com valores elevados em $58 \%$ dos homens e $85 \%$ das mulheres, com média de $163 \pm 79 \mathrm{mg} / \mathrm{dl}(16-850)$, valor este considerado de alto risco.

Esses valores elevados de LDL-C podem estar sendo influenciados pelo tipo de alimentação consumida, que será analisada posteriormente, ou também pelos medicamentos utilizados. Estes podem alterar também os níveis de HDL-C, reduzindo-os, ainda que em grau variável ${ }^{(34)}$.

FIGUEIRA e col. ${ }^{(43)}$ encontraram valores normais para homens e mulheres no que se refere à HDL-C e médias de LDL-C inferiores a $160 \mathrm{mg} / \mathrm{dl}$ para ambos os sexos.

MATHIAS e col. ${ }^{(82)}$ estabeleceram, respectivamente, 47 e $128 \mathrm{mg} / \mathrm{dl}$ como valores médios para HDL-C e LDL-C, em indivíduos adultos e idosos de ambos os sexos.

Os resultados dos trabalhos de RON et al.(106) mostram que os grupos de homens e mulheres positivos para doença isquêmica do coração apresentam niveis de HDL-C mais baixos do que aqueles negativos para a doença, ainda que não fosse constatada diferença estatisticamente significante.

LIBERMAN e col. ${ }^{(72)}$, estudando alguns fatores de risco de doença cardiovascular em pacientes idosos, verificaram que aqueles encontrados com maior freqüência foram níveis baixos de HDL-C $(<35 \mathrm{mg} / \mathrm{dl})$ em $68,65 \%$ da população estudada (292 idosos) e altos de LDL-C (>160mg/dl) em 41,1\% da população, além do diagnóstico de hipertensão arterial. MARTINEZ e col.(77) encontraram 29,5\%, de 300 idosos avaliados, com HDL-C menor que 35mg/dl e $37,5 \%$ com LDL-C maior que $160 \mathrm{mg} / \mathrm{dl}$.

A LDL-C tende a aumentar entre a terceira e quinta décadas nos homens e depois permanecer estável até 70 anos, quando começa a declinar. Já nas mulheres, os níveis de LDL-C continuam aumentando até os 70 anos, apresentando níveis mais elevados que nos homens. Parece, então, que o processo de envelhecimento é o fator responsável pela elevação desses níveis. No entanto, os 
mecanismos pelos quais as concentraçōes de LDL-C aumentam com a idade ainda não estão muito bem esclarecidos $(38,43)$ e alguns estudos $(38)$ têm demonstrado que a qualidade da dieta pode ser fator mais importante na alteração da LDL-C do que o resultado do envelhecimento.

Enfim, considerando os riscos que os níveis inadequados de LDL-C podem causar aos indivíduos é que se recomenda o controle e tratamento deles, entre os quais a dieta desempenha papel relevante $(13,34,35,38)$. O estudo realizado por CENDOROGLO e col. (25) mostrou que modificação na dieta de indivíduos idosos propiciou redução nos valores de LDL-C.

ETTINGER et al. ${ }^{(38)}$ recomendam a aplicação das orientações do NCEP, referente à modificação do conteúdo de gordura da dieta de acordo com os níveis de LDL-C. Segundo aquele Programa, pacientes com altos níveis dessa fraçāo do colesterol poderiam ser tratados com a Fase I da dieta proposta. Se for constatada redução da LDL-C para níveis normais em três meses, os pacientes devem continuar cumprindo a mesma dieta. Em caso negativo, deve-se aplicar a Fase II da dieta, que restringe ainda mais a quantidade de gordura saturada e colesterol dietéticos, e deve ser cumprida por um período de 3 meses $(13,38)$.

Ainda que seja improvável que a redução dos níveis de LDL-C possam implicar em aumento da expectativa de vida em indivíduos acima de 75 anos, esforços para prevenção de coronariopatias em pessoas com idade inferior a essa, especialmente nas mulheres, devem ser realizados $(38)$.

Analisando ainda as frações do colesterol, verifica-se que a lipoproteína de muito baixa densidade (VLDL-C) apresenta média aceitável: $27 \pm 12 \mathrm{mg} / \mathrm{dl}$ (10 - 75), Quadro $\mathrm{n}^{9} 4$, tendo em vista o valor de referência ( $\left.40 \mathrm{mg} / \mathrm{dl}\right)$. No entanto, $12 \%$ dos homens e $11 \%$ das mulheres têm os seus níveis acima desse valor. Esta elevação provavelmente está contribuindo para os altos níveis de LDL$\mathrm{C}$, uma vez que a maior parte desta é derivada da VLDL-C.

\subsection{Triglicérides}

Da mesma maneira que a VLDL-C, os triglicérides apresentam média adequada: $138 \pm 59 \mathrm{mg} / \mathrm{dl}\left(53\right.$ - 375), Quadro $\mathrm{n}^{\varrho} 4$, já que dentro dos limites 
( $200 \mathrm{mg} / \mathrm{dl}$ ) admitidos como normais. Porém, $16 \%$ dos homens e $13 \%$ das mulheres encontram-se com valores acima daquele de referência, o que talvez possa justificar os níveis elevados de VLDL-C, uma vez que esta é constituída em grande parte por aquele componente.

Mais uma vez o uso de drogas anti-hipertensivas pode estar influenciando esses níveis elevados, conforme referido em DECOURT ${ }^{(34)}$, sem, no entanto, deixar de considerar a possível contribuição da dieta.

Nos estudos de MARTINEZ e col.(77) e CENDEROGLO e col. ${ }^{(25)}$ os valores médios encontrados para triglicérides em idosos foi $271,0 \mathrm{mg} / \mathrm{dl}$ e $214,8 \mathrm{mg} / \mathrm{dl}$ respectivamente, portanto acima dos valores de referência. Já na investigação de FIGUEIRA e col. ${ }^{(43)}$ os níveis, tanto para mulheres como para homens idosos estiveram dentro dos limites recomendados $(125,78 \pm .53,13 \mathrm{e}$ $124,54 \pm 45,23 \mathrm{mg} / \mathrm{dl}$, respectivamente).

Ainda que os triglicérides por si só não representem fator de risco para coronariopatias, eles podem estar associados com outros (obesidade, intolerância à glicose e hipo-alfalipoproteinemia), os quais estão relacionados com essas doenças $(38)$.

FIGUEIRA e col. ${ }^{(43)}$ sugerem que a determinação isolada de triglicérides, bem como a de colesterol, possa ser adotada nos exames clínicos de rotina como preditores de doenças coronarianas. Esse fato se justificaria tendo em vista que alterações desses componentes podem ser reflexo das variações das lipoproteínas em virtude destas apresentarem, em sua composição, frações diferentes daqueles. 


\section{Análise das variáveis antropométricas:}

A análise das variáveis antropométricas foi realizada, da mesma maneira que para as variáveis sangüíneas, para 127 idosos (44 homens e 83 mulheres), correspondendo a $41 \%$ do total.

Os indicadores antropométricos foram utilizados neste trabalho para contribuir na avaliação nutricional do grupo estudado.

Esses indicadores de avaliação podem ser considerados confiáveis quanto aos resultados obtidos desde que executados por pessoas experientes (118). Além disso, apresentam vantagens, tendo em vista utilizarem métodos não invasivos, equipamentos de uso relativamente simples e serem de baixo custo $(41,58$, 118). No entanto, a conclusāo de um diagnóstico a partir da avaliação antropométrica não pode pautar-se em um único, mas sim em um conjunto de indicadores. Assim, para o presente estudo foram avaliados: peso, altura, circunferência do braço e prega cutânea triciptal. Ainda que outras medidas pudessem ter sido realizadas, optou-se por estas, tendo em vista a sua maior utilização quando da avaliação de indivíduos, possibilitando, assim, a comparação entre grupos.

Para complementar a avaliação, analisou-se o índice de Quetelet ou índice de massa corporal (IMC), dado pela relação peso (em quilogramas) por altura (em metros) ao quadrado.

Os resultados obtidos das variáveis antropométricas estudadas estão apresentados no Quadro $n^{\circ} 5$. 
Quadro $n^{\circ} 5$

Médias e desvios-padrão de variáveis antropométricas, distribuídos segundo sexo dos idosos estudados e para ambos os sexos. São Paulo, 1989-1990.

\begin{tabular}{|c|c|c|c|}
\hline Variáveis antropométricas & Masculino & $\begin{array}{l}\text { La } \pm \text { Desvio } \\
\text { Feminino }\end{array}$ & $\begin{array}{l}\text { Ambão } \\
\text { Ambos os } \\
\text { Sexos }\end{array}$ \\
\hline eso $(\mathrm{kg})$ & $66 \pm 10$ & $64 \pm 11$ & $65 \pm 11$ \\
\hline ltura (m) & $1,64 \pm 0,07$ & $1,53 \pm 0,05$ & $1,57 \pm 0,08$ \\
\hline ircunferência do braço (cm) & $28,4 \pm 3,2$ & $30,3 \pm 3,8$ & $29,7 \pm 3,7$ \\
\hline ega cut. triciptal (mm) & $14,0 \pm 7,6$ & $22,3 \pm 6,9$ & $19,5 \pm 8,1$ \\
\hline dice de Quetelet $(\mathrm{kg} / \mathrm{m}$ & $24,6 \pm 3,2$ & $27,1 \pm 4,5$ & $26,2 \pm 4,2$ \\
\hline
\end{tabular}




\subsection{Peso:}

O peso corporal representa a soma de todos os componentes do organismo, incluindo: proteína, gordura, água e massa óssea e pode servir como indicador das reservas nutricionais $(51)$.

Em geral, o peso é relacionado à altura para avaliar o estado nutricional, considerando que para uma determinada altura está associado um peso corporal ideal ou desejável. Tabelas de peso/altura, como, por exemplo da Metropolitan Life Insurance Company $(83,84)$ têm sido utilizadas como parâmetro. No entanto, essas tabelas podem ser inadequadas, pois, às vezes, podem indicar "excesso de peso" como indicativo de obesidade, quando, na realidade, pode referirse a um grande desenvolvimento muscular como verificado em jogadores de futebol australianos e americanos $(117,120)$. Alguns autores $(51)$ também se manifestaram contrariamente à comparação com valores dessas tabelas e propõem utilizar a variação percentual do peso habitual na avaliação nutricional, admitindo que o peso habitual indica o melhor peso ou o peso "ideal" para um indivíduo, sendo, no entanto, imprescindível a avaliação clínica.

Por essas razões, ao invés de utilizar tais tabelas como referência, preferiu-se comparar os resultados obtidos neste estudo com aqueles encontrados por outros autores que avaliaram grupos semelhantes. Além disso, excesso de peso por si só nāo indica obesidade e não é considerado um fator causal para doenças do coração, nem significa fator de risco para essas doenças $(41,46)$. Ainda, excesso de peso e excesso de gordura não são a mesma coisa ${ }^{(58)}$.

O peso é uma variável que reflete o estado nutricional mais recente e medidas periódicas são de fundamental importância para determinar se houve alteração em um certo período de tempo, especialmente na vigência de doenças crônicas que, em geral, são comuns em idosos.

Assim, a variação de peso poderá indicar mudança no estado nutricional e, ainda que não identifique a variável em modificação, alertará para uma avaliação mais detalhada e profunda ${ }^{(51)}$. A composição dos elementos que compõem o peso pode alterar-se sobremaneira em função de sexo, idade, estados fisiológicos específicos ou patológicos. 
O estudo de PRATES e col. ${ }^{(99)}$ mostrou diferença significativa $(p<$ $0,05)$ nas médias de peso de homens e mulheres.

As investigações de WASWA et al.(119) e de BURR et al.(18) revelaram declínio do peso dos indivíduos com o avanço da idade, ainda que estudando grupos populacionais de nível sócio-econômico diferente.

A avaliaçāo de 58 pacientes idosos internados, com média de 74 anos, e que apresentavam queixas de emagrecimento, revelou que as maiores perdas de peso foram relacionadas a distúrbios endócrinos $(2,6 \mathrm{~kg} / \mathrm{mês})$ e neoplásicos (2,3kg/mês). Nesse estudo, as causas do emagrecimento identificadas em $94,8 \%$ dos pacientes - incluem: distúrbios neuro-psiquiátricos, infecções, problemas gatrointestinais, neoplasias, doenças cardiovasculares e endócrinas $(104)$.

A média de peso encontrada para os idosos estudados neste trabalho foi $65 \pm 11 \mathrm{~kg}$ para ambos os sexos, sendo $66 \pm 10 \mathrm{~kg}$ para os homens e $64 \pm 11 \mathrm{~kg}$ para as mulheres (Quadro $n^{2} 5$ ). Em nosso meio, o estudo de PRATES e col. ${ }^{(99)}$ mostrou valor igual para as mulheres e média superior $(76 \pm 10 \mathrm{~kg}$ ) para os homens, quando estudaram 40 idosos ambulatoriais com idade entre 57 e 80 anos. No exterior, em Nápoles, Itália, o estudo de CONTALDO et al.(28) em 136 idosos saudáveis, vivendo na comunidade, revelou valores médios mais elevados em ambos os sexos ( $72 \pm 13,6 \mathrm{~kg}$ para os homens e $70 \pm 19,9 \mathrm{~kg}$ para as mulheres) do que aqueles encontrados no presente estudo. Já FINDANZA et al.(44), avaliando o estado nutricional de idosos institucionalizados em Perúgia, Itália, constatou variação de peso de 43,5 a 91,5kg para os homens e de 41,0 a $74,5 \mathrm{~kg}$ para as mulheres, sendo que os valores para o percentil 50 foram 56,5 e $60 \mathrm{~kg}$, respectivamente.

\subsection{Altura:}

A altura é utilizada para avaliar desnutrição crônica. No caso particular de idosos, essa medida antropométrica pode ser problemática, porque, devido aos efeitos do processo de envelhecimento, podem surgir severas alteraçōes esqueléticas, com mudanças na coluna vertebral, como por exemplo a cifose. Além disso, tem-se verificado que a altura sofre declínio com o avanço da idade (18, $^{114}$, $119)$, quer pelas alterações na coluna, quer por um adelgaçamento de todas as 
cartilagens que suportam o peso corporal, ou ainda a tendência de andar com os joelhos curvados, devido à dificuldade de manter uma posição ereta, que é parcialmente conseqüência de insuficiência muscular ${ }^{(85)}$.

Tendo em vista esses aspectos, foi adotada a mesma conduta em relação à medida do peso, ou seja, comparar os valores encontrados com os de outros autores.

A média de altura para homens e mulheres deste estudo foi $1,64 \mathrm{~m}$ e $1,53 \mathrm{~m}$ respectivamente (Quadro $\mathrm{n}^{9} 5$ ). PRATES e col. ${ }^{(99)}$ constataram valores semelhantes: $1,66 \mathrm{~m}$ para o sexo masculino e $1,55 \mathrm{~m}$ para o sexo feminino, assim como CONTALDO et al. ${ }^{(28)}$ (1,65m para homens e 1,53 para mulheres), sendo que estes últimos referem-se a grupo populacional europeu, vivendo na comunidade. Ainda com relação à população idosa européia, porém institucio-nalizada, FINDANZA et al. ${ }^{(44)}$ observaram variaçōes de 1,42 a $1,67 \mathrm{~m}$, com $1,60 \mathrm{~m}$ no percentil 50 para homens, e 1,32 a $1,54 \mathrm{~m}$, com $1,50 \mathrm{~m}$ no mesmo percentil para as mulheres.

\subsection{Circunferência do braço:}

A circunferência do braço é variável utilizada para avaliar o estado nutricional de indivíduos $(47)$. Ela representa a somatória das áreas constituídas pelos tecidos ósseo, muscular, gorduroso e epitelial do braço ${ }^{(118)}$ e a sua medida é usada para estimar reservas de proteína muscular ${ }^{(47)}$.

Estudos têm demonstrado que o valor da circunferência do braço, assim como verificado para a altura, tende a diminuir com o avanço da idade $(16,17$, $45,119)$, o que pode sugerir perda progressiva da massa muscular.

No Quadro $\mathrm{n}^{9} 5$, observa-se que a média da circunferência do braço encontrada para ambos os sexos foi $29,7 \mathrm{~cm}$, enquanto na mulheres, esse valor foi $30,3 \pm 3,8 \mathrm{~cm}$ e nos homens $28,4 \pm 3,2 \mathrm{~cm}$. 
A análise de dados, colhidos durante o Health and Nutrition Examination Survey (HANES) de 1971 a 1974, feita por BISHOP et al. (16) mostrou que a média da circunferência do braço em homens com 55 a 64 anos foi $31,5 \mathrm{~cm}$ e para mulheres do mesmo grupo etário, $30,7 \mathrm{~cm}$. No grupo de 65 a 74 anos, essa média diminui, sendo de 30,5 e $30,1 \mathrm{~cm}$, para homens e mulheres, respectivamente.

Análise realizada por FRISANCHO ${ }^{(45)}$, também a partir de dados do HANES $71 / 74$, mostrou valores referentes ao percentil 50 , de 31,7 e $30,3 \mathrm{~cm}$ para homens e mulheres respectivamente, no grupo etário de 55 a 64,9 anos, e de 30,7 e $29,9 \mathrm{~cm}$ no grupo de 65 a 74,9 anos.

O estudo de WASWA et al.(119) em indivíduos de 50 anos e mais, residentes em área rural, no Kenya, mostrou valores de 24,4, 23,4 e 22,7cm, respectivamente nos grupos etários de 60-69, 70-79 e 80 e mais anos, no sexo masculino. Para o sexo feminino, as médias encontradas foram 23,8, 22,2 e 22,3cm para os mesmos grupos de idade. Observa-se que os valores da circunferência do braço encontrados no estudo de WASWA et al.(119) são inferiores àqueles mostrados em outros trabalhos $(16,45,99)$, inclusive neste, sugerindo que a população estudada por aqueles. autores apresenta desnutrição protéica.

WOO et al.(121) verificaram que houve diferença significativa $(p<0,001)$ nos valores da circunferência do braço entre indivíduos idosos que morreram $(20,1 \mathrm{~cm})$ após três meses de investigação e aqueles que sobreviveram $(22,7 \mathrm{~cm})$, sendo que os primeiros, apresentavam desnutrição protéico-calórica, constatada inclusive por outros indicadores.

A avaliação de PRATES e col. ${ }^{(99)}$ indica que, a exemplo das análises feitas em nível internacional, o valor médio de circunferência do braço encontrado em homens $(28,07 \mathrm{~cm})$ é maior do que nas mulheres $(27,83 \mathrm{~cm})$, ainda que não tenha sido constatada diferença significante.

Os valores encontrados para a circunferência do braço, tanto em nível internacional como nacional, são indicativos de que os homens apresentam maior quantidade de massa muscular do que as mulheres. Neste estudo, foi excepcional o fato de se encontrar valor maior para os indivíduos do sexo feminino. 


\subsection{Prega cutânea triciptal:}

Assim como a circunferência do braço, a prega cutânea é variável também utilizada para avaliar o estado nutricional de indivíduos e a triciptal é a mais comum delas $(51)$.

A medida da prega cutânea contribui para avaliação da composição corporal, uma vez que possibilita a estimativa da quantidade de gordura total do corpo, "assumindo que $50 \%$ da gordura corporal é subcutânea"(71) e pode ser indicativa de obesidade, melhor do que a medida isolada de peso, ou a simples relaçāo peso/altura.

À medida que o indivíduo envelhece há mudança da composição corporal: a massa corporal magra diminui e a quantidade de gordura aumenta, geralmente até os 70 anos, quando, então, começa a diminuir.

Estudos têm demonstrado que o valor da prega cutânea triciptal tende a diminuir com o avanço da idade, podendo sugerir perda de gordura com a idade, e é mais elevado nas mulheres do que nos homens $(16,17,45,88)$.

Na população estudada neste trabalho a média da variável em questão foi $19,5 \pm 8,1 \mathrm{~mm}$ para ambos os sexos, apresentando-se, como em outros estudos $(16$, $17,45)$ mais elevada nas mulheres $(22,3 \pm 6,9 \mathrm{~mm})$ do que nos homens $(14,0 \pm 7,6 \mathrm{~mm})$.

WASWA et al. (119) encontraram os seguintes valores de prega cutânea triciptal em idosos do sexo masculino: 5,8, 8,2 e 9,1mm, respectivamente para os grupos de 60-69, 70-79 e 80 e mais anos. Para as mulheres, os valores foram $11,7,10,7$ e $10,0 \mathrm{~mm}$ nos mesmos grupos etários. Note-se que os valores encontrados no presente trabalho são muito superiores, em ambos os sexos, em relação ao estudo de WASWA et al. ${ }^{(119)}$, representando praticamente o dobro em relação às mulheres e de 1,5 a 2,5 vezes no caso dos homens.

Investigação conduzida por MUNRO et al. ${ }^{(88)}$ em 691 idosos, de ambos os sexos, isentos de doenças incapacitantes, revelou valores médios de prega cutânea triciptal maiores que aqueles encontrados nos estudos de WASWA et 
al. ${ }^{(119)}$ e no presente, sendo 18,4 e 16,4mm, nos homens dos grupos etários de 60-75 e 76 anos e mais, respectivamente, e 29,5 e $24,5 \mathrm{~mm}$ nas mulheres dos mesmos grupos etários.

BISHOP et al. ${ }^{(16)}$ fornecem valores de referência para prega cutânea triciptal, distribuídos em 7 percentis $(5,10,25,50,75,90$ e 95), obtidos de dados colhidos de população adulta não institucionalizada, representativa dos Estados Unidos, mas incluindo indivíduos com até 74 anos. O mesmo ocorre com os valores de FRISANCHO ${ }^{(45)}$. Vale ressaltar que 74 anos é a média e a mediana de idade da população do presente estudo. Os valores propostos por CHUMLEA et al., referidos em WAITZBERG ${ }^{(118)}$, incluem idosos até 90 anos, mas são considerados somente 3 percentis $\left(5,50\right.$ e 95). Os valores estabelecidos por BURR \& PHILLIPS ${ }^{(17)}$ para a população idosa da Inglaterra consideram indivíduos a partir de 65 anos de idade e incluem o grupo de 85 e mais, distribuídos também em 7 percentis $(5,10,25,50,75$, 90 e 95), que, no entanto, apresentam valores muito inferiores àqueles verificados em BISHOP et al. ${ }^{(16)}$ e FRISANCHO ${ }^{(45)}$.

As médias da prega cutânea triciptal encontradas na população estudada no presente trabalho são sugestivas de obesidade e indicam que as mulheres apresentam maior quantidade de gordura que os homens.

\subsection{Indice de Quetelet (Índice de massa corporal):}

O índice de Quetelet ou índice de massa corporal (IMC) definido pela relação peso (em quilogramas) e altura (em metros) ao quadrado, tem sido grandemente utilizado como um indicador da gordura corporal ${ }^{(36)}$ e parece ser mais apropriado que outros índices de peso/altura, porque sua correlação com porcentagem de gordura corporal, fornecendo estimativas precisas desta, é alta e com a altura é baixa. Além disso, é um método considerado simples, de baixo custo e menos dependente dos erros intra e inter-observadores do que as medidas de pregas cutâneas $(37)$.

THOMAS et al. ${ }^{(112)}$ propōem um nomógrafo para avaliar o IMC, mas alertam quanto à necessidade de se fazer o julgamento em termos clínicos, 
baseado também em outros indicadores como a proporção de massa muscular em relaçã̃o à gordura. Segundo esses autores, apesar de o IMC apresentar limitaçōes, ainda a avaliação do peso relativo, quando interpretada com precaução, parece ser um guia adequado para verificar o estado nutricional.

BURR \& PHILLIPS ${ }^{(17)}$ apresentam os dados de IMC obtidos a partir de estudo feito em cerca de 1500 idosos do sul do País de Gales, distribuindo esses valores em forma de percentis e propondo-os como padrão de referência para os idosos da Inglaterra.

Na Pesquisa Nacional sobre Nutrição e Saúde - PSNS, recentemente realizada pelo Instituto Nacional de Alimentação e Nutrição - INAN(27), sobre as condições nutricionais de adultos e idosos brasileiros, o IMC foi utilizado como indicador e o parâmetro foi o mesmo adotado neste estudo.

Os critérios propostos por GARROW et al., referidos em DEURENBERG et al. ${ }^{(36)}$ são geralmente aceitos e foram utilizados como parâmetro para comparação dos dados encontrados neste trabalho. Estes autores estabelecem o seguinte:

IMC entre 20 e $25 \mathrm{~kg} / \mathrm{m}^{2}$ indica peso normal

IMC entre 25 e $30 \mathrm{~kg} / \mathrm{m}^{2}$, sobrepeso e

IMC maior do que $30 \mathrm{~kg} / \mathrm{m}^{2}$, obesidade.

A média de IMC, para ambos os sexos, encontrada na população deste estudo foi $26,2 \pm 4,2 \mathrm{~kg} / \mathrm{m}^{2}$. Se se considerar apenas este valor, poder-se-ia dizer que os idosos estudados apresentam-se com sobrepeso segundo os critérios adotados.

No entanto, observando a média por sexo, verifica-se que os homens $\left(24,6 \mathrm{~kg} / \mathrm{m}^{2}\right)$ seriam considerados normais quanto ao peso e apenas as mulheres $\left(27,1 \mathrm{~kg} / \mathrm{m}^{2}\right)$ estariam com sobrepeso.

Para melhor estudar essas diferenças de acordo com o sexo, a Tabela $\mathrm{n}^{\circ} 9$ apresenta a distribuição de idosos segundo os valores de IMC. Verifica-se que $46 \%$ das mulheres estão com sobrepeso e praticamente um quarto delas (24\%) podem ser consideradas obesas. No caso do sexo masculino, $50 \%$ sāo normais para o peso, enquanto $41 \%$ manifestam sobrepeso e somente $2 \%$ seriam obesos. Estes 
dados, de alguma forma, se superpõem àqueles do $\operatorname{INAN}^{(27)}$ e às considerações feitas em relação à prega cutânea triciptal, cujos resultados foram superiores nas mulheres.

Tabela $\mathrm{n}^{2} 9$.

Distribuição dos idosos estudados segundo os valores de IMC. São Paulo, 1989-1990.

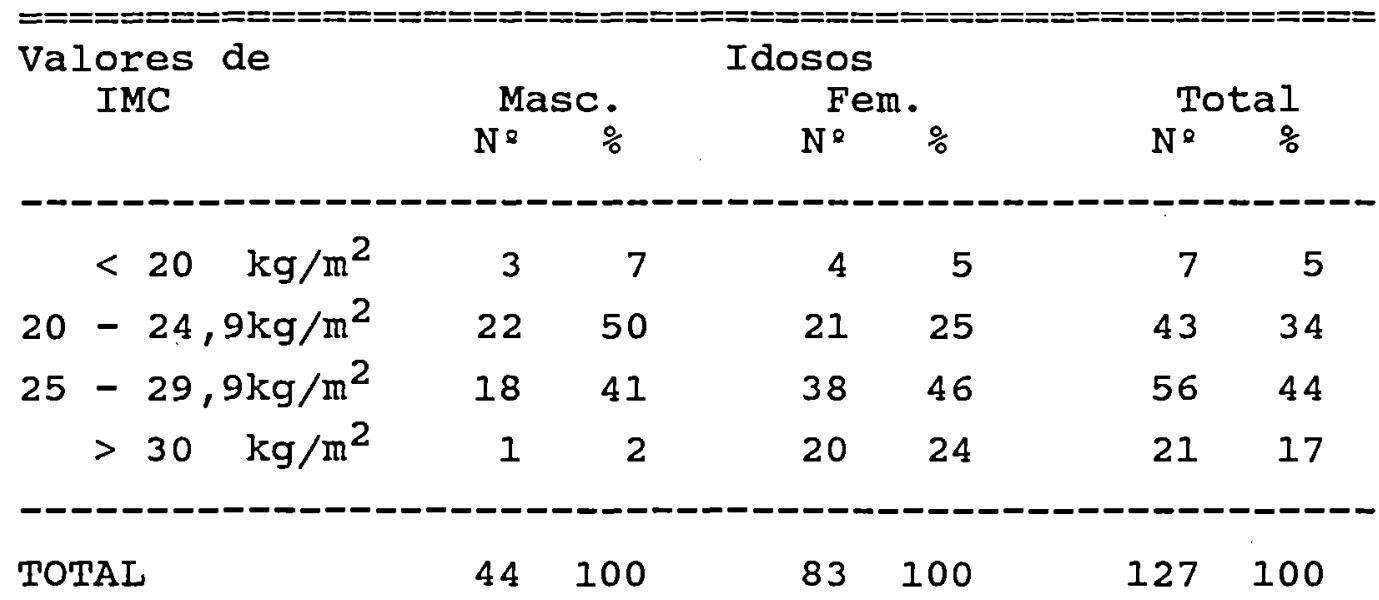

Os valores de IMC para os homens variaram de 16,9 a $30,7 \mathrm{~kg} / \mathrm{m}^{2}$ e para as mulheres de 17,8 a $39,1 \mathrm{~kg} / \mathrm{m}^{2}$. No estudo de FINDANZA et al. ${ }^{(44)}$ esses valores foram: 20,4 a 39,1 e 17,9 a $35,0 \mathrm{~kg} / \mathrm{m}^{2}$, respectivamente, para homens e mulheres.

As médias de IMC encontradas neste estudo, praticamente correspondem aos valores do percentil 50 estabelecidos por FINDANZA et al. ${ }^{(44)}$ especialmente no caso das mulheres $\left(27,3 \mathrm{~kg} / \mathrm{m}^{2}\right)$; para os homens, o valor é $22,7 \mathrm{~kg} / \mathrm{m}^{2}$. Por outro lado, ao se compararem os dados deste trabalho com os de CONTALDO et al. ${ }^{(28)}$ verifica-se que a média encontrada por esses autores é superior tanto nos homens $\left(26,1 \mathrm{~kg} / \mathrm{m}^{2}\right)$ quanto nas mulheres $\left(29,8 \mathrm{~kg} / \mathrm{m}^{2}\right)$.

PRATES e col.(99) encontraram valores mais elevados: $27,3 \pm 4,06$ $\mathrm{kg} / \mathrm{m}^{2}$ e $26,6 \pm 5,25 \mathrm{~kg} / \mathrm{m}^{2}$, respectivamente, para homens e mulheres e, considerando 
esses e valores de outras variáveis, sugerem maior atenção à obesidade após a menopausa.

A pesquisa do $\operatorname{INAN}^{(27)}$, comparando os dados obtidos em 1989 com os do Estudo Nacional de Despesa Familiar (ENDEF) 74/75, constatou que, em relação ao sobrepeso e obesidade, a sua prevalência para os homens aumentou de 15,1 para $23,4 \%$ e de 2,65 para $4,98 \%$, respectivamente. No que concerne às mulheres, a situação é igual, verificando-se que a prevalência de sobrepeso elevou-se de 22,9 para $32,4 \%$ e a de obesidade, de 9,96 para $17,9 \%$. Considerando que a obesidade está associada a diversas doenças, esses dados mostram a gravidade da situação nutricional desse grupo etário e alertam quanto às providências a serem tomadas pelo setor saúde.

Estudos realizados por MARTINS e col. $(78,79)$ sobre fatores de risco para doenças cardiovasculares, constataram que a obesidade, isolada ou associada, foi o fator de risco mais relevante para todos os grupos etários de ambos os sexos. 


\section{Análise dos aspectos dietéticos.:}

A nutrição desempenha papel relevante na saúde dos indivíduos e vários fatores (fisiológicos, sociais, econômicos, culturais) podem contribuir para a alteração do seu estado nutricional ${ }^{49)}$. Entre esses fatores, os padrões alimentares constituem importante aspecto. Assim, neste estudo, identificou-se a dieta habitual, bem como a freqüência de alimentos consumidos pelo grupo analisado, considerando o total de 308 idosos.

A Tabela $\mathrm{n}^{2} 10$ apresenta a distribuição do número de refeições consumidas por idoso.

Tabela $\mathrm{n}^{2} 10$.

Número de refeições consumidas por idoso estudado. São Paulo, 1989-1990.

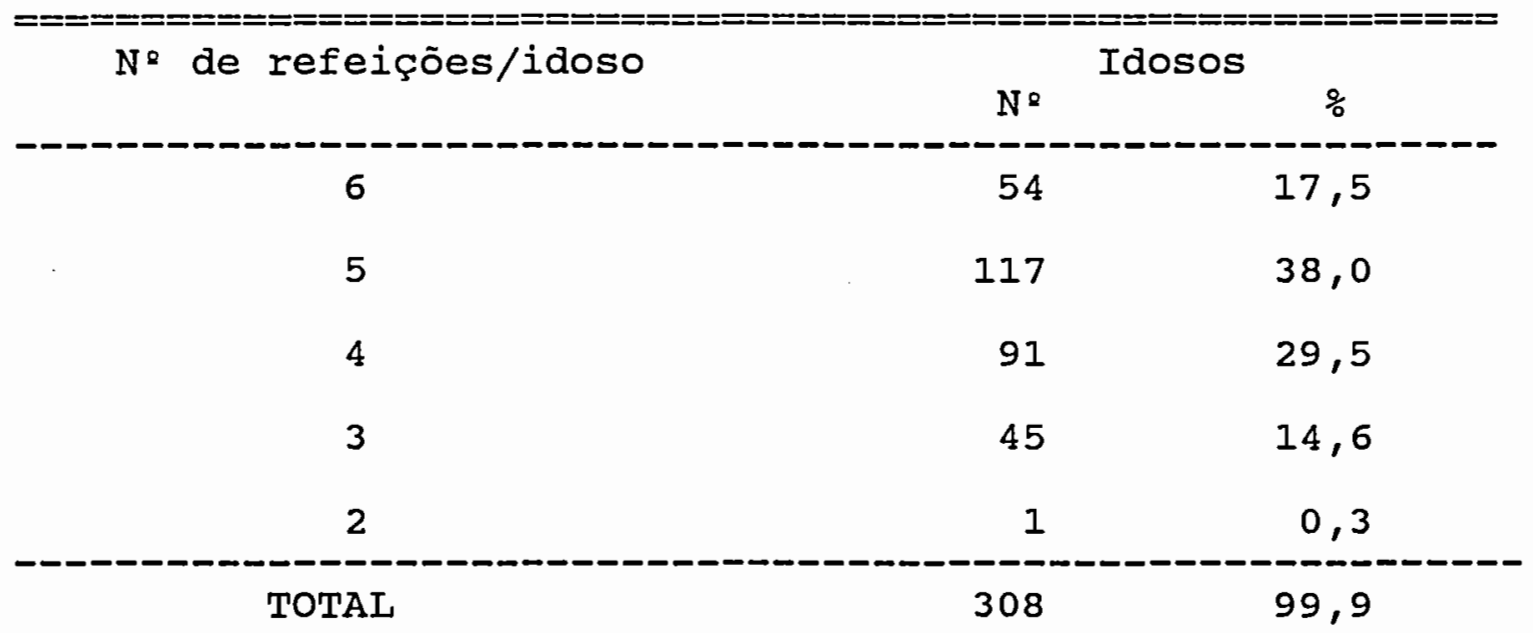

As refeiçōes identificadas foram: desjejum (ou café da manhã), colação (ou lanche matutino), almoço, lanche da tarde, jantar e ceia (ou lanche noturno). Observa-se, na Tabela $\mathrm{n}^{2} 10$, que maior número de idosos $(67,5 \%)$ consome 4 ou 5, sendo 4,6 a média de refeições por idoso. Este resultado pode ser considerado satisfatório, uma vez que esse número de refeições é recomendado por 
vários autores $(7,19,71,110)$, tendo em vista as alteraçōes do processo de envelhecimento. Diminuição de sensaçōes visuais, olfativas e de paladar, reduzindo o prazer de comer, diminuição do metabolismo basal e da produção de enzimas e sucos gástricos, são alguns dos fatores que justificam maior número de refeições, com menor volume de alimentos cada, ao invés de somente três (desjejum, almoço e jantar), consideradas principais. Além disso, esse fracionamento maior evita que haja intervalo muito grande entre as refeiçōes, especialmente entre a última (jantar) e a primeira (desjejum).

YEUNG et al. ${ }^{(125)}$ referem a importância de os idosos manterem rotina alimentar que thes seja familiar e proporcione satisfação, e consideram que três refeições regulares, complementadas com lanches, atendem a essa particularidade da vida diária. Mencionam que os lanches podem contribuir com oferta de energia e nutrientes, bem como satisfazer a fome ou o apetite para outros tipos de alimentos, que possam proporcionar prazer.

NASCIMENTO e col.(91), avaliando o estado nutricional de 110 indivíduos, com idade entre 49 e 64 anos, constataram que o número de refeições desse grupo foi inadequado. CORRÊA e DUARTE ${ }^{(30)}$ também verificaram inadequação no fracionamento de refeiçōes de clientes do Grupo de Assistência Multidisciplinar ao Idoso Ambulatorial (GAMIA) do HC-FMUSP.

O desjejum geralmente era constituído por pão com margarina, café com leite e açúcar. Esta refeição assemelha-se, nos seus componentes, àquela verificada por MARUCCI ${ }^{(80)}$, quando da análise das dietas oferecidas em vinte instituiçōes para idosos, localizadas no Município de São Paulo. Com exceçāo do leite e da margarina, os demais componentes também foram identificados no desjejum de $80 \%$ de idosos, estudados por AZOUBEL(11), em Ribeirão Preto.

Vale ressaltar que os alimentos: pão, café e açúcar estão presentes na dieta de todos os indivíduos estudados, desde aquele que consome apenas duas refeições até àqueles que consomem seis.

A colação, quando realizada, incluía principalmente café com açúcar, pão e/ou frutas. 
No almoço, os alimentos mais freqüentes foram: arroz com feijão, macarrão, carne ou ovos, hortaliças e frutas.

O lanche da tarde, quando presente, assemelhava-se ao desjejum.

O jantar era semelhante ao almoço, mas podia ser substituído por lanche ou sopa de diversos tipos: hortaliças, feijão com macarrão, carne com hortaliças e outros tipos.

A ceia (ou lanche noturno) constituia-se, principalmente, em leite ou chá com bolachas.

Para a análise da freqüência dos alimentos, utilizou-se a classificação dos mesmos em três grupos: construtores, energéticos e reguladores, tendo em vista a importância individual desses conjuntos de alimentos na nutrição dos indivíduos.

Os alimentos do primeiro grupo são indicados principalmente como fontes de cálcio e proteínas; os do segundo, de energia e os do terceiro grupo, vitaminas, minerais e fibras e recomenda-se como adequado que as refeições, especialmente as três consideradas principais, contenham pelo menos um alimento de cada grupo $(108)$.

A freqüência absoluta dos alimentos, segundo os grupos, e considerada como o número de vezes que foram citados, está apresentada no Gráfico $n^{2} 4$. Observa-se que as carnes, os cereais e derivados e as frutas ocupam as primeiras posições dentro dos respectivos grupos.

O Gráfico $n^{0} 5$ apresenta a distribuição das freqüências absolutas dos alimentos do grupo dos construtores. Nota-se que as carnes destacam-se entre esses alimentos, com uma freqüência de $16,3 \%$. Segue-se-lhes leite e derivados, ovos e leguminosas, correspondendo, respectivamente a 5,8, 4,5 e 3,7\% da freqüência.

Com relação às carnes, a mais freqüente foi de origem bovina $(6,4 \%)$, sendo que os miúdos (fígado, coração, rim, língua, dobradinha, miolo) contribuíram com $1,6 \%$, correspondendo a $25 \%$ do total da carne bovina. Em seguida, aparece a carne de aves $(4,5 \%)$, cujos miúdos são menos freqüentes $(0,4 \%)$ do que os de origem bovina, correspondendo a $9 \%$ do total da carne de aves. 
Os miúdos são ricas fontes de colesterol ${ }^{(42)}$ e sua freqüência relativamente alta pode estar influenciando nos níveis elevados de colesterol encontrados da população estudada.

Os embutidos (linguiça e salsicha) aparecem em terceiro lugar $(2,4 \%)$, seguidos dos peixes $(2,2 \%)$, frios $(0,5 \%)$ e por último, a carne suína $(0,3 \%)$. 


\section{Alimentos}

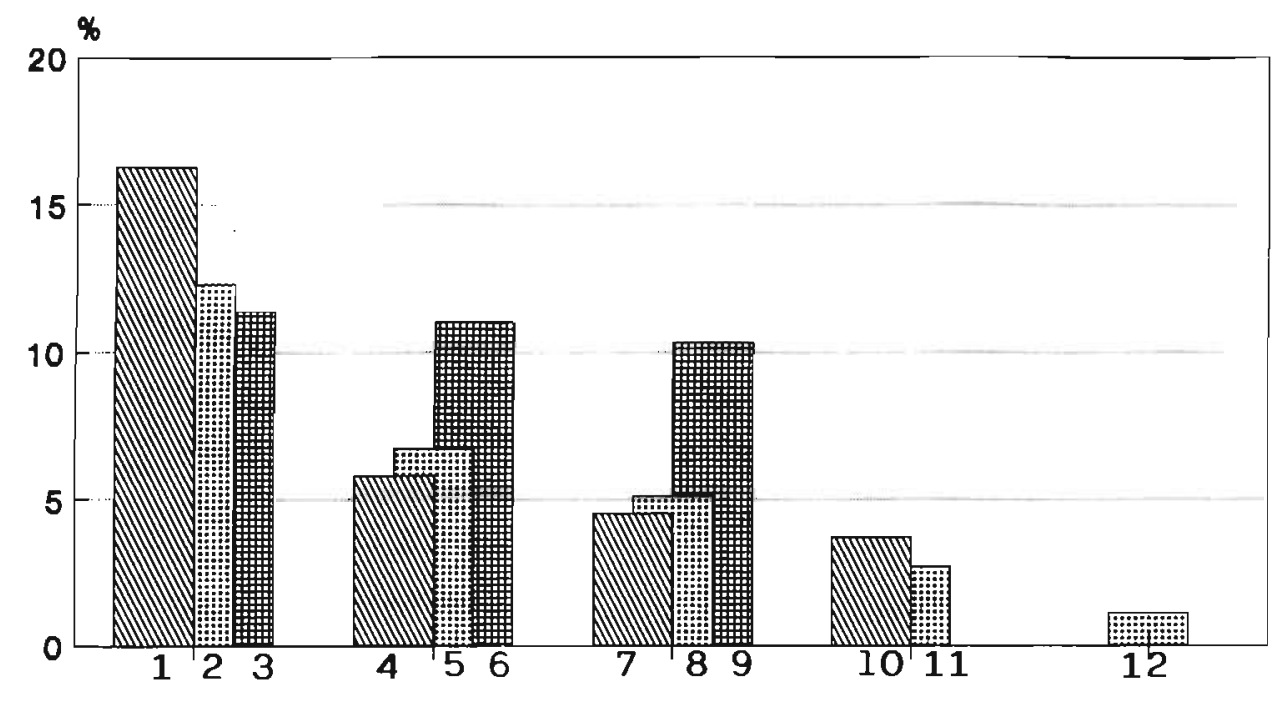

1. Carnes

2. Cereais e derivados

3. Frutas

4. Leite e derivados

5. Gorduras

6. Legumes

7. Ovos

8. Feculentos

9. Verduras

10. Leguminosas

11. Açúcar e doces

12. Outros

Construtores Energéticos

Gráfico $n^{9} 4$.

Distribuição da freqüência absoluta dos alimentos, segundo os grupos analisados.

Sãc Paulo, 1989-1990.

\section{Alimentos construtores}

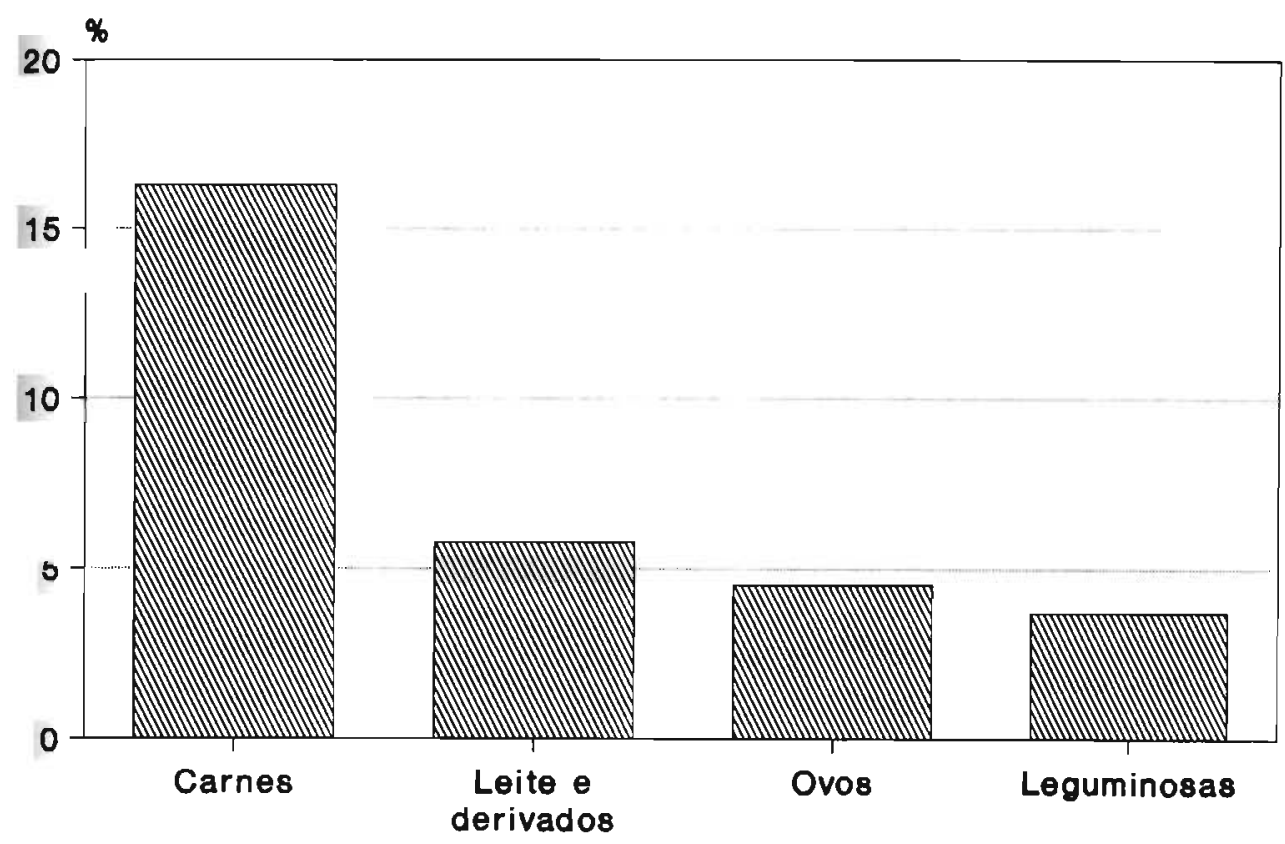

Gráfico $n^{2} 5$.

Distribuição da freqüência absoluta dos alimentos do grupo dos construtores. São Paulo, 1989-1990. 
A presença de linguiça, normalmente com alto teor de colesterol, assim como os miúdos, provavelmente contribui para a alteração dos valores de colesterol.

Esses alimentos, fontes, principalmente de proteínas, são preparados fritos, cozidos ou assados. No entanto, frituras não são recomendadas para idosos pela quantidade de gordura que contém e que, entre outras desvantagens, são de digestão mais difícil para este grupo etário, devido a fatores fisiológicos, próprios da idade $(71,86)$.

No que se refere ao leite e derivados, (com exceção da manteiga que foi incluída entre as gorduras), a principal contribuição deve-se ao leite propriamente dito $(4,5 \%)$, seguido dos queijos $(1,2 \%)$ e do iogurte $(0,1 \%)$.

Entre as leguminosas, merece destaque o feijāo (3,5\%). As outras que apareceram foram: grão de bico, lentilha e ervilha, com freqüência bem menor $(0,2 \%)$.

No Gráfico $\mathrm{n}^{\mathrm{9}} 6$, verifica-se que os cereais e seus derivados participam com a maior freqüência $(12,3 \%)$ em relação aos demais alimentos incluídos nesse grupo. As gorduras contribuem com 6,7\%, os feculentos, com 5,1\%, o açúcar e os doces com $2,7 \%$ e os alimentos incluídos no ítem "Outros", com 1,1\%.

Entre os cereais e derivados destacam-se: o pão (4,5\%), o arroz $(4,1 \%)$, o macarrāo $(1,8 \%)$, os biscoitos $(0,9 \%)$, farinhas $(0,7 \%)$ e bolos $(0,3 \%)$, sendo que os dois primeiros estão presentes na dieta de todos os idosos.

Das gorduras, a mais freqüente é o óleo vegetal $(3,4 \%)$ e, praticamente, coincide com a freqüência $(3,3 \%)$ de todas as outras juntas: manteiga, margarina, banha, toucinho.

A batata predomina sobremaneira $(2,2 \%)$ sobre os outros feculentos (0,5\%): mandioca, mandioquinha, cará, assim como no estudo de MARUCCI ${ }^{(80)}$, no qual, esse alimento esteve presente em $95 \%$ das instituiçōes estudadas, refletindo a preferência alimentar por esse feculento. 
Com relação a açúcar e doces, o primeiro aparece numa frequiência de $1,8 \%$ contra $0,9 \%$ de doces (pudim, bala, marmelada, goiabada, sorvetes, doces de leite, coco, mamão e outros).

No item "Outros" foram incluídos: refrigerantes $(0,5 \%)$; bebidas alcóolicas $(0,3 \%)$, salgadinhos $(0,2 \%)$ e pizza $(0,1 \%)$.

As bebidas alcoólicas, ainda que pouco freqüentes, podem estar colaborando para a elevação dos níveis de triglicérides, verificados anteriormente.

O Gráfico $\mathrm{n}^{2} 7$, mostra a distribuição absoluta dos alimentos reguladores. As frutas contribuem com $11,4 \%$ da freqüência total dos alimentos, os legumes e as verduras com 11 e $10,3 \%$, respectivamente.

Verifica-se que os legumes foram mais freqüentes do que as verduras. Este fato pode estar associado ao hábito alimentar, refletido pela presença de sopas, muitas das quais preparadas com legumes, e também ao problema dentário. Em geral, os idosos preferem esses alimentos cozidos, uma vez que, quando crus, apresentam consistência endurecida, dificultando a mastigação, seja pela ausência de dentes, ou pelo mau estado em que se encontram, ou ainda, devido ao uso de próteses, conforme verificado por vários autores $(5,30,90)$. 
As frutas predominantes foram laranja e banana, sendo acompanhadas em menor freqüência por: mamão, pera, melancia, melão e outras.

Entre os legumes, destacam-se chuchu, tomate, cenoura, abobrinha, seguidos de: vagem, pepino, beterraba, berinjela, jilo, quiabo.

As verduras mais comuns foram: alface, escarola e repolho. Ainda apareceram: couve, almeirão, agriāo, rúcula.

No que concerne aos alimentos mais freqüentes no almoço, bem como aos tipos e variedade de frutas e hortaliças, os resultados obtidos, assim como no caso de desjejum,assemelham-se àqueles encontrados por MARUCCI $(80)$.

Ainda merecem atenção alguns alimentos ou formas de preparação que não foram incluídos dentro dos grupos de alimentos, mas que tiveram participação importante porque expressam hábitos alimentares $\mathrm{e} / \mathrm{ou}$ necessidade de utilizaçāo. Assim, o café foi o principal representante e ocupou a 2a. posição (a 1a. foi o pão), quando se considerou a freqüência absoluta de alimentos, individualmente, ou seja, independentemente de grupos. Esse fato confirma a idéia generalizada de que o café, embora não ofereça contribuição nutricional significativa, especialmente se não se considerar o açúcar que lhe é adicionado, já está incorporado aos hábitos dos indivíduos brasileiros.

As sopas de vários tipos (somente com legumes, com carne e legumes, com feijão e macarrão, com fubá e outros) também estiveram presentes na dieta dos idosos. Este fato pode estar relacionado a vários fatores: hábito alimentar, aspecto sócio-econômico e/ou praticidade de preparo.

NEWMAN \& LUDMAN ${ }^{(92)}$ verificaram que $90 \%$ de 337 idosos chineses utilizam essa preparação em suas refeições.

MARUCCI ${ }^{(80)}$ constatou que $60 \%$ das instituiçōes para idosos, cujas dietas foram analisadas, serviam essa preparação culinária no jantar.

AZOUBEL $^{(11)}$ encontrou que sopa de verduras era consumida no almoço e jantar de $80 \%$ dos 556 idosos estudados, dos quais, a maioria (65\%) tinha 
renda de 0,5 a 1,5 salário mínimo. CORRÊA e DUARTE ${ }^{(30)}$ também constaram freqüente utilização de sopas pelos clientes do GAMIA.

É importante lembrar que preparações desse tipo, podem apresentar valor nutricional inadequado, dependendo dos ingredientes utilizados e do modo de preparo. Assim, as hortaliças, que são consideradas fontes de vitaminas e minerais, além de fibras, podem ter seu valor nutricional alterado, porque a cocção desses alimentos pode afetar o teor de determinadas vitaminas $(29,53,96)$.

Preparações como "chás" dos mais diversos tipos: preto, mate e ervas como: cidreira, hortelā, carqueja, pata de vaca, também estiveram presentes e podem refletir hábito alimentar, ou então, representar alguma forma de medicação, conforme identificado por HIRAMATSU e col. ${ }^{(61)}$. Esses autores estudaram 600 pacientes idosos, atendidos ambulatorialmente, com o objetivo de verificar o padrão de consumo de medicamentos, e constataram que os "chás", juntamente com os analgésicos, constituiam $50,4 \%$ dos medicamentos auto-administrados.

Com relação ao hábito, MARUCCI ${ }^{(80)}$ observou que essa infusão era oferecida com freqüência no lanche da tarde ou no lanche noturno a idosos institucionalizados e NEWMAN \& LUDMAN $^{(92)}$ verificaram que $27 \%$ de idosos chineses a consumiam.

Apesar dessas consideraçōes, não se pode descartar a hipótese de substituição do leite pelos "chás" nas refeiçōes em que são consumidos, tendo em vista a grande diferença de preço entre os dois. Esse fato pode afetar em muito o estado nutricional dos idosos, uma vez que a contribuição dos "chás" reside no açúcar, quando este é adicionado, em detrimento de nutrientes importantes para a saúde dos idosos como cálcio, proteínas e algumas vitaminas, fornecidas pelo leite.

Estudos realizados por vários autores $(5,65,80,94,124)$ demonstraram que o cálcio foi o mineral que se mostrou mais inadequado nas dietas dos idosos estudados. YEARICK et al. ${ }^{(124)}$ verificaram, em 100 idosos, de ambos os sexos, com idade entre 63 e 96 anos, que o cálcio é um dos nutrientes mais deficientes na dieta desses indivíduos, onde um terço das mulheres e um sexto dos homens apresentaram valores baixos para esse mineral. O'HANLON \& $\operatorname{KOHRS}^{(94)}$, sumarizando trabalhos sobre ingestão de alimentos, avaliada por diversas metodologias de inquérito, para verificar adequação de energia e nutrientes, 
mostraram também que o cálcio é um dos nutrientes mais freqüentemente deficiente nas dietas de indivíduos acima de 59 anos. Dois desses trabalhos $(54,65)$ mostram que, praticamente, $50 \%$ dos indivíduos estudados apresentaram dietas com quantidade de cálcio abaixo do recomendado.

Pesquisas realizadas pela Secretaria de Estado da Promoção Social $(64,107)$ - SEPS em 1975; em instituições de idosos, e em 1980, nos mesmos locais, mostram que o número de idosos entrevistados que referiram a presença de leite nas instituições em que residiam diminuiu de 91,0 para $28,4 \%$.

Esses aspectos são de relevância, especialmente considerando que a carência ou a deficiência de cálcio, entre outros fatores, contribui para o desenvolvimento de problemas de saúde, como por exemplo, a osteoporose, comum em idosos, especialmente do sexo feminino, e/ou para o seu agravamento $(2,52,74)$. Neste estudo foi constatado que $4,8 \%$ dos idosos apresentavam osteoporose (Anexo 3).

A Tabela $\mathrm{n}^{\varrho} 11$ apresenta a freqüência absoluta dos alimentos subdivididos por grupos e incluindo, separadamente, café, sopas e "chás". 
Tabela $\mathrm{n}^{2} 11$.

Distribuição da freqüência absoluta dos alimentos segundo os grupos adotados, incluindo café, sopas e "chás". São Paulo, 1989-1990.

\section{Alimentos}

Freqüência

CONSTRUTORES

Carnes

Leite e derivados

ovos

Leguminosas

ENERGÉTICOS

Cereais

Gorduras

Feculentos

Açúcar e doces

outros

REGULADORES

Frutas

Legumes

verduras

Café

Sopas

"Chás"
16,3

5,8

4,5

3,7
12,3

6,7

5,1

2,7

1,1

TOTAL

11,4

11,0

10,3

4,4

1,6

1,2

98,1

O total de $100 \%$ da Tabela $\mathrm{n}^{\complement} .11$, pode ser completado com o item "sucos" (naturais e artificiais), que apareceram com freqüência de 1,1\%, e o item "adoçantes artificiais", com $0,9 \%$, utilizado principalmente pelos idosos diabéticos.

O Quadro $\mathrm{n}^{\curvearrowright} 6$ apresenta os doze alimentos, por ordem de freqüência nas dietas dos idosos, segundo o número de refeiçōes. 
Quadro $n^{9} 6$.

Distribuição dos alimentos, por ordem de freqüência, segundo o número de refeições. São Paulo, 1989-1990.

\begin{tabular}{|c|c|c|c|c|c|}
\hline Alimentos & 3 & $\mathrm{~N}^{2}$ & $\begin{array}{l}\text { de } \\
4\end{array}$ & $\underset{5}{\text { refeições }}$ & 6 \\
\hline café & $3^{2}$ & & $4^{\circ}$ & 12 & $4^{2}$ \\
\hline pão & $4^{2}$ & & 18 & $2^{2}$ & $2^{2}$ \\
\hline açúcar & $7^{\circ}$ & & $6^{2}$ & $3^{2}$ & $1^{2}$ \\
\hline carne bovina & 12 & & $3^{\circ}$ & $5^{2}$ & 59 \\
\hline arroz & $2^{9}$ & & $2^{8}$ & $4^{2}$ & $6^{2}$ \\
\hline leite & $8^{2}$ & & $5:$ & $6^{2}$ & $3^{2}$ \\
\hline feijão & $4^{2}$ & & $7^{\circ}$ & $7^{\circ}$ & $7^{\circ}$ \\
\hline carne de aves & $5 ?$ & & $8^{\circ}$ & $8^{\circ}$ & $8^{\circ}$ \\
\hline óleo & 99 & & - & $9^{\circ}$ & $11^{8}$ \\
\hline ovo & $11^{2}$ & & 98 & $10^{\circ}$ & 98 \\
\hline alface & $12^{\circ}$ & & - & $11^{\circ}$ & - \\
\hline feculentos & $10 ?$ & & - & $12^{\circ}$ & $10^{\circ}$ \\
\hline
\end{tabular}

A ordem de freqüência verificada para quem consome apenas duas refeições foi igual para todos os alimentos.

Observa-se no Quadro $n^{2} 6$, que, à medida que aumenta o número de refeiçōes, a ordem da freqüência dos alimentos varia. Assim, café e pão tornam-se mais freqüentes quanto maior o número de refeições, porque esses alimentos são aqueles mais comumente consumidos nas chamadas pequenas refeições: lanche matutino e da tarde. A carne bovina e o arroz aparecem em seguida. Chama a atenção, a freqüência com que se apresenta o feijão na dieta dos idosos que realizam três refeiçōes e o leite, naqueles com seis refeiçōes. 
Pode-se deduzir que a dieta básica desses idosos, considerando as três principais refeições, se constituiria de: café com açúcar e pão, arroz com feijão e carne.

Essa dieta leva à suposição de que as proteínas são nutrientes que não constituem problema para a população estudada. Fato semelhante foi verificado por MARUCCI ${ }^{(80)}$, que identificou inadequação de proteínas na dieta de apenas uma instituição, de um total de vinte, sendo que nas demais a adequação foi acima de $100 \%$. Também O'HANLON \& KOHRS ${ }^{(94)}$ observaram que esse nutriente foi um dos mais frequentemente encontrado ser suficiente, nos vários estudos analisados, com exceção de um, mesmo considerando que o seu consumo foi avaliado por diversas metodologias de inquérito alimentar e confrontado com vários padrões.

Quando o número de refeições se eleva até seis, o leite adquire maior importância, em detrimento do feijão, enquanto os demais alimentos permanecem constantes.

Nessa dieta básica, os alimentos construtores e energéticos estão contemplados, mas os reguladores estão ausentes, contrariando a recomendação da sua presença nas refeições. Esses alimentos só começam a fazer parte da dieta a partir do $11^{\varrho}$ lugar quando se considera a ordem de freqüência dos alimentos. Esse fato pode estar relacionado à falta de hábito alimentar para consumo desses alimentos, por desconhecimento do seu valor nutricional e consequentemente da sua importância para a saúde, ou ainda, devido aos problemas dentários já referidos.

Tendo em vista a sua importância nutricional, no que concerne a vitaminas, minerais e fibras, pode-se supor que os idosos estudados apresentem ou venham a apresentar problemas nutricionais devido à deficiência desses nutrientes.

O estudo de MARUCCI ${ }^{(80)}$ mostrou inadequação de vitamina $A, B_{1}$, $\mathrm{B}_{2}$ e $\mathrm{C}$, além de fibras nas dietas de idosos institucionalizados, provavelmente relacionada à baixa freqüência de frutas e hortaliças.

Estudo de ARAÚJO e col.(10), em idosos institucionalizados, mostrou deficiência de vitamina A nesses indivíduos e, segundo esses autores, provavelmente devido à ingestão inadequada desse nutriente e à alta prevalência de doenças infecciosas e crônico-degenerativas. 
ALENCAR e col. ${ }^{(6)}$, estudaram 600 idosos ambulatoriais, com o objetivo de identificar hipovitaminoses e encontraram freqüências elevadas (acima de 70\%) de sinais sugestivos de carência de vitamina $\mathrm{A} \mathrm{e}_{2}$, como xerose cutânea, blefarite periférica, cicatrizes angulares e queilose.

Ainda com relação às vitaminas, o ácido ascórbico poderia representar problema para os idosos estudados, devido à baixa freqüência de frutas e hortaliças e inclusive considerando que estas últimas, em geral são cozidas e o teor de vitamina C pode ser afetado pela cocção $(29,53,96)$.

PORRINI et al. ${ }^{(98)}$, analisando os níveis de vitaminas de 313 idosos não institucionalizados, do norte da Itália, verificaram que mais de $50 \%$ desse grupo etário apresentavam taxas inadequadas de vitamina $\mathrm{C}$.

Vale ressaltar que essa vitamina exerce efeito intensificador na absorção de ferro $(87)$ e a sua ausência ou deficiência pode contribuir para o aparecimento de anemia, problema comum em idosos. Neste estudo, 3,2\% (Anexo $\mathrm{n}^{\mathrm{Q}}$ 3) apresentaram diagnóstico para essa enfermidade. ARAÚJO e col. ${ }^{(9)}$ encontraram prevalência de anemia em $25 \%$ de idosos institucionalizados: $12,5 \%$ no sexo masculino e $28,6 \%$ no feminino, sendo que as mulheres necessitaram ser submetidas a intervenção, tendo em vista valores muito abaixo daqueles considerados normais.

Ainda há que se lembrar que a vitamina $C$ tem sido apontada, em estudos epidemiológicos, como elemento protetor em relação a determinados tipos de câncer, especialmente no estômago, evitando a formação de nitrosaminas, consideradas cancerígenas $(23,76)$.

A compilação e análise de vários trabalhos, feita por O'HANLON \& $\mathrm{KOHRS}^{(94)}$, também mostra que várias vitaminas e minerais foram considerados deficientes na alimentaçāo de indivíduos com 59 anos e mais.

Com relação aos minerais, merece atenção especial o potássio. As frutas e hortaliças são importantes fontes desse nutriente na alimentação e os idosos estudados podem estar sendo espoliados no que se refere a ele, devido ao uso de medicamentos, particularmente diuréticos. 
WOO et al. ${ }^{(122)}$ analisaram a ingestão e os níveis sangüíneos de vários minerais, inclusive o potássio, em 400 idosos, aparentemente saudáveis e verificaram que $82 \%$ dos homens e $77 \%$ das mulheres apresentavam níveis baixos, indicando que, provavelmente, grande proporção dos indivíduos tinham alguma depleção desse mineral. Esses autores referem também a possível contribuição da baixa ingestão de potássio na alta incidência de doenças cerebrovasculares na comunidade estudada, considerando a influência da primeira na etiologia da hipertensão e mortes associadas a acidente vascular cerebral, independentemente de hipertensāo.

A importância da fibra é reconhecida na manutençāo da motilidade intestinal e esta apresenta-se diminuída em idosos, conduzindo freqüentemente a problemas de obstipação $(71)$, sendo que para prevenir esse transtorno, vários autores $(55,69,75,81,97)$ recomendam, para os idosos, dietas contendo frutas e hortaliças cruas, além de cereais integrais.

CORREA e DUARTE ${ }^{(30)}$, investigando os hábitos alimentares de idosos freqüentadores do GAMIA, constataram baixa ingestão de frutas e hortaliças e presença de obstipação intestinal, a qual pôde ser minimizada quando houve modificação do hábito alimentar, com aumento do consumo desses alimentos. Essa alteração foi possivel graças à orientação e acompanhamento nutricionais, realizadas individualmente ou em grupos. Esses autores verificaram também inadequada distribuiçāo dos alimentos na refeição.

Também com relação às frutas e hortaliças, as pesquisas da SEPS $(64$, 107), mostram uma queda acentuada na freqüência desses alimentos, conforme relatado por idosos institucionalizados. Em 1975, 94,5\% dos idosos referiram a presença de frutas, 97,0\%, verduras e 94,0\%, legumes nas instituições. Em 1980, esses percentuais diminuíram para 47,8, 74,7 e 36,9\%, respectivamente.

Considerando os resultados encontrados, bem como as consideraçōes feitas no que se refere ao grupo dos alimentos reguladores, julga-se conveniente e oportuno dedicar mais atenção ao cuidado nutricional dos idosos estudados, preconizando e incentivando maior consumo de frutas e hortaliças. 
A freqüência relativa dos alimentos, segundo os grupos, e considerada como o número dos idosos que os citaram, está apresentada no Gráfico $\mathrm{n}^{\circledR} 8$.

O Gráfico $n^{2} 8$ mostra que somente os cereais são consumidos por $100 \%$ dos idosos estudados, seguidos pelas carnes e depois pelas frutas e hortaliças. Considerando a importância do leite e dos alimentos reguladores na alimentação. desse grupo etário, faz-se mister atuaçào no sentido de orientar os idosos quanto à necessidade de incluir esses alimentos em suas dietas.

O Gráfico $\mathrm{n}^{\mathrm{Q}} 9$ mostra os alimentos construtores e verifica-se que, com exceção das leguminosas, os outros alimentos (carnes, leite e derivados e ovos) estão presentes na dieta de mais de $80 \%$ dos indivíduos estudados, com destaque para as carnes.

Os resultados obtidos assemelham-se àqueles encontrados por NAJAS e col. ${ }^{(89)}$. Esses autores estudaram 283 indivíduos, de ambos os sexos, do Projeto Multicêntrico: "Avaliação das condições de saúde dos idosos residentes em zona urbana" e verificaram que $70 \%$ ou mais dos idosos consumiam alimentos do grupo dos construtores.

KORNITZER \& BARA ${ }^{(70)}$ verificaram que mais de $85 \%$ de idosos, de ambos os sexos, estudados na Bélgica, consumiam carne bovina. 
Considerando que as carnes, especialmente de origem bovina, são alimentos considerados fonte de colesterol e gordura saturada $(34)$, é provável que a freqüência elevada desse alimento na dieta dos idosos estudados esteja contribuindo com os altos valores de colesterol total e de LDL, observados quando da análise das variáveis sangüíneas.

No Gráfico $\mathrm{n}^{2} 10$ observa-se que $100 \%$ dos idosos incluem cereais e derivados em suas refeiçōes. Esses alimentos são representados, principalmente pelo pão e arroz, como já mencionado anteriormente. Esses dados se superpõem àqueles verificados por NAJAS e col. ${ }^{(89)}$ quanto a esses alimentos. No que concerne aos outros alimentos do grupo dos energéticos, $80 \%$ incluem feculentos, enquanto, no Projeto Multicêntrico, mais de $90 \%$ consomem esses alimentos.

As pesquisas da $\operatorname{SEPS}(64,107)$ mostram que os cereais passaram a ter maior participação nas refeições servidas nas instituições, em prejuízo de outros (carnes, leite, ovos, frutas e hortaliças), como já verificado. Essa substituição pode estar refletindo problemas econômico-sociais. Em geral, os alimentos ricos em carboidratos são de preço mais baixo e este é um aspecto relevante quando se considera a condição social da maioria dos idosos brasileiros, cujos valores de aposentaria não são suficientes para garantir padrão de vida semelhante àquele vivenciado antes da saída do mercado de trabalho. Ainda que não tenha sido objetivo deste trabalho verificar a condição sócio-econômica da população estudada, é de se supor que esse grupo enquadra-se na situação mencionada.

Além disso, esses alimentos são de mais fácil preparo, quando este é exigido, pois, muitas vezes, nem é necessário , como no caso de pão (com grande freqüência) e biscoitos. Ainda, eles são preferidos pelos idosos porque são mais macios, exigindo menos trabalho de mastigação, a qual pode estar dificultada, como já mencionado anteriormente.

Esses aspectos foram confirmados por CORREAA e $\operatorname{DUARTE}^{(30)}$, quando da avaliação de idosos do GAMIA.

Quanto aos alimentos reguladores, apresentados no Gráfico $\mathrm{n}^{2} 11$, estão presentes na dieta de mais de $80 \%$ dos idosos, resultado semelhante àquele encontrado por NAJAS e col. ${ }^{(89)}$ (85\%). Esses autores verificaram que o consumo desses alimentos era maior entre os idosos de melhor nível sócio-econômico. 
A freqüência relativa de frutas e hortaliças verificada na dieta dos idosos, reforça a necessidade de educação alimentar para esse grupo com o objetivo de garantir o consumo desses alimentos por $100 \%$ da população estudada. A mesma recomendação é válida com relação ao consumo de leite e derivados. 
V. CONCLUSÕES 


\section{CONCLUSÕES}

Considerando os objetivos propostos e os resultados obtidos, chegouse às seguintes conclusōes:

\section{Quanto ao perfil de morbidade:}

1.1. O perfil de morbidade identificado mostrou que a doença hipertensiva é a mais prevalente, representando $21 \%$ do total de diagnósticos e afetando $49 \%$ dos idosos estudados.

1.2. As doenças do sistema osteomuscular e tecido con juntivo aparecem em seguida com $14 \%$ dos diagnósticos e presente em 32,5\% dos idosos.

1.3. As doenças endócrinas e metabólicas ocuparam o $3^{\circ}$. lugar $(11,8 \%$ dos diagnósticos e $27 \%$ dos idosos), com destaque para diabetes melito.

1.4. A análise dos diagnósticos revelou que o grupo estudado apresenta várias enfermidades ao mesmo tempo, com média de 2,3 diagnósticos/idoso.

\section{Quanto às variáveis sangǘneas:}

2.1. A análise das variáveis sangüíneas revelou que várias delas apresentaramse com valores inadequados, quando comparados com aqueles considerados de referência, seja com relação à média encontrada para ambos os sexos, ou então ao número de idosos que manifestaram essas inadequações.

2.2. A albumina, a HDL-C, a VLDL-C e os triglicérides encontravam-se normais no que se refere à média, para ambos os sexos, mas as duas primeiras estavam abaixo dos valores de referência e os dois últimos acima desses valores, em certo percentual de idosos, quando considerados segundo o sexo. 
2.3. A glicose, o colesterol total e a LDL-C ficaram acima dos valores considerados normais, tanto no que se refere à média para ambos os sexos, quanto em certo percentual de idosos, quando separados por sexo.

\section{Quanto às variáveis antropométricas:}

3.1. As variáveis antropométricas apresentaram valores semelhantes àqueles encontrados por outros autores, no que se refere a peso e altura.

3.2. As médias de prega cutânea triciptal e índice de Quetelet são sugestivas da presença de obesidade no grupo estudado.

3.3. Quanto à circunferência do braço, foi excepcional o fato de encontrar valor mais elevado nas mulheres do que nos homens.

\section{Quanto d̀ analise da dieta:}

4.1. A análise da dieta mostrou que há adequação quanto ao número de refeições consumidas (média de 4,6/idoso) e que os hábitos alimentares podem estar influenciando os níveis de algumas variáveis sangüíneas.

4.2. No grupo dos alimentos construtores, as carnes se destacaram, representando $16,3 \%$ do total de alimentos e estando presente em mais de $80 \%$ das dietas dos idosos. O alto conteúdo de colesterol e gordura saturada desses alimentos, provavelmente estejam interferindo nos níveis de colesterol e LDL-C.

4.3. Os cereais e derivados sobressaíram-se no grupo dos alimentos energéticos, com predominância do pão e arroz, presentes nas dietas de todos os idosos. Aqueles alimentos contribuíram com 12,3\% do total e estiveram presentes em $100 \%$ das dietas. 
4.4. Com relação ao grupo dos alimentos reguladores, verificou-se que sıa freqüência, especialmente quando analisada do ponto de vista da suc ordenação, começa a ser verificada a partir do $11^{\circ}$. lugar, sugerindo falta de hábito alimentar para esses alimentos e a presença de possíveis deficiências nutricionais dos principais nutrientes veiculados por eles (vitaminas, minerais e fibras). 
VI. RECOMENDAÇÕES 


\section{RECOMENDAÇÕES}

Tendo em vista o estudo realizado, considerou-se imperioso fazer algumas recomendaçōes:

1. A orientação dietética deve ser uma atividade constantemente desenvolvida. nos grupos etários com 60 anos e mais, tendo em vista que a dieta é um fator que interfere no estado nutricional desses indivíduos e que modificaçōes nos seus hábitos alimentares mostraram-se eficientes quando do tratamento de diferentes enfermidades, contribuindo, positivamente, para a saúde e, consequentemente, para a qualidade de vida dos idosos.

2. O consumo de leite, frutas e hortaliças deve ser incentivado nesse grupo etário, uma vez que esses alimentos são de fundamental importância na alimentaçāo de idosos e a sua presença não ocorreu em 100\% das dietas dos indivíduos estudados.

3. A elaboração de manual de orientação dietética sob forma ilustrada deve ser realizada, a fim de melhor atender parcela da populaçāo matriculada no ambulatório geriátrico, tendo em vista o grande número (33\%) de indivíduos analfabetos.

4. Esforços devem ser empreendidos pelos pesquisadores da área, tanto em nível individual como em grupo, no sentido de que metodologias utilizadas em diversos estudos nacionais sejam uniformizadas e/ou unificadas, a fim de possibilitar a comparaçāo dos resultados obtidos e tentar estabelecer padrōes de referência para os idosos brasileiros, ainda que em níveis regionais. 


\section{REFERÊNCIAS BIBLIOGRÁFICAS}




\section{REFERENCIAS BIBLIOGRÁFICAS}

1. AGING and dietary fat cholesterol transport. Nutr. Rev. 47(10):334-6, 1989.

2. ALBANESE, A.A. Osteoporosis. J. Amer. pharm. Ass., 17:252-3, 1977.

3. ALENCAR, Y.M.G.; CARVALHO FILHO, E.T.; RONCADA, M.J.; HIRAMATSU, C.S.; PIRES E.A.C.; QUENTAL, I.A. Comportamento do colesterol total (CT) e suas fraçōes HDL E LDL em idosos. In: Congresso Brasileiro de Geriatria e Gerontologia, $9^{0}$., São Paulo, 1991. Resumo. São Paulo, Sociedade Brasileira de Geriatria e Gerontologia, 1991. Tema Livre $\mathrm{n}^{\mathrm{2}} 115$.

4. ALENCAR, Y.M.G.; RONCADA, M.J.; CARVALHO FILHO, E.T.; QUENTAL, I.A.; OKANI, E.T. Níveis de vitamina C, colesterol e complicaçōes de aterosclerose em indivíduos com mais de 80 anos. In: Congresso Brasileiro de Geriatria e Gerontologia, $9^{\circ}$., São Paulo, 1991. Resumo. Sāo Paulo, Sociedade Brasileira de Geriatria e Gerontologia, 1991. Tema Livre $n^{9} 73$.

5. ALENCAR, Y.M.G.; RONCADA, M.J.; CORREA, N.C.; ALENCAR, I.A.; BAXTER, Y.C.; LOUETTE, S.C.C.; CARVALHO FILHO, E.T.; WILSON, D. Problemas odontológicos e seus efeitos sobre os hábitos alimentares do idoso. In: Congresso Nacional de Alimentaçāo e Nutriçāo, $2^{\circ}$., Sāo Paulo, 1990. Anais. São Paulo, Sociedade Brasileira de Alimentação e Nutriçāo, 1991, p. 146.

6. ALENCAR, Y.M.G.; RONCADA, M.J.; MESSLAS, M.P.; HIRAMATSU, C.S.; OKANI, E.T.; CARVALHO FILHO, E.T. e WILSON, D. Sinais clínicos de hipovitaminoses em idosos. In: Congresso Nacional de Alimentação e Nutrição, $2^{\circ}$., Sāo Paulo, 1990. Anais. São Paulo, Sociedade Brasileira de Alimentaçāo e Nutrição, 1991, p. 145.

7. AMÂNCIO, A \& CAVALCANTI, P.C.U. Clínica geriátrica. Rio de Janeiro, Livraria Atheneu, 1975. 
8. ANDERSON, E.L. Eating patterns before and after dentures. J. Amer. diet. Ass., 58:421-6, 1971.

9. ARAÚJO, M.A.A.; TAVARES, E.M.S.; TAVARES, C. Anemia em idosos institucionalizados em Maceió, AL. In: Congresso Nacional de Alimentação e Nutrição, $2^{\circ}$., São Paulo, 1990. Anais. São Paulo, Sociedade Brasileira de Alimentação e Nutrição, 1991, p. 142.

10. ARAÚJO, M.A.A.; TAVARES, E.M.S.; TAVARES, C.; FERREIRA, H. Níveis de retinol sérico em idosos institucionalizados em Maceió, AL. In: Congresso Nacional de Alimentação e Nutrição, 20 ., São Paulo, 1990. Anais. São Paulo, Sociedade Brasileira de Alimentação e Nutrição, 1991, p. 141.

11. AZOUBEL, L.M.O. A fome, uma realidade na vida do idoso de Ribeirão Preto. In: Congresso Brasileiro de Geriatria e Gerontologia, $9^{\circ}$., São Paulo, 1991. Resumo. São Paulo, Sociedade Brasileira de Geriatria e Gerontologia, 1991. Tema Livre $\mathrm{n}^{\circ} 42$.

12. BALCELLS, A. La clínica y el laboratorio. $7^{\mathrm{a}}$. ed. Barcelona, Editorial Marian S.A., 1970.

13. BECKER, D.M.; LAROSA, J.H.; WATSON, J.E. CE: interpreting the new guidelines. Amer. J. Nurs., 89(12):1622-4, 1989.

14. BENGOA, J.M.; TORÚN, B.; BÉHAR, M.; SCRIMSHAW, N. Metas nutricionales y guias de alimentacion para America Latina: bases para su desarrollo. Arch. latinoamer. Nutr., 38(3):373-426, 1988.

15. BERQUÓ, E.S. \& LEITE, V.M. Algumas considerações sobre a demografia da população idosa no Brasil. Ciênc. Cult., 40(7):679-88, 1988.

16. BISHOP, C.W.; BOWEN, P.E.; RITCHEY, S.J. Norms of nutritional assessment of American adults by upper arm anthropometry. Amer. J. clin. Nutr., 34:2530-9, 1981. 
17. BURR, M.L. Anthropometric norms in the elderly. Brit. J. Nutr., 51:165-9, 1984.

18. BURR, M.L.; MILBANK, J.E.; GIBBS, D. The nutritional status of the elderly. Age Ageing, 11:89-96, 1982.

19. BURTON, B.T. Nutrição humana. São Paulo, Ed. McGraw-Hill do Brasil, 1979.

20. CAMARGO, A.B.M. \& SAAD, P.M. A transiçāo demográfica no Brasil e seu impacto na estrutura etária da população. In: Fundação SEADE. O idoso na Grande São Paulo. São Paulo, 1990. p. 9-25. (Coleção Realidade Paulista).

21. CAMARGO, A.B.M. \& YAZAKI, L.M. Características demográficas e sócioeconômicas da população idosa. In: Fundação SEADE. O idoso na Grande São Paulo. São Paulo, 1990. p. 41-100. (Coleção Realidade Paulista).

22. CAMARGO, A.B.M. \& YAZAKI, L.M. Diferenças intra-regionais na Grande São Paulo. In: Fundação SEADE. O idoso na Grande São Paulo. São Paulo, 1990. p. 101-22. (Coleção Realidade Paulista).

23. CASTRO, J.A. Cancer, alimentación y alimento: epidemiologia y etiologia del cancer de estomago I. Acta Bioquím. Clín. latinoamer., 17:203-12, 1983.

24. CENDOROGLO, M.S.; SALHANI, R.C.; TONIOLO NETO, J.; NASRI, F.; EBEL, S.J.; SIGNORINI, T.B.; GONÇALVES, M.; CARVALHAES, N.; SUSTOVICH, D.R. Estudo dos fatores de risco para doença cardiovascular de 300 idosos. In: Congresso Brasileiro de Geriatria e Gerontologia, $9^{\circ}$., São Paulo, 1991. Resumo. São Paulo, Sociedade Brasileira de Geriatria e Gerontologia, 1991. Tema Livre $\mathrm{n}^{\mathrm{Q}} 108$. 
25. CENDOROGLO, M.S.; YTO, M.A.R.; ALMADA FILHO, C.M.; GARCIA, J.T.; NAJAS, M.S.; SACHS, A.; DIAZ, R.B.; PERRACINI, M.R.; MARTINEZ, T.L.R. Estudo de prevenção primária dos fatores de risco cardiovascular de 64 idosos. In: Congresso Brasileiro de Geriatria e Gerontologia, $9^{\circ}$., São Paulo, 1991. Resumo. São Paulo, Sociedade Brasileira de Geria-tria e Gerontologia, 1991. Tema Livre $n^{0} 77$.

26. CID: Classificação internacional de doenças; adaptada para uso em processamento de dados. Porto Alegre, Editora Sagra, 1990.

27. COITINHO, D.C.; LEĀO, M.M.; RECINE, E.; SICHIERI, R. Condições nutricionais da população brasileira: adultos e idosos. Brasília, INAN, 1991. (Pesquisa Nacional sobre Saúde e Nutrição).

28. CONTALDO, F.; DI BLASI, G.; LANZETTA, R.; LANZILLI, A.; SIMONETTI, M.S.; FINDANZA, F. Nutritional status of the elderly in Naples. Int. J. Vitam. Nutr. Res., 57(2):193-203, 1986.

29. COOPER, J.K. \& GARDNER, C. Effect of aging on serum albumin. J. Amer. Geriatr. Soc., 37:1039-42, 1989.

30. CORREA, N.C \& DUARTE, A.L.N. Atividade da nutricio-nista. In: Jacob Filho, W., ed. Relatório da prática em evoluçāo do Grupo de Assistência Multidisciplinar ao Idoso Ambulatorial (GAMIA). Sāo Paulo, HC/FMUSP/BAYER, 1991. p. 20-1.

31. CURIATI, J.A.E; VENTURA, M.M.; CARVALHO FILHO, E.T.; GIANNATTASIO, F.C.; COSTA, E.F.A. Resultado de avaliação mental em idosos. In: Congresso Brasileiro de Geriatria e Gerontologia, $9^{\circ}$., São Paulo, 1991. Resumo. São Paulo, Sociedade Brasileira de Geriatria e Gerontologia, 1991. Tema Livre $n^{\mathfrak{Q}} 49$.

32. DAVIDSON, C.S.; LIVERMORE, J.; ANDERSON, P.; KAUFMAN, S. The nutrition of a group of apparently healthy aging persons. Amer. J. clin. Nutr., 10:181-99, 1962. 
33. DAVIDSON, M.B. The effect of ageing on carbohydrate metabolism: a review of the english literature and a practical approach to the diagnosis of diabetes mellitus in the elderly. Metabolism, 28:688-705, 1979.

34. DÉCOURT, L.V. Medicina preventiva em cardiologia. São Paulo, Sarvier Ed. Livros Médicos, 1988.

35. DENKE, M.A. \& GRUNDY, S.M. Hypercholesterolemia in elderly persons: resolving the treatment dilemma. Ann. Intern. Med., 112(10):789-92, 1990.

36. DEURENBERG, P.; KOOY, K. van der; HULSHOF, T.; EVERS, P. Body mass index as a measure of body fatness in the elderly. Eur. J. clin. Nutr., 43:231-6, 1989.

37. DEURENBERG, P.; WESTSTRATE, J.A.; SEIDELL, J.C. Body mass index as a measure of body fatness: age- and sex- specific prediction formulas. Brit. J. Nutr., 65:105-114, 1991.

38. ETTINGER, W.H. Lipid levels and risk of atheros-clerotic coronary heart disease in older person. Med. Clin. North Amer., 73(6):1525-30, 1989.

39. FABBRI, R.M.A \& GORZONI, M.L. Afecçōes em nonagenários. In: Congresso Brasileiro de Geriatria e Gerontologia, 9º., São Paulo, 1991. Resumo. São Paulo, Sociedade Brasileira de Geriatria e Gerontologia, 1991. Tema Livre $\mathrm{n}^{\circ} 57$.

40. FABBRI, R.M.A; GORZONI, M.L.; LIMA, C.A. Análise de população geronte em consultório médico. In: Congresso Brasileiro de Geriatria e Gerontologia, $9^{0}$., São Paulo, 1991. Resumo. São Paulo, Sociedade Brasileira de Geriatria e Gerontologia, 1991. Tema Livre $n^{0} 58$.

41. FAINTUCH, J.; PEREIRA, M.L.; FAINTUCH, B.L.; MACHADO, M.C.C.; PINOTTI, H.W. Novos parâmetros para avaliação nutricional investigação preliminar. Rev. Hosp. Clin. Fac. Med. Univ. S. Paulo, 38(4):164-6, 1983. 
42. FEELY, R.M.; CRINER, P.A.; WATT, B.K. Cholesterol contents of foods. J. Amer. diet. Ass., 61:134-49, 1972.

43. FIGUEIRA, J.L.; PAPALEO NETTO, M.; CARVALHO FILHO, E. T.; PASINI, V.; GIANNINI, S.D.; FORTI, N.; JACOB FILHO, W.; ANDRIOLLO, A. Perfil lipídico em indivíduos idosos normais. Arq. bras. Cardiol., 48(2):77-81, 1987.

44. FINDANZA, F.; COLI, R.; DAMIANI, P.; FIORINI, D.; MAURIZI COLI, A.; SIMONETTI, M.S. Nutritional status of a group of institutionalized elderly people in Perugia (Italy). Int. J. Vitam. Nutr. Res., 58:85-91, 1987.

45. FRISANCHO, A.R. New norms of upper limb fat and muscle areas for assessment of nutritional status. Amer. J. clin. Nutr., 34:2540-5, 1981.

46. FRISANCHO, A.R. Nutritional anthropometry. J. Amer. diet. Ass., 88(5):553$5,1988$.

47. FRISANCHO, A.R. Triceps skinfold and upper arm muscle size norms for assessment of nutritional status. Amer. J. clin. Nutr., 27:1052-7, 1974.

48. FUNDAÇĀO SEADE O idoso na Grande São Paulo. São Paulo, 1990. (Coleção Realidade Paulista).

49. GAMBERT, S.R. Nutritional assessment in the elderly. Wisc. Med. J., 81:1821, 1982.

50. GARCIA, J.T.; NAGASHIMA, M.R.; NAJAS, M.S.; SPEEDO, S.S.; TONIOLO NETO, J.; ALMADA, C.M.; RAMOS, L.R. O idoso no centro de saúde. In: Congresso Brasileiro de Geriatria e Gerontologia, $9^{\circ}$., São Paulo, 1991. Resumo. São Paulo, Sociedade Brasileira de Geriatria e Gerontologia, 1991. Tema Livre ${ }^{\circledR} 59$. 
51. GRANT, J.P.; CUSTER, P.B.; THURLOW, J. Técnicas atuais para avaliação nutricional; Simpósio sobre Nutriçāo Cirúrgica. In: Mullen, J.L.; Crosby, L.O.; Rombeau, J.L., eds. Clínicas cirárgicas da América do Norte. Rio de Janeiro, Interamericana, 1981.

52. GRILLS, N.J. Nutritional needs of elderly women. Clin. Obstet. Ginec., 20(1):137-43, 1977.

53. GRISWOLD, R.M. Estudo experimental dos alimentos. São Paulo, Ed. Edgard Blücher, 1972.

54. HANKIN, J.H. \& ANTONMATTEI, J.C. Survey of food service practices in nursing homes. Amer. J. publ. Hlth., 50(8):1137-44, 1960.

55. HARPER, A.E. Recomended dietary allowances for the elderly. Geriatrics, 33(5):73-80, 1978.

56. HAVLIR, D.V.; MURILLO, S.; ROBLES,E.; TREJOS, A.; MATA, L. Nutritional status of the elderly in Palmares, Costa Rica. Arch. lationoamer. Nutr., 33(2):409-22, 1983.

57. HEDAYA, C.B.; CARVALHO FILHO, E.T.; SOARES, S.A.; LIBERMAN, S.; KLEIN, E.L. Manifestaçōes cardio-circulatórias em idosos portadores do diabetes mellito (DM). In: Congresso Brasileiro de Geriatria e Gerontologia, $9^{\circ}$., São Paulo, 1991. Resumo. São Paulo, Sociedade Brasileira de Geriatria e Gerontologia, 1991. Tema Livre $n^{\circledR} 40$.

58. HEYMSFIELD, S.B.; McMANUS, C.; SMITH, J.; STEVENS, V.; NIXON, D.W. Anthropometric measurement of muscle mass: revised equations for calculating bone-free arm muscle area. Amer. J. clin. Nutr., 36:680-90, 1982.

59. HICKLER, R.B. \& WAYNE, K.S. Nutrition and the elderly. Amer. Fam. Physic., 29(3):137-145, 1984. 
60. HIRAMATSU, C.S.; ALENCAR, Y.M.G.; RONCADA, M.J.; CARVALHO FILHO, E.T.; MESSIAS, M.P.; MARUCCI, M.F.N. Diagnósticos clínicos em pacientes de idade avançada. In: Congresso Brasileiro de Geriatria e Gerontologia, $9^{\circ}$., São Paulo, 1991. Resumo. São Paulo, Sociedade Brasileira de Geriatria e Gerontologia, 1991. Tema Livre n 55.

61. HIRAMATSU, C.S.; ALENCAR, Y.M.G.; RONCADA, M.J.; CARVALHO FILHO, E.T.; MESSIAS, M.P.; MARUCCI, M.F.N. Uso de medicamentos em população idosa ambulatorial. In: Congresso Brasileiro de Geriatria e Geronto-logia, 9o., São Paulo, 1991. Resumo. São Paulo, Sociedade Brasileira de Geriatria e Gerontologia, 1991. Tema Livre n $^{0} 150$.

62. HO, S.C.; DONNAN, S.; SHAM, A. Dietary intake among elderly Chinese in Hong Kong. J. Hum. Nutr. Diet., 1:205-15, 1988.

63. HORWITZ, A. Guias alimentarias y metas nutricionales en el envejecimiento. Arch. latinoamer. Nutr., 38(3):723-49, 1988.

64. JORDÃO NETTO, A. A segregação do velho na sociedade. São Paulo, Secretaria de Descentralizaçāo e Participação / Conselho Estadual do Idoso, 1986.

65. JUSTICE, C.L.; HOWE, J.M.; CLARK, H.E. Dietary intake and nutritional status of elderly patients. J. Amer. diet. Ass., 65:639-46, 1974.

66. KALACHE, A.; VERAS, R.P.; RAMOS, L.R. O envelhecimento da população mundial: um desafio novo. Rev. Saúde públ., São Paulo, 21(3):200-10, 1987.

67. KAMADA, M.Y.; COSTA VAZ, M.A.; LIMA, N.S.H.S.; KUCZYNSKY, E.; TONDATO, F.J.T.; JACOB FILHO, W. Evoluçāo clínica dos clientes do GAMIA. In: Congresso Brasileiro de Geriatria e Gerontologia, $9^{0}$., São Paulo, 1991. Resumo. São Paulo, Sociedade Brasileira de Geriatria e Gerontologia, 1991. Tema Livre $n^{9} 56$.

68. KLEIN, E.L.; CARVALHO FILHO, E.T.; LIBERMAN, S.; HEDAYA, C.B.; SOARES, S.A. Aspectos do diabetes mellito (DM) em população idosa ambulatorial. In: Congresso Brasileiro de Geriatria e Gerontologia, $9^{\circ}$., São 
Paulo, 1991. Resumo. São Paulo, Sociedade Brasileira de Geriatria e Gerontologia, 1991. Tema Livre $\mathbf{n}^{\circledR} 39$.

69. KOHRS, M.B. New perspectives on nutritional conseling for the elderly. Bol. Asoc. med. Puerto Rico, 75:363-5, 1983.

70. KORNITZER, M. \& BARA, L. Differences between north and south in coronary risk factors, food habits and mortality in Belgium: for the B.I.R.N.H. study group. Acta cardiol., 44(2):145-55, 1989.

71. KRAUSE, M.V. \& MAHAN, L.K. Alimentos, nutrição e dietoterapia. $7^{\mathrm{a}}$. ed. São Paulo, Livr. Roca Ltda., 1991.

72. LIBERMAN, S.; CARVALHO FILHO, E.T.; ALENCAR, Y.M.G.; RONCADA, M.J. Alguns fatores de risco de doença cardiovascular em pacientes idosos. In: Congresso Brasileiro de Geriatria e Gerontologia, $9^{\circ}$., São Paulo, 1991. Resumo. São Paulo, Sociedade Brasileira de Geriatria e Gerontologia, 1991. Tema Livre $n^{\mathfrak{Q}} 105$.

73. LUND, M.D. \& DUTHIE JR, E.H. Drug usage in the elderly. Wis. Med. J., 81:21-5, 1982.

74. LUTWAK, L. Continuing need for dietary calcium throughout life. Geriatrics, 29:171-8, 1974.

75. MÄKILÄ, E. Milk and vegetables in the diet of institutionalized elderly people in Finland. J. prosthet. Dent., 45:134-7, 1981.

76. MAR'TINEZ, L.; PÉREZ, F.; VILLANUEVA, J.C.; WIDERSTRÖM, J.; WILDNER, V. Alimentación y cancer. Rev. chile. Nutr., 12:15-21, 1984. 
77. MARTINEZ, T.L.R.; CENDOROGLO, M.S.; PINTO, L.E.S.; TONIOLO NETO, J.; YTO, M.A.R.; NAJAS, M.S.; MEDINA, M.; PRATES, A; SANTOS, F.R.G.; RAMOS, L.R. Estudo da prevalência dos fatores de risco para doença cardiovascular em indivíduos com mais de 60 anos de idade residentes em zona urbana, em São Paulo. In: Congresso Brasileiro de Geriatria e Gerontologia, $9^{\circ}$., São Paulo, 1991. Resumo. São Paulo, Sociedade Brasileira de Geriatria e Gerontologia, 1991. Tema Livre $\mathrm{n}^{\circledR} 110$.

78. MARTINS, I.S.; COELHO, L.T.; MATOS, I.M.S.; MAZZILLI, R.N.; TRIGO, M.; WILSON, D. Dislipidemias e alguns fatores de risco associados em uma populaçāo periférica da região metropolitana de São Paulo, S.P. - Brasil: um estudo piloto. Rev. Saúde públ., S. Paulo, 23(3):236-43, 1989.

79. MARTINS, I.S.; GOMES, A.D.; PASINI, V. Níveis lipêmicos e alguns fatores de risco de doenças cardiovasculares em população do Município de São Paulo, S.P. (Brasil). Rev. Saúde públ., S.Paulo, 23(1):26-38, 1989.

80. MARUCCI, M.F.N. Avaliação das dietas oferecidas em instituiçōes para idosos, localizadas no Município de São Paulo. São Paulo, 1985. [Dissertação de Mestrado - Faculdade de Saúde Pública da USP].

81. MASSLER, M. Geriatric nutrition. Part IV: the role of fiber in the diet. J. prosthet. Dent., 50:5-7, 1983.

82. MATHIAS, M.R.C.; CERVI, E.C.; MIRA, L.R.; CURI, P.R.; BURINI, R.C. Estabelecimento das faixas de normalidade de variáveis hematológicas e bioquímicas de indivíduos adultos: influência do sexo e da faixa etária. Rev. bras. Patol. clín., 22(4):106-112, 1986.

83. METROPOLITAN LIFE INSURANCE COMPANY. Metropolitan height and weight tables. Stat. Bull., 64:1, 1983.

84. METROPOLITAN LIFE INSURANCE COMPANY. New weight standars for men and women. Stat. Bull., 40:1, 1959. 
85. MITCHELL, C.O. \& LIPSCHITZ, D.A. Amm lenght measurement as an alternative to height in nutritional assessment of elderly. J. parent. ent. Nutr., 6(3): 226-9, 1982.

86. MITCHELL, H.S. Nutrição. $16^{\mathrm{a}}$. ed. Rio de Janeiro, Ed. Interamericana, 1978.

87. MONSEN, E.R. \& BALINTFY, J.L. Calculating dietary iron bioavaiability: refinement and computerization. J. Amer. diet. Ass., 80:307-11, 1982.

88. MUNRO, H.N.; McGANDY, R.B.; HARTZ, S.C.; RUSSEL, R.M.; JACOB, R.A.; OTRADOVEC, C.L. Protein nutriture of free-living elderly. Amer. J. clin. Nutr., 46:586-92, 1987.

89. NAJAS, M.S.; ANDREAZZA, R.; SACHS, A.; SOUZA, A.L.M.; SCHIMIDER, K.F.; RAMOS, L.R.; NOVO, N.F.; TUDISCO, E.S. Consideraçōes sobre o padrão alimentar de idosos de diferentes extratos sócio-econômicos no Município de Sāo Paulo. In: Congresso Nacional de Alimentação e Nutrição, $2^{\circ}$., São Paulo, 1990. Anais. p. 137.

90. NAJAS, M.S.; SACHS, A.; WAJSBERG, M.; SOUZA, A.L.M.; TONIOLO, J.N.; EBEL, S.J.; RAMOS, L.R.; TUDISCO, E.S. Condiçāo bucal de idosos e sua relação com habilidade de mastigação e seu estado nutricional. In: Congresso Brasileiro de Geriatria e Gerontologia, 9º., São Paulo, 1991. Resumo. São Paulo, Sociedade Brasileira de Geriatria e Gerontologia, 1991. Tema Livre $\mathrm{n}^{\circ} 86$.

91. NASCIMENTO, M.L.; PRATES, A.; LIBERMAN, S.; TANAKA, W.H.; PERRACINI, N. Avaliaçāo nutricional em indivíduos de meia idade e idosos jovens. In: Congresso Brasileiro de Geriatria e Gerontologia, $9^{\circ}$., Sāo Paulo, 1991. Resumo. São Paulo, Sociedade Brasileira de Geriatria e Gerontologia, 1991. Tema Livre $\mathrm{n}^{\circ} 170$.

92. NEWMAN, J.M. \& LUDMAN, E.K. Chinese elderly: food habits and beliefs. J. Nutr. Elderly., 4(2):3-13, 1984. 
93. NNANYELUGO, D.O.; KUBIANGHA, L.O.; AKPANYUNG, U.O. Food intake and pattern of consuption among elderly nigerians with a low income. Ecol. Food Nutr., 8:79-86, 1979.

94. O'HANLON, P. \& KOHRS, M.B. Dietary studies of older Americans. Amer. J. clin. Nutr., 31:1257-69, 1978.

95. ORGANIZAÇÃO MUNDLAL DA SAÚDE. Manual de classificação estatística de doenças, lesões e causas de óbitos. Sāo Paulo, Centro da OMS para Classificação de Doenças em Português, 1978. v. 1.

96. ORNELLAS, L.H. Técnica dietética: seleção e preparo dos alimentos. Rio de Janeiro, Júlio C. Reis Livr., 1979.

97. PELCOVITS, J. Nutrition to meet the human needs of older Americans. J. Amer. diet. Ass., 60:297-300, 1972.

98. PORRINI, M. SIMONETTI, P.; CIAPEPLLANO, S.; TESTOLIN, G. Vitamin $A, E$ and $C$ nutriture of elderly people in North Italy. Int. J. Vitam. Nutr. Res., 57(4): 349-55, 1987.

99. PRATES, A.; LIMA, N.K.C.; e SOARES, J. Composição corporal e perfil lipídico em idosos ambulatoriais de ambos os sexos. In: Congresso Brasileiro de Geriatria e Gerontologia, $9^{\circ}$., São Paulo, 1991. Resumo. Sāo Paulo, Sociedade Brasileira de Geriatria e Gerontologia, 1991. Tema Livre $n^{\circledR} 154$.

100. PRESTON, S.H.; HIMES, C.; EGGERS, M. Demographic conditions responsible for population aging. Demography, 26(4): 691-704, 1989.

101. RAFTERY E.B. The metabolic effects of diuretics and other antihypertensive drugs: a perspective as of 1989. Int. J. Cardiol, 28:143-50, 1990.

102. RAMOS, L.R. \& SAAD, P.M. Morbidade na população idosa. In: Fundação SEADE. O idoso na Grande São Paulo. São Paulo, 1990. p. 161-72. (Coleção Realidade Paulista). 
103. RAMOS, L.R.; VERAS, R.P.; KALACHE, A. Envelhecimento populacional: uma realidade brasileira. Rev. Saúde públ., S. Paulo, 21(3):211-24, 1987.

104. REIS, M.; CHIBA, T.; MORIGUTI, J.C.; MIKSIAN, R.; CHIAMOLERA, M.; JACOB FILHO, W.; CURIATI, J.A.E.; PASINI, V. Emagrecimento em idosos: estudo retrospectivo. In: Congresso Brasileiro de Geriatria e Gerontologia, $9^{\circ}$., São Paulo, 1991. Resumo. São Paulo, Sociedade Brasileira de Geriatria e Gerontologia, 1991. Tema Livre $n^{9} 87$.

105. ROBERT, J.J.; CUMMINS, J.C.; WOLFE, R.R.; DURKOT, M.; MATTHEWS, D.E.; ZHAO, X.H.; BIER, D.M. Quantitative aspects of glucose production and metabolism in healthy elderly subjects. Diabetes, 31: 203-11, 1982.

106. RON, D.; AVIRAM, M.; BROOK, J.G. High density lipoprotein in octagenarians. Bioch. Med., 30:253-60, 1983.

107. SECRETARIA DE ESTADO DA PROMOÇĀO SOCIAL. Investigação preliminar sobre a situação do idoso internado em estabelecimentos particulares na Cidade de São Paulo. São Paulo, 1976. (Documento Técnico $\left.n^{9} 6\right)$.

108. SECRETARIA DE ESTADO DA SAÚDE. Instituto de Saúde. Manual básico de nutrição. São Paulo, 1975. (Publ. $n^{2} 23$, Ser. E, n 3, Seção de Nutrição).

109. SLESINGER, D.P.; McDIVITT, M.; O'DONELL, F.M. Food patterns in a urban population: age and sociode-mographic correlates. J. Geront., 35(3):432-41, 1980.

110. SORENSON, A.W. \& HANSEN, R.G. Index of food quality. J. Nutr. Educ., 7:53-7, 1975.

111. STEINBERG, D.; CAREW, T.E.; FIELDING, C.; FOGELMAN, A.M.; MAHLEY, R.W.; SNIDERMAN, A.D.; ZILVERSMIT, D.B. Workshop I: Lipoproteins and pathogenesis of atherosclerosis. Circulation, 80(3):719-23, 1989. 
112. THOMAS, A.E.; McKAY, D.A.; CUTLIP, M.B. A monograph method for assessment body weight. Amer. J. clin. Nutr., 29:302-4, 1976.

113. THOMSEN, Y.G.; CARVALHO FILHO, E.T.; KNOBEL, M.; TAKESHITA, O.T.; MORETTO, O.P.; PAPALEO NETTO, M. Disfunçōes tireoidianas em idosos. Rev. paul. Med., 105(4):189-94, 1987.

114. TROTTER, M. \& GLESER, G. The effect of ageing status on stature. Amer. J. phys. Anthrop., 9(3):311-23, 1951.

115. UNITED NATIONS DEVELOPMENT PROGRAM (UNDP). Human development report 1991. Oxford, Oxford University Press, 1991.

116. VERAS, R.P.; RAMOS, L.R.; KALACHE, A. Crescimento da população idosa no Brasil: transformações e conseqüências na sociedade. Rev. Saúde pábl., S. Paulo, 21(3):225-33, 1987.

117. WAHLQVIST, M.L. \& FLINT, D.M. Nutrition assessment. Med. J. Aust., 16:505-12, 1981.

118. WAITZBERG, D.L. Nutrição enteral e parenteral na prática clínica. Rio de Janeiro, Livraria Atheneu Editora, 1990. p. 123-42: Avaliação nutricional.

119. WASWA, J.K.; JANSEN, A.A.J.; MINAWA, A.; GEKONYO, J.M. The nutritional status status of an elderly population in a rural area in Embu District, Kenya. East Afr. med. J., 65(9):578-87, 1988.

120. WELHAM, W.C. \& BEHNKE, A.R. The specific gravity of health man. J. Amer. med. Assoc., 118:498, 1942.

121. WOO, J.; CHAN, S.M.; MAK, Y.T.; SWAMINATHAN, R. Biochemical predictors of short term mortality in elderly residents of chronic care institutions. J. clin. Pathol., 42:1241-5, 1989.

122. WOO, J.; HO, S.; MAK, Y.T. DONNAN, S.P.B.; SWAMINATHAN, R. Intake and blood levels of some minerals in a elderly Chinese population. Clin. Nutr., 9:9-16, 1990. 
123. YAZAKI, L.M. \& SAAD, P.M. Mortalidade da população idosa. In: Fundação SEADE. O idoso na Grande São Paulo. São Paulo, 1990. p. 125-59. (Coleção Realidade Paulista).

124. YEARICK, E.S. Nutritional status of the elderly: dietary and biochemical findings. J. Geront., 35:663-71, 1980.

125. YEUNG, D.L.; SCYTHES, C.A.; PENNELL, M.D. Sources of energy and nutrients in diets of the elderly living in Toronto. J. Nutr. elderly., 9(2):2540, 1989. 


\section{ANEXOS}




\section{ANEXO 1}

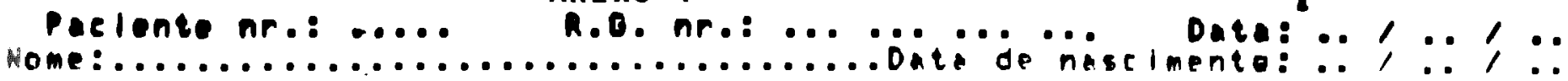
mexo: ( Ifem. - ( Imasc. cor: $\ldots$

Mazuralldade:.

Procedincla atual: ramota:

...................................

quanto tomoo: ...... quanto tempo: .

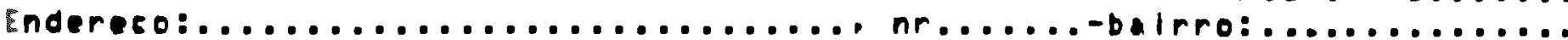
telefone:........... iresldenciale leomercials irecados com:. .......... irestdenclale scomerclale irecados com:.

ocunacao:.......... Instrucao:........

1

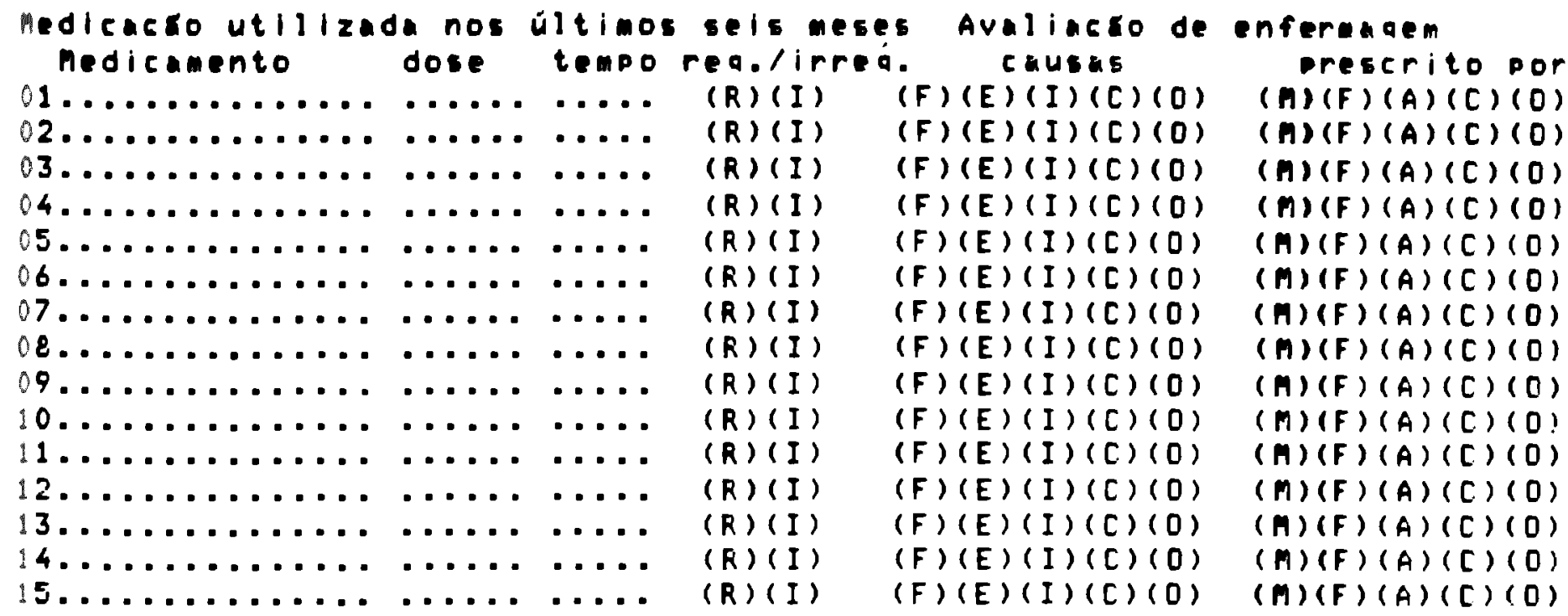

tis inas:

Medicamer.a dose tempo rea.lirrea. causas prescritopor

$\ldots \ldots \ldots \ldots \ldots \ldots \ldots \ldots \ldots(R)(F) \quad(F)(E)(I)(C)(D)$

$\ldots \ldots \ldots \ldots \ldots \ldots \ldots \ldots \ldots \ldots \ldots(R)(I) \quad(F)(E)(I)(C)(D)$

$\ldots \ldots \ldots \ldots \ldots \ldots \ldots(R)(I) \quad(F)(E)(I)(C)(D)$

$(A)(F)(A)(C)(O)$

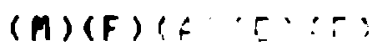

$(M)(F)(A)(C)(C$

$\ldots \ldots \ldots \ldots \ldots \ldots \ldots \ldots \ldots$ (F) $(I) \quad(F)(E)(I)([)(0)$

$(M)(F)(A)(C)(O)$

ETEnd:

caus $\rightarrow 5:$

prescrito for:
(e)firaresira (E)estlectarete
(c)efeites colaterite
$\cos 01,100$

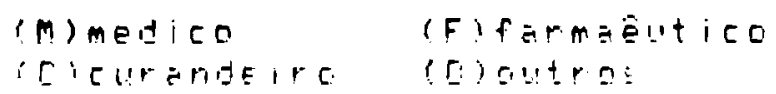

(A) auto-medicacac.

- - - - - -

Dianosticos:

CIT

1

r.

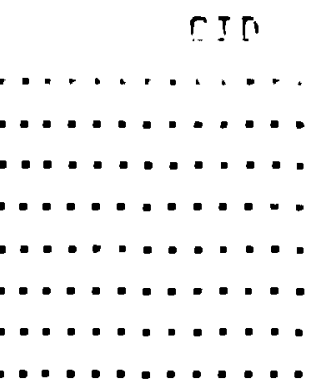


Exame clínico esoecifico: 1 - Pele:

$5($ )N( )P( )?( )xerose Cutánea S( IN( )P( )? ( )Hiperceratose

Folucular: $5($ )

5( )N( )P( )?( )Perifoliculose

S( )N( )P( )? ( )Petéquias

S( )N( )P( )? ( )PürDura

S( )N( )P( )? ( ) Seborreia

$5($ ) $N($ ) P( )?( )Lesáo Vest. Nasal

III - BOCA:

S( )N( )P( )?( )Estomatite Anqular

S( )N( )P( )?( )Cicatrizes Anqulares

S( )N( )P( )? ( ) Oueilose

$5($ )N( )P( )? ( L L nqua Máqenta

S( )N( )P( )?( )Atrofia PaDilas Linquais

Prótese: ( )superior

() inferior

IU - Esqueleto:

S( )N( )P( )? ) Deformidades coluna

S( )N( )P( )? ( Deformidade torácic

$5($ )N( )P( )? ()Alaraamento epifisarico doloroso

W Reflexo Patelar:

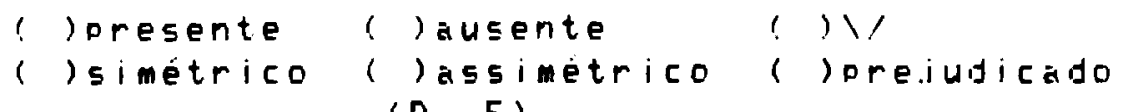

( D E )

Pesultados de Exames:

Caroteno:

Vit. A:

vit. C:

it.i 25 OH: $\ldots \ldots$

D \1:25 OH: .......

Fe: $\ldots$

Manesio:

CElcio:

Fosforo:

$N a:$

$k:$

Zinco:

Ureia:

Creatinina: losf. Alcalina:

Glicemia:

Irialicerides:

creat. Urin.:

Calciúria:

Fosfaturia:
. .

-.

.

-.

-

..

-.

-

.

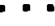

- -

-. -

... .

. . .

.. colesterol

1
1
1
1

(.) $)$

Dentes: ( )bom estado

() metu estado

() ausentes

II - OIhOS:

S( )N( )P( )? ( )Blefarite Anaular

S( )N( )P( )? ( )Blefar. Periferica

S( IN( )P( )?( )Blefarite Completa

S( )N( )P( )?( )Cicatrizes Anqul.

S( )N( )P( )?( )Xerose Coniuntival

S( )N( )P( )? ( )Xerose Corneal

S( )N( )P( )? ( Manch de Bitot

S( )N( )P( )? ( )Vasculariz. Cornea

S( )N( )P( )? ( ) Ulcera Córnea

Sanaramento $($ ) ausente

qenaival: ( )trauma minimo

()espontaneo 


\section{1 - Tem dificuldades ou dores quando mastia os al imentos? () sim ( Inso \\ 2 - Mudou a forma de preparar os alimentos por causa disto? () sim ( ) nato}

$\overline{3}$ - Ounis os al imentos?

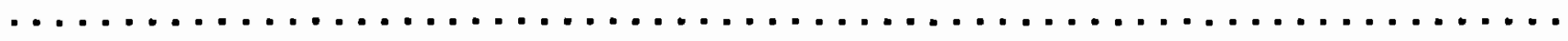

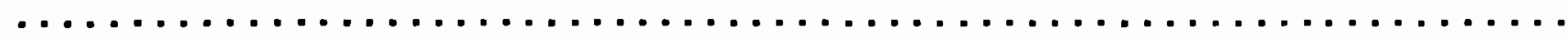

4 - Tem al aum al imento que náo come?
$($ ) $51 \mathrm{~m}($ ) ño
Quล่?

5 - Por que?

()fazmal ()dificuldades finamceiras () dif. para mastiaer

() nóo tolera i ldificuldades no preparo

() outros:

6 - Tem fialta He apetite?

() sim ( ) nato

7 - Tem habito de tomar sol?

() sim () nato

Frequência:....... /mim. à diá.

8 - Toma bebidas alcólicas?

() ) sim ( ) náo

Quantidade:.................

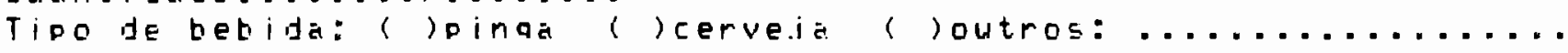

Q - Duantos copos o(a) Sria). toma por dia de aqua sucos refriqerantes cife, etc.?

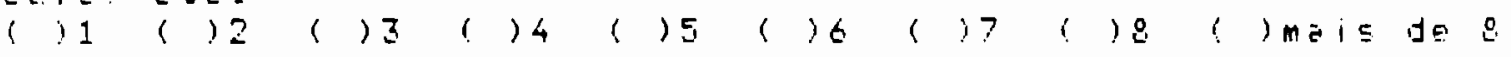

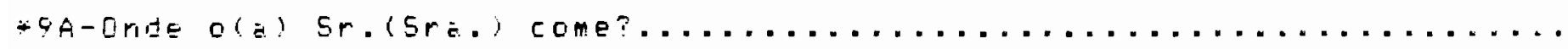

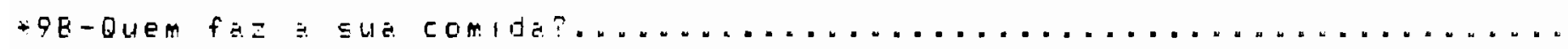

10 - Como costuma cozinhar verguras e lequmes?

!) sem áqua ( jcom àque - Costuma anroveiter á eque?

() 5 im inén

11 - Pars estes alimentos o sr(a). cozinha com:

() tampa aberta () tampa fechada ? Jpressác

12 - Como funcions o intestino?

(Joreso ( )normal () biarreia

13 - Quantias evacuacoes à dia? ......

14 - Fezes (consistencia):

l) liquide ( )engurecida) () nastose

I - DADOS ANTROPOMETRICOS:

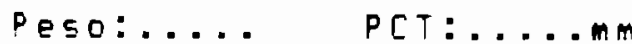

ijtura: ...

$P C \varsigma u b e s c$ apular: .....mm

PAB: ...mm

PE:.... Cm CME: .... Lm LE:...mm 
III - ANAMNESE ALIMENTAR (recordatório de 24 horas):

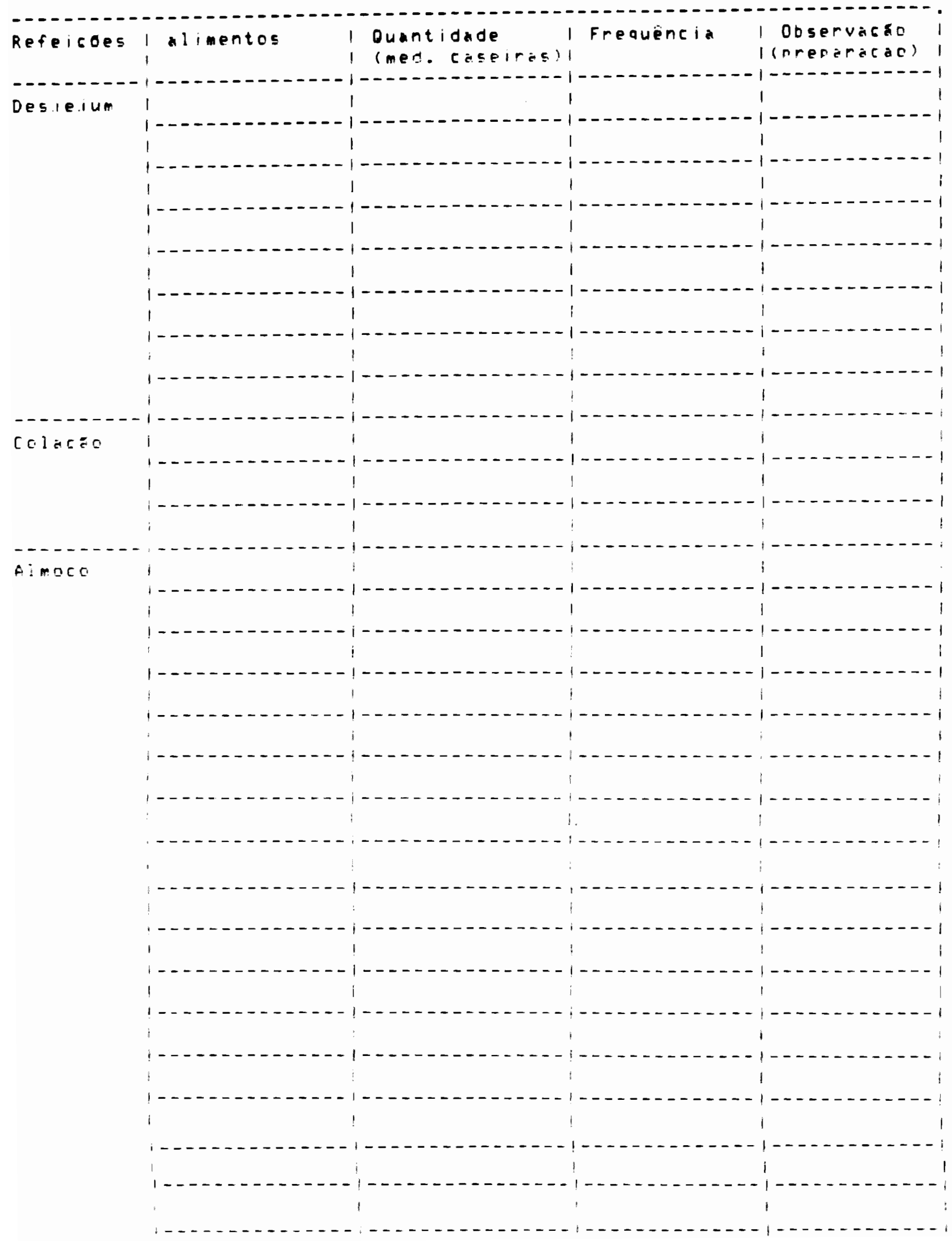




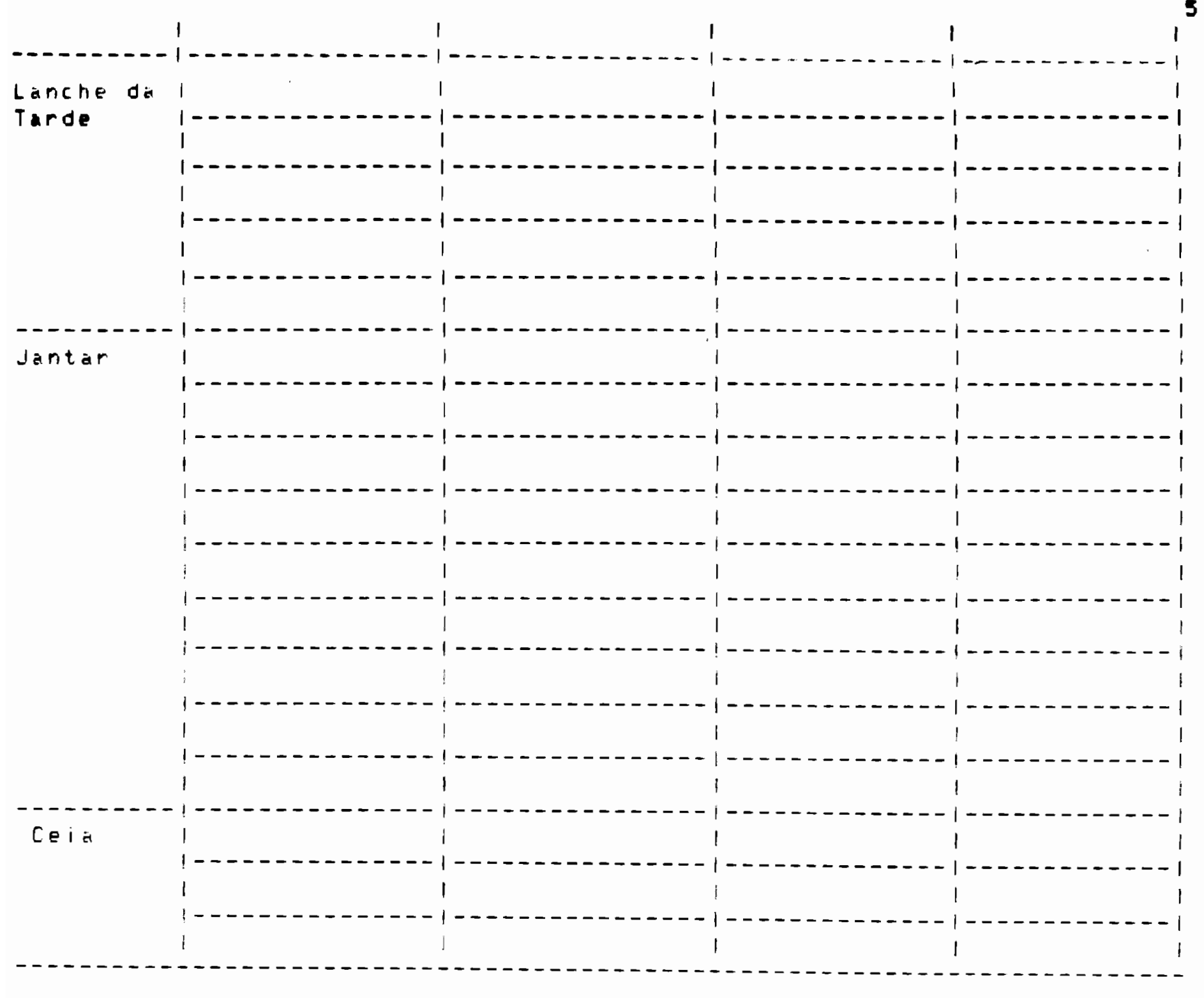

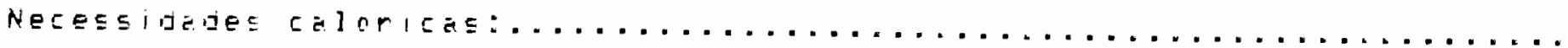

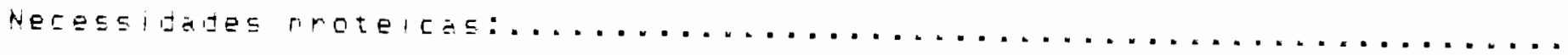

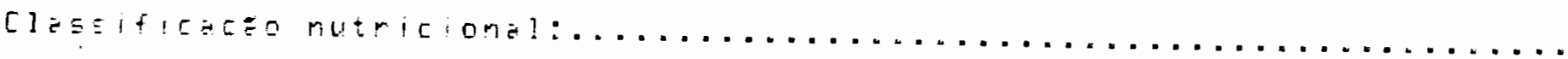

putrieconista: $\ldots \ldots \ldots \ldots \ldots \ldots \ldots \ldots \ldots \ldots \ldots$ 


\section{NICAS - FMUSPI \\ - NIT:IÇAO - DND}

ORIENTAÇÃO DIETÉTICÁ PARÁ IDOSOS

is alteraçōes que ocorrem no organismo com o envelhecimento, exigem de cada individuo cuidados especiais em todos os aspectos, entre eles, a Nutrição.

A Nutrição do idoso é tão importante como o é para uma crian ça em fase de crescimento. Sua alimertação não é muito diferente da alimentação do adulto. É importante basicamente para conservar umí velhice saudável, sem provocar a diminuicão ou o aumento de peso. Daí, a preocupação em se criar um veiculo de informação sobre os cuidados nutricionais nessa fase.
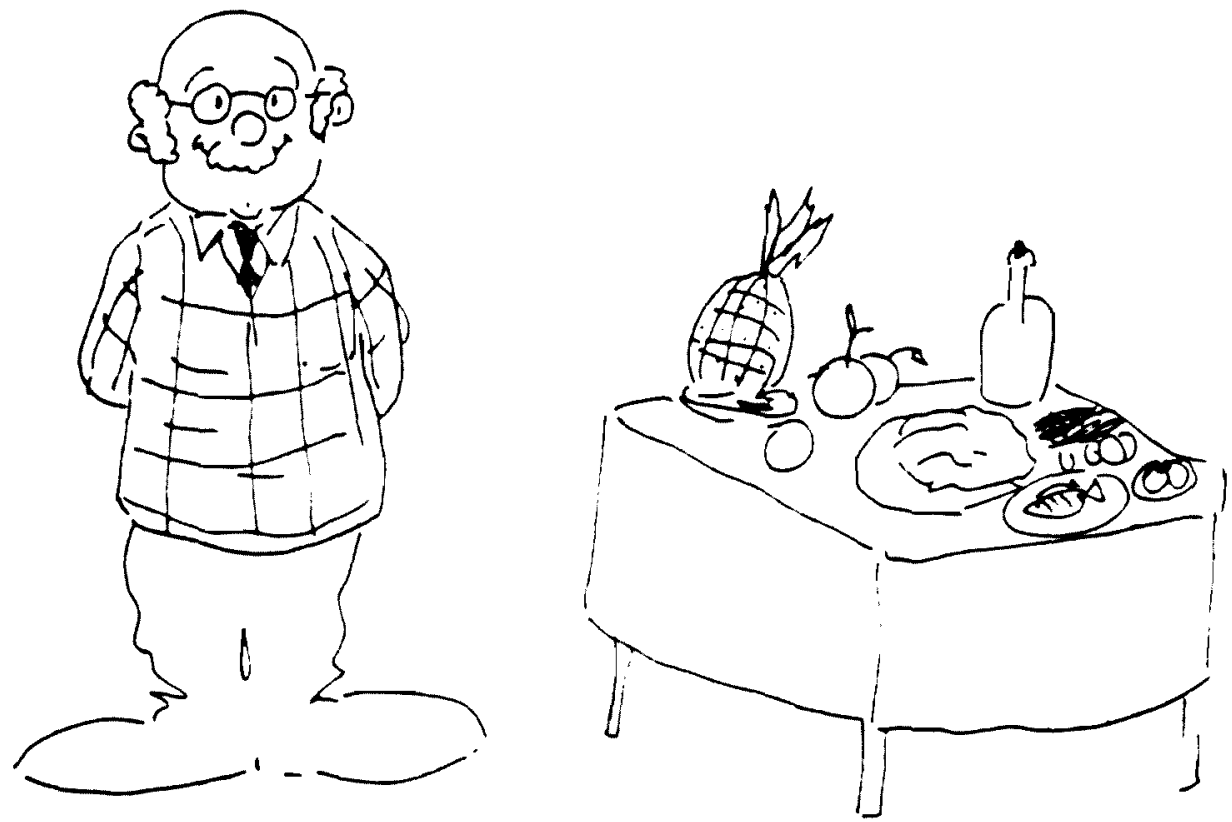
I - Para evitar o intestino preso. deve-se:

- Ingerir diariamente alimentos ricos em fibras, que facilitem - funcionamento intestinal, como:

-verduras cruas como alface, almeirão, agrião, couve, escarola, etc.

- frutas cruas como laranja (c/bagaço), mamão, banana nanica, pera (c/casca). frutas secas (ameixa, uva passa), etc.
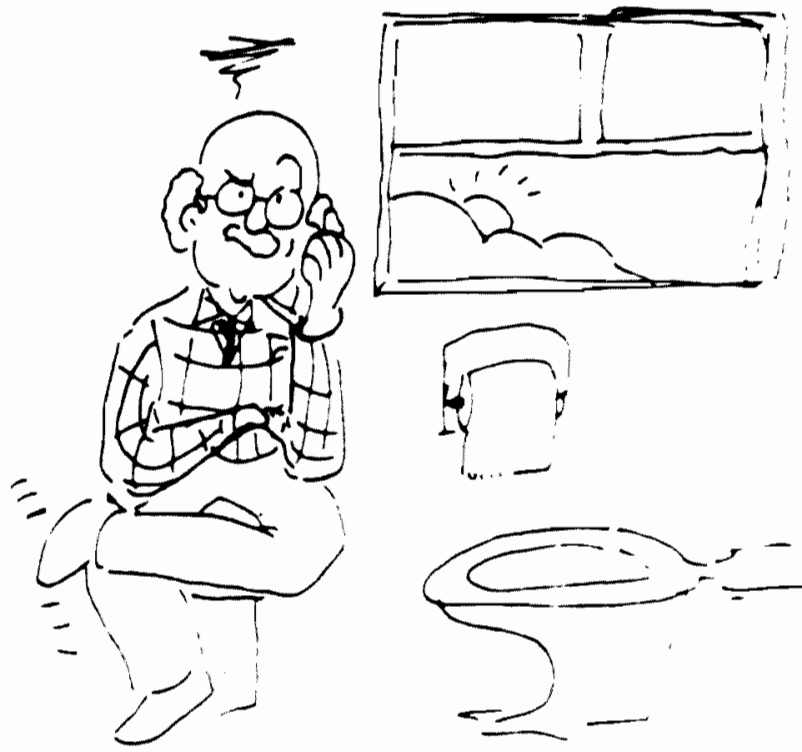

- legumes: abobrinha, abóbora, cenoura, vagem. quiabo, jilt mandioca, etc.

-alimentos integrais: arroz, pão integral, aveia, $\epsilon$

-outros: farelo e germe de trigo (com frutas, leite, sucos. feijào)

- Tomar de 4 a 8 copos de líquidos (água, chá, leite ou succ de (rutas). Nāo ingerir durante 0 almoço ou jantar para que - I íquido nào ocupe o espaço no estomago que o alimento deveria ocupar.

- Realizar diariamente atividades leves. Ex.: andar

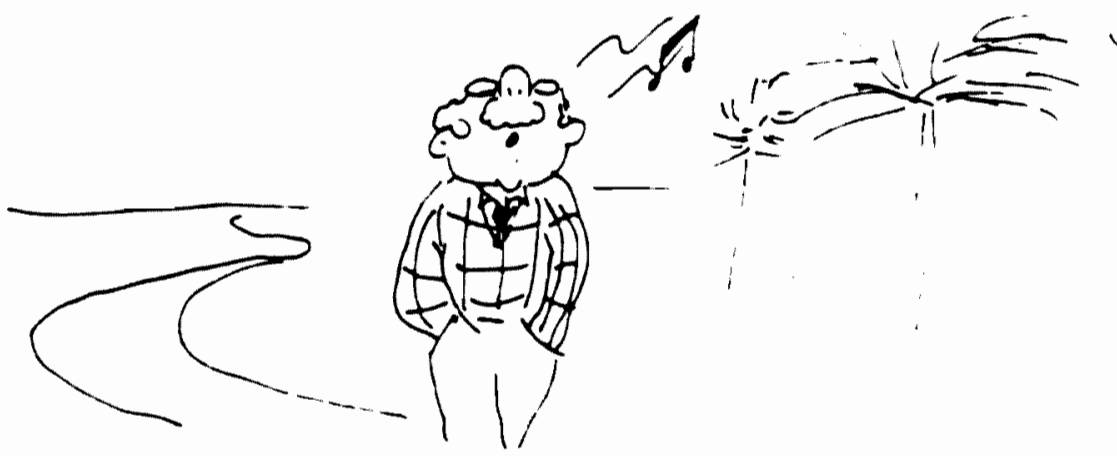

- Evitar o uso constante de laxante, pois o organismo poze se acostumar, e somente funcionar quancio o remédio for usado. 
II - Evitar o consumo exagerado de sal, pols pode causar o aumento da piressāo arterlal e a retencào de liquidos (1nchaço).

III - Nāo ingerir multos acúcares, massas e doces para evitar excesso de peso.

Por 1sso, preferir as Irutas como sobremesa. ilem de fac1litarem o funcionamento do intestino sāo ricas en. vitaminas.

IV - Ingerir alimentos ricos em ferro, tais como: figado, rins coraçào, carnes em geral, ovos, feijào, verduras iespinafre, couve;, para evitar a anemia.

V - Para que os alimentos sejam melhor aproveitados, precisar ser bem mastigados. nào esquecendo os cuidados cor froiest $\epsilon$ dentaduras muito gastas e maj ajustadas.

Nào deixar de ingerir carnes, legumes, verduras e frutas. As carnes pooer ser cortadas desfiadas, moidas ou batidas no liquidificador.

Os legumes e as verduras cruas podem ser picadas. As frutas mais "duras" podem ser cortadas ou cozidas com casca.

VI - Deve-se dar preferêncla à utilizaçào de óleos vegetais no preparo e cozimento de alimentos (óleo de soja, de milho, aigodào, girassol) sempre em pequenas quantidades.

VII - Ainda para facilitar a digestão. Deve-se dividir as refei çöes em pequenas quantidades (em média 5 a 6 refeiçōes ao dia - café da manhà, lanche da manhì, almoçc, lanche da tarde, jantar e ceia).

VIII - A ingestão correta de cálcio e a vitamına o previnem problemas nos ossos e fraturas com facilidade. Portanto. deve-se ingerir diariamente alimentos que contem esses nutrientes, tais como: leite, ovos, queijos, coalnadas, carne, peixe e aves. Para o aproveitamento da vitamina $D$ é indis pensável tomar sol diariamente.

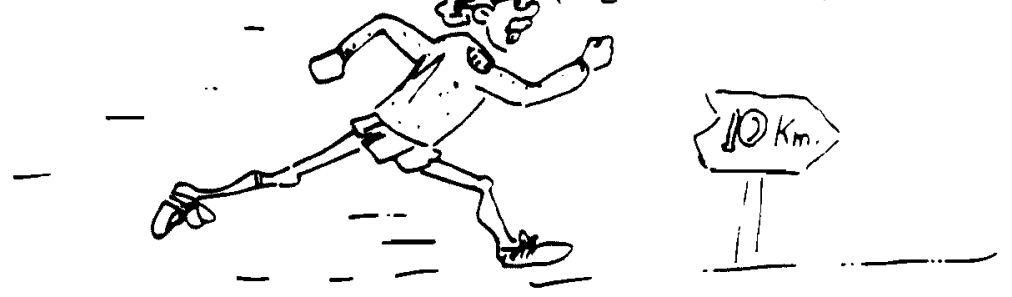




\section{IX - Vitaminas}

São os nutrientes indispensàveis ao bom funclonamento do organismo. Para garantirmos o recebimento de todas as $\mathbf{v}$ taminas é necessário ter uma alimentaçào variada e mista No caso dos ldosos, as vitaminas mals importantes são: Vitamina $A$ - cenoura, plmentão vermelho, abóbora, miúdos gema de ovo, leite e queijos.

Vitamina $B_{1}$ e $B_{2}$ - cereats integrais (aveia, arroz integral, farelo de trigo), leguminosas (feijāo, ervilha,soja), ovo, visceras (figado), leite, quejjo, carnes, horta liças de folhas verdes.

Vitamina C - Hortaliças cruas e frutas como laranja, limàc goilaba, manga, morango.

Vitamina D - Figado, gema de ovo, leite.

Por isso, é importante ingerir frequentemente esses alimen tos.

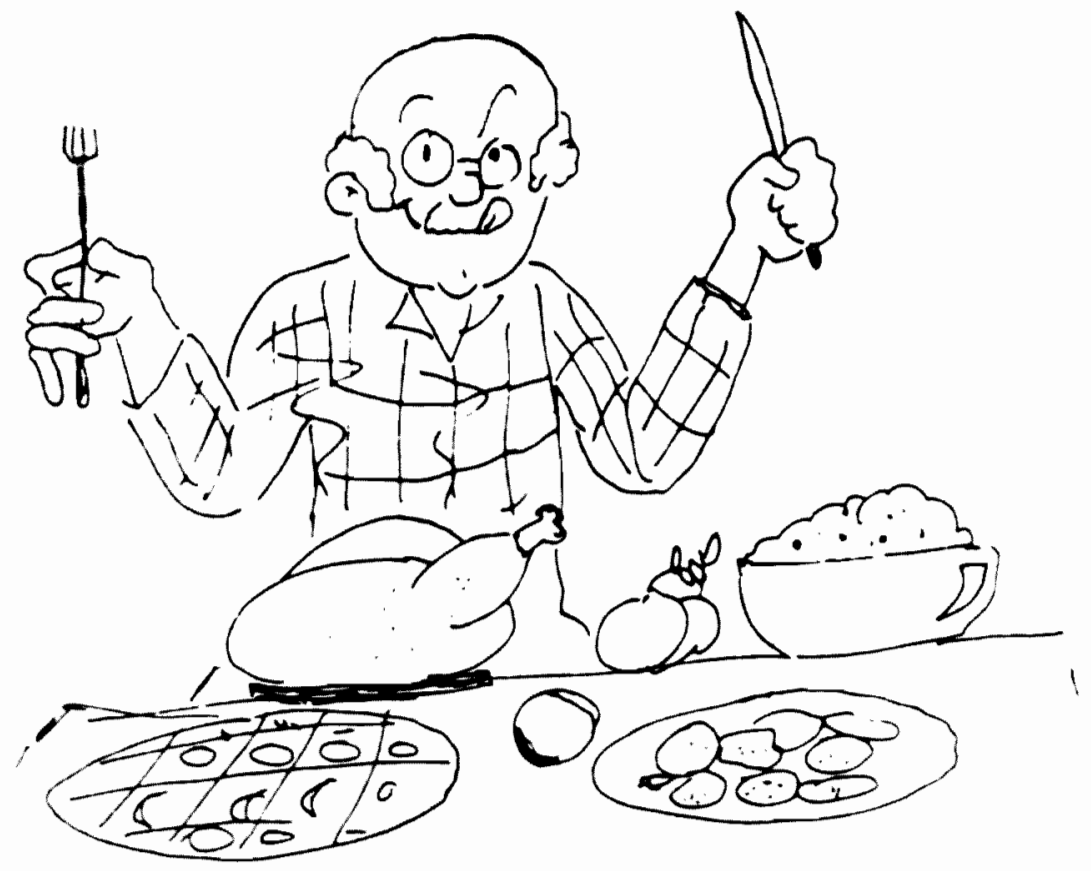


$x$ - Variar os alimentos diariamente em cada refelcão. Ingerir un alimento (ou uma porção) de cada tipo no almoco e jantar:

Exemplo

Arroz

Fe1jāo

Legumes (cozidos ou

em forma de purê)

Verduras de folhas

(salada ou refogada)

Carne (ou miudos)

Frutas
Substituiçōes e/ou variaçōes

Macarrào, polenta

Lentilha, ervilha, soja, grào de bico.

Batata, cenoura, abóbora.

chuchu, beterraba e outros.

Escarolá, agrião. alface.

couve, espinafre, etc.

Vaca, peixe, frango, figax.

coraçàc, rim, ovos.

Mamào, laranja. banana. verá.

maçà. et: .

no desjsjur, iancne ca tarce e a nolie

Exemplo

1 copo de leite

1 un. pào

1 fruta
Substi tuiçào e/ou varıaçàc

Iogurte, mingau, ovo, que 1 jo. coalhada.

Bolacha (4)

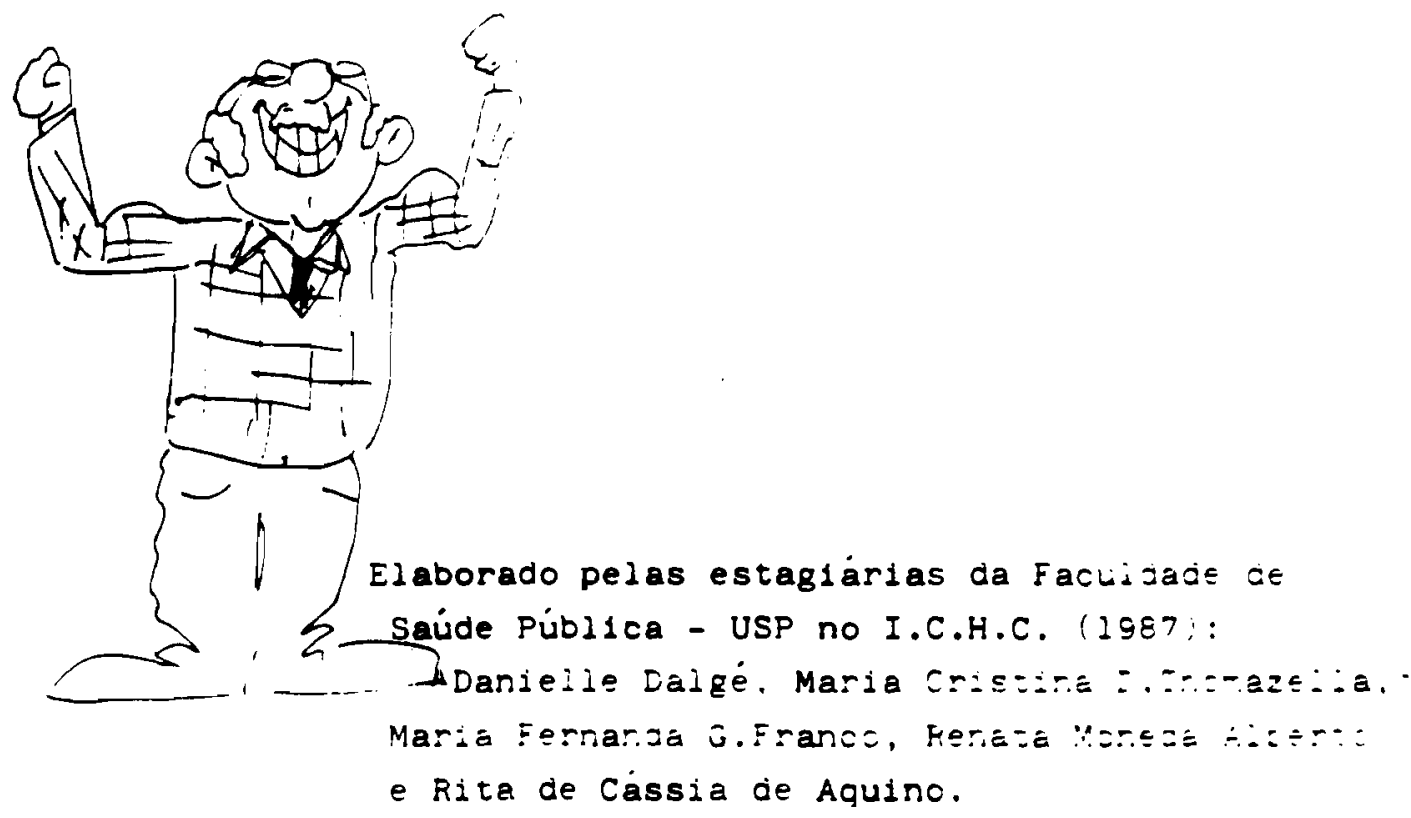

Futricioniete upervisores Hine de Coste Corria 


\section{ANEXO 3}

Distribuição das doenças dos idosos estudados, segundo o total de diagnósticos e a proporção de idosos que apresentam o diagnóstico referido.

São Paulo, 1989-1990.

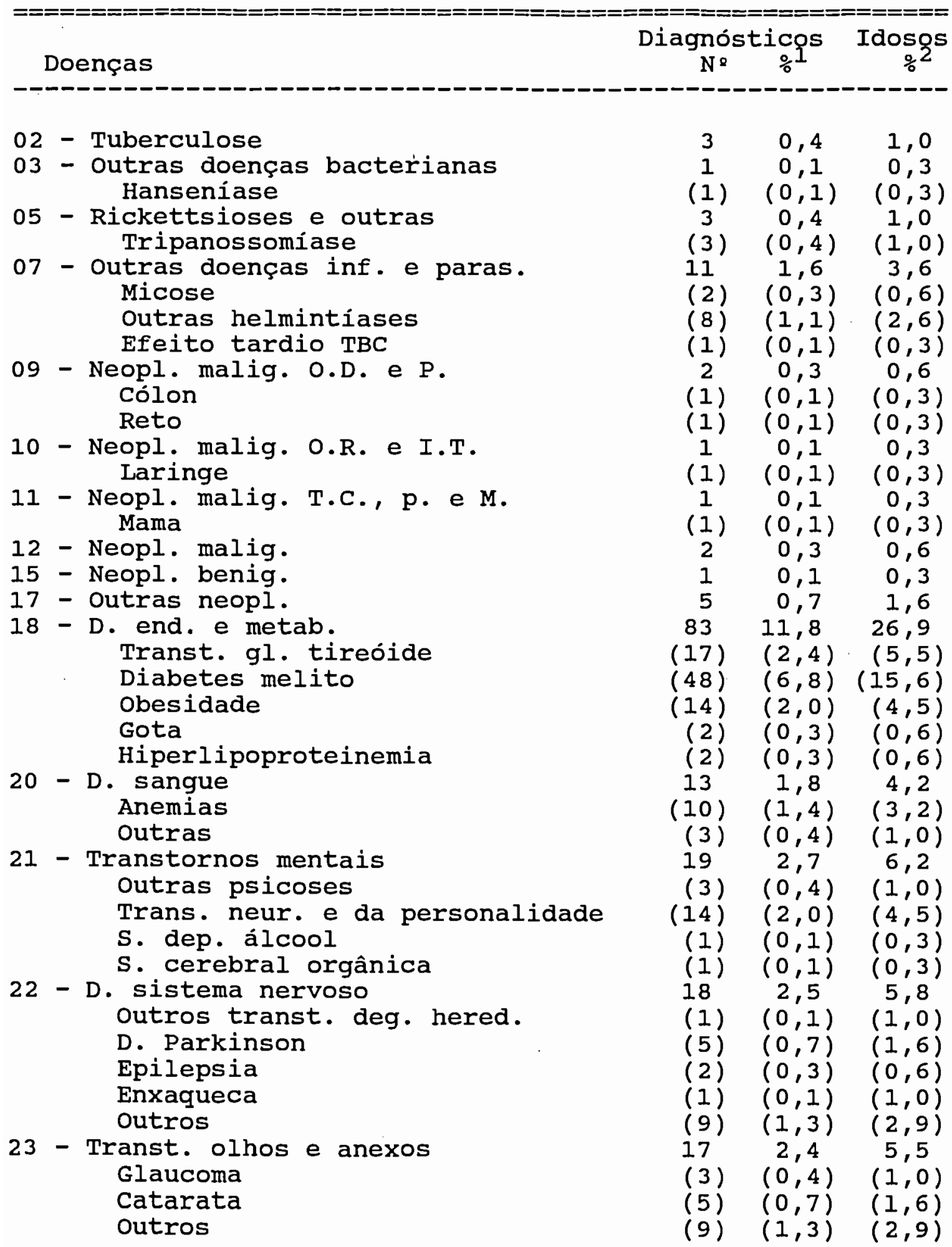


24 - D. ouvido

26 - D. hipertensiva

Hipertensāo arterial

D. hip. coração

27 - D. isquêmica do coração

28 - D. circ. pulm. e outros

29 - D. cerebrovascular

30 - D. ap. circulatório

31 - D. trato resp. superior

32 - Outras D. ap. respiratório

D. Pulm obstr. crônica

Outras

33 - D. boca, gl. sal. e maxilares

34 - D. outras partes do ap. dig.

D. esôfago

Úlc. est. e duodeno

Hérnia da cavidade abdom.

Diverticulo do intestino

outros transt. digest. func. (obst.)

D. crônica do fíg. e cirrose

Colelitiase e colecistite

outras (gastrites e dispepsias)

35 - D. ap. urinário

Nefrite, S.N. e nefrose

Outras (ITU)

36 - D. órgãos genitais masculinos

37 - D. órgãos genitais femininos

42 - D. pele e tecido celular subcut.

43 - D. sist. osteomuscular e Tec. conj. Artrite reumatóide

outras artropatias

Outras dorsopatias

Reumatismo

Osteoporose

46 - Sinais, sint. e afec. mal definidos $\begin{array}{ccc}24 & 3,4 & (7,8) \\ 151 & 21,4 & 49,0 \\ (149) & (21,1) & (48,3) \\ (2) & (0,2) & (0,6) \\ 25 & 3,5 & 8,1 \\ 49 & 6,9 & 15,9 \\ 13 & 1,8 & 4,2 \\ 15 & 2,1 & 4,8 \\ 1 & 0,1 & 0,3 \\ 20 & 2,8 & 6,5 \\ (11) & (1,6) & (3,6) \\ (9) & (1,3) & (2,9) \\ 1 & 0,1 & 0,3 \\ 60 & 8,5 & 19,5\end{array}$

(4) $(0,6) \quad(1,3)$

(5) $(0,7) \quad(1,6)$

(11) $\quad(1,6) \quad(3,6)$

(1) $\quad(0,1) \quad(1,0)$

(8) $(1,1) \quad(2,6)$

(2) $(0,3) \quad(0,6)$

(13) $(1,8) \quad(4,2)$

$(16) \quad(2,3) \quad(5,2)$

$15 \quad 2,1 \quad 4,8$

(2) $(0,3) \quad(0,6)$

$\begin{array}{ll}(13) & (1,8) \quad(4,2\end{array}$

$10 \quad 1,4 \quad 3,2$

$4 \quad 0,6 \quad 1,3$

$6 \quad 0,8 \quad 1,9$

$100 \quad 14,2 \quad 32,5$

(3) $(0,4) \quad(1,0)$

$(67) \quad(9,5) \quad(21,7)$

(11) $\quad(1,6) \quad(3,6)$

(4) $\quad(0,6) \quad(1,3)$

(15) $(2,1) \quad(4,9)$

$32 \quad 4,5 \quad 10,4$

TOTAL

$706 \quad 99,5 \quad 228,7^{3}$

* Segundo a Lista Básica para Tabulação - OMS, 1985, v. . (95)

1 Refere-se ao total de diagnósticos levantados.

2 Refere-se à proporção de idosos que apresentam o diagnóstico referido.

3 A soma é superior a $100 \%$, porque cada idoso estudado pode apresentar mais de um diagnóstico. 